\title{
WestVirginiaUniversity
}

THE RESEARCH REPOSITORY @ WVU

Graduate Theses, Dissertations, and Problem Reports

2017

\section{Evidence Utility in Forensic Intelligence Models}

Jamie S. Spaulding

Follow this and additional works at: https://researchrepository.wvu.edu/etd

\section{Recommended Citation}

Spaulding, Jamie S., "Evidence Utility in Forensic Intelligence Models" (2017). Graduate Theses, Dissertations, and Problem Reports. 6697.

https://researchrepository.wvu.edu/etd/6697

This Thesis is protected by copyright and/or related rights. It has been brought to you by the The Research Repository @ WVU with permission from the rights-holder(s). You are free to use this Thesis in any way that is permitted by the copyright and related rights legislation that applies to your use. For other uses you must obtain permission from the rights-holder(s) directly, unless additional rights are indicated by a Creative Commons license in the record and/ or on the work itself. This Thesis has been accepted for inclusion in WVU Graduate Theses, Dissertations, and Problem Reports collection by an authorized administrator of The Research Repository @ WVU. For more information, please contact researchrepository@mail.wvu.edu. 


\title{
Evidence Utility in Forensic Intelligence Models
}

\author{
Jamie S. Spaulding, B.S., B.A. \\ Thesis submitted \\ to the Eberly College of Arts and Sciences \\ at West Virginia University \\ in partial fulfillment of the requirements for the degree of \\ Master of Science in \\ Forensic \& Investigative Science
}

Keith Morris, Ph.D., Chair

James Nolan, Ph.D.

Robert O'Brien, M.S.

Department of Forensic \& Investigative Science

Morgantown, West Virginia

2017

Keywords: Forensic, Intelligence, Evidence Interpretation, Case Assessment, AFIS, IBIS, CODIS

Copyright 2017 Jamie S. Spaulding, B.S., B.A. 


\title{
ABSTRACT \\ Evidence Utility in Forensic Intelligence Models
}

\author{
Jamie S. Spaulding, B.S., B.A.
}

Forensic intelligence is the accurate, timely, and useful product of logically processing forensic case data for investigation and/or intelligence purposes. The most important facet of any investigation is the decision making process due to significant influence and direction of the downstream investigation. Wrong decisions can lead to an unsolved case or implication of an innocent individual. Accurate decision making can be reinforced by linkages or relationships uncovered within a case. Analysis of evidence can also create a link between cases leading to more effective case closure. Application of forensic intelligence seeks to rectify this problem; more open and fluid communication across all law enforcement agencies will uncover more inter and intra-case linkages. Graphical distribution of evidence enhances this process and creates a user-friendly interface analytical environment for investigators. Meaningful utilization of forensic intelligence at all levels of a given investigation serves to close more cases, provide case assessment/interpretation of all evidence, and give investigators higher confidence for testimony in court.

In order achieve a forensic intelligence case assessment model, the linkage analysis software IBM ${ }^{\circledR}$ i2 ${ }^{\circledR}$ Analyst's Notebook ${ }^{\circledR}$ was employed. Analyst's Notebook ${ }^{\circledR}$ is a visual intelligence analysis environment that enables the user to quickly collate, analyze, and visualize data from numerous sources while reducing the time required to discover key information. The application of the resulting model within the software delivers timely, actionable intelligence to help identify, predict, prevent, and disrupt criminal, terrorist, and fraudulent activities based upon evidentiary value. Additionally, this software can be used in conjunction with an agency's current database or information repository to develop critical linkages between criminal activity.

Import specification models were developed and refined throughout the course of this project. The three step model serves to compile case information automatically and draw links for the investigator. Firstly, a model was developed as an import mechanism for case files into an intelligence network within Analyst's Notebook ${ }^{\circledR}$. The significance of an import mechanism is that case files can be incorporated to the network in order to develop a repository of case files. Secondly, import specifications were developed to integrate articles of evidence with the case file. Finally, AFIS, CODIS, and IBIS database search results were incorporated with the cases and evidence already present in the forensic intelligence network. Complete integration of database results can be utilized for case assessment and interpretation by the investigator, and also to draw linkages with other cases in the network in a multi-case approach. 


\section{Acknowledgements}

I would first like to acknowledge my chair, Dr. Keith Morris. Thank you for all of your great contributions, mentorship, and guidance. Thanks to your wisdom I have achieved more than I could have ever thought.

I would also like to thank the other members of my committee who have provided insight to the work: Dr. James Nolan and Mr. Robert O'Brien.

Lastly, I wish to thank the Granville Police Department, more specifically Chief J.C. Corkrean for assistance with this research. 


\section{Contents}

1 Introduction 1

2 Test Scenario $\quad 20$

3 Complete Utilization of Forensic Evidence Through Incorporation in Forensic Intelligence Networks

4 Integration of AFIS, CODIS, and IBIS Data to Forensic Intelligence Networks for Real-Time Case Assessment 49

5 Future Directions 


\section{Introduction}

\subsection{Defining Forensic Intelligence}

In order to define forensic intelligence it is necessary to break down the concept into each of its components. The term "forensic science" involves an extensive range of areas and disciplines, each with their own discrete practices. Forensic science is known to be the application of scientific or technical practices to the recognition, collection, analysis, and interpretation of evidence for criminal and civil law or regulatory issues [1]. Effectively, forensic science is a multidisciplinary subject which draws from the numerous scientific disciplines in order to provide factual information for the application in court. Forensic science can either be laboratory based or be comprised of expert interpretations with regards to observed patterns. Intelligence is defined as the ability to acquire and apply both knowledge and skills [2]. Integration of the terms yields the definition that forensic intelligence is "the accurate, timely and useful product of logically processing (analysis of) forensic case data (information) for investigation and/or intelligence purposes" [3]. The combination of these definitions can also be expressed as the ability to develop linkages or derive conclusions from available criminal case data and activity.

As shown in Figure 1.1, the process of forensic intelligence draws several parallels to the scientific method. Forensic intelligence can also be viewed in two separate regards, one relating to the delivery of intelligence in forensic casework; the other considering performance within forensic casework, termed as "business intelligence" [5]. Cases utilizing forensic science are processes which inherently produce an intelligence product useful for police investigation. Traditionally, forensic intelligence production has been confined to discipline specific activity meaning that it is not typically integrated with other interpretations of evidence in a larger case assessment process [5]. However, intelligence production can be completed to yield a priori information for other investigations and extend to drawing links with other unsolved cases. Each additional linkage and correlation uncovered within a given criminal investigation enables further levels of consideration to the facts and nature of the evidence. Linkages ensure that conclusions are accurate, and as the number of linkages increases the confidence of an investigator.

Establishment of working definitions regarding forensic intelligence are necessary for the design of intelligence networks. Firstly, to ensure that there is transparency in the process. Secondly, proper terminology is crucial in creating a network that can be used 

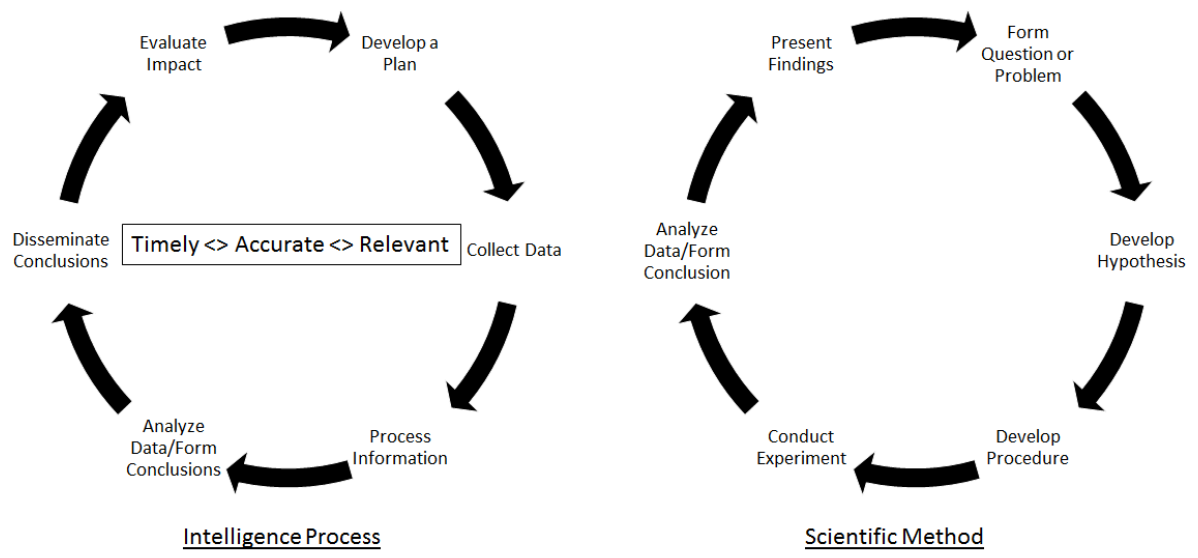

Figure 1.1: The cyclical nature of intelligence compared with the scientific method. Adapted from Ross[4].

among several ranks and agencies. Additionally, consistent definitions show the implications that such a network would have on the landscape of forensic science and the overall nature of investigations. A single nomenclature would be an improvement for the field of forensic science and would be parallel with the current progression of the field. Recently, the Presidents Council of Advisors on Science and Technology (PCAST) called upon the field of forensic science to develop a "standardization of terminology used in reporting and testifying about the results of forensic sciences" [1]. This view is not necessarily alone. The National Commission on Forensic Science (NCFS) urges the forensic community to "establish research-based means of effectively and accurately communicating forensic science information with the judicial system and the public" [6]. The NCFS also stated that there is also concern that even when information is accurately reported and testified to, a lack of forensic-related knowledge within the judicial system (judges, lawyers, and juries) can lead to confusion. Forensic intelligence could chart/represent the information that could aid in the communication of investigative and forensic information. Inn addition, consistency within terminology may bridge the current gap. This could reduce the impact of implementing a forensic intelligence or analytical system to forensic casework and stimulate a transition forward.

\subsection{Value of Intelligence Based Systems}

The value of forensic intelligence systems are initially dependent on the value of analytical results generated through forensic techniques. Forensic science plays an integral role for investigative purposes through the application of analytical processes to collected evidence. According to the influential report regarding the landscape of the field by the National 
Academy of Sciences in 2009; forensic science "attempts to uncover the actions or happenings of an event... by way of (1) identification (categorization), (2) individualization, (3) association, and (4) reconstruction" [7]. Evidence also has the purpose of excluding individuals or sources through the very same analysis. This has great value because there is the potential to connect individuals to an incident, or the potential to determine sources through pattern analysis. The analysis of physical evidence is often a critical witness for the case against an individual. However, with physical evidence there is similar potential for the exclusion of an individual as well.

Additionally, forensic evidence exemplifies value to police and prosecutors through the ability to interpret multiple physiological aspects of a crime scene. In this respect, it is of central importance to recognize that in any criminal case there are actually four crime scenes involved, each with its own set of rules and guiding principles [8]. Primarily there is the physical crime scene which is created and left by the perpetrator of the incident. A subsection of the primary scene is the crime scene material collected by the crime scene personnel which is a sample or representation of the actual crime scene. Another subsection of the collected material is the crime scene material capable of being tested by the crime lab and the results of any such tests which could provide any additional information. This is physical in nature and can be presumptive, exclusionary, supportive, or confirmatory. Finally, the smallest subsection exists as the crime scene information permitted as evidence by the trial court according to the case issues and the Federal Rules of Evidence [8]. There are numerous versions of the actual crime scene, even on location of the incident itself. All of these different scenes can be evaluated through an intelligence network and the underlying analytical process. The graphical environment serves as an valuable check for an investigator in the case assessment and interpretation process. However, the four cases could exist as the totality of a separate network altogether. Such a network would represent the scope of the investigation and could be beneficial as an instructional aid both in the classroom and during trial proceedings. Furthermore, this four tiered depiction of the case shows a narrowing of the scope and would allow for better recurring analysis throughout the course of the investigation to prevent any form of investigative failure. Recurring analysis is critical to continually update one's beliefs about the case at hand and to continually incorporate newly uncovered facts in order to prevent tunnel vision in directing an investigation. The sharing of such a network would also allow for greater collaboration between law enforcement, even among different agencies; forensic scientists, both in the crime laboratory and in the field; and attorneys, at both trial and appellate levels. Compilation of such vast information serves to prevent mistakes within investigations.

Forensic intelligence systems are also of value to the criminal investigation process and provide integrated knowledge and communication. The incorporation of information from analysis into intelligence networks serves as an improvement in decision making. Forensic intelligence plays a new role in forensic science through its extension of a case-by-case approach into a more "phenomenological and proactive approach" [9]. This is a great innovation to the nature of investigations because the current paradigm restricts the field 
to a reactive nature. Strategic, operational, and tactical levels will all be greatly impacted through a shift to forensic intelligence based models due to support with environmental context and decision making. Environmental context is an analysis of the criminal activity, trends, and series within the area. The design of this intelligence process strives to find the best balance between simplicity, flexibility, rapidity, and selectivity [9]. These features are the systematic design to enable a user friendly interface that functions efficiently for case assessment.

Another fundamental principle of forensic intelligence networks is the implications toward relevance. Relevance is evaluated with respect to the criminal context, the existing rational constraints, and other parameters imposed by the criminal justice system. The rational constraints are outlined in Rule 401 within the Federal Rules of Evidence; relevant evidence has any tendency to make the existence of any fact that is of consequence to the determination of the action more or less probable than it would be without the evidence. Other parameters are set out by Rule 402: General Admissibility of Relevant Evidence; and Rule 403: Excluding Relevant Evidence for Prejudice, Confusion, Waste of Time, or Other Reasons [10]. The inference structures found are then compiled for the specific process of crime analysis. These structures show how forensic science can become part of an approach that facilitates the resolution of problems by sharing the knowledge of investigators, crime analysts, and forensic scientists [3]. Shared knowledge is vital because not only is it more holistic in its scope, but also because it creates linkages between separate incidents and investigations. This is applicable as long as the linkages are created from relevant notions, for example the traditional debate between correlation and causation. In fact, the role of forensic intelligence is not solely limited to investigations or to confirm hypotheses suggested by conventional police means, but also to proactively provide insight into criminal activity and to support the elicitation of relevant hypotheses [9]. The visualization of the case data as laid out in an intelligence network helps the investigators to develop hypotheses. These should be of the utmost relevance and value because the totality of the evidence is visible before them as displayed in the network. The visual nature serves as a simple tool for investigators to accurately develop hypotheses which guide the direction and course of the investigation.

Forensic intelligence systems have great value and are critical to the linkage development within criminal cases regarding individuals, objects, and virtually any form of evidence as seen in Figure 1.2. Also the process shown in Figure 1.2 shows the logical assessment that is undertaken to link two separate incidents. Such analysis is instrumental to the progression of investigations and critical case management. In fact, there are a few intelligence systems that are at the forefront of forensic science and criminal investigations.

\subsection{Current Intelligence Based Systems}

Forensic intelligence systems and databases serve as repositories of information which can be searched and collated to form links between the case at hand and others in the repository. Among the most notable intelligence databases are the Next Generation Iden- 


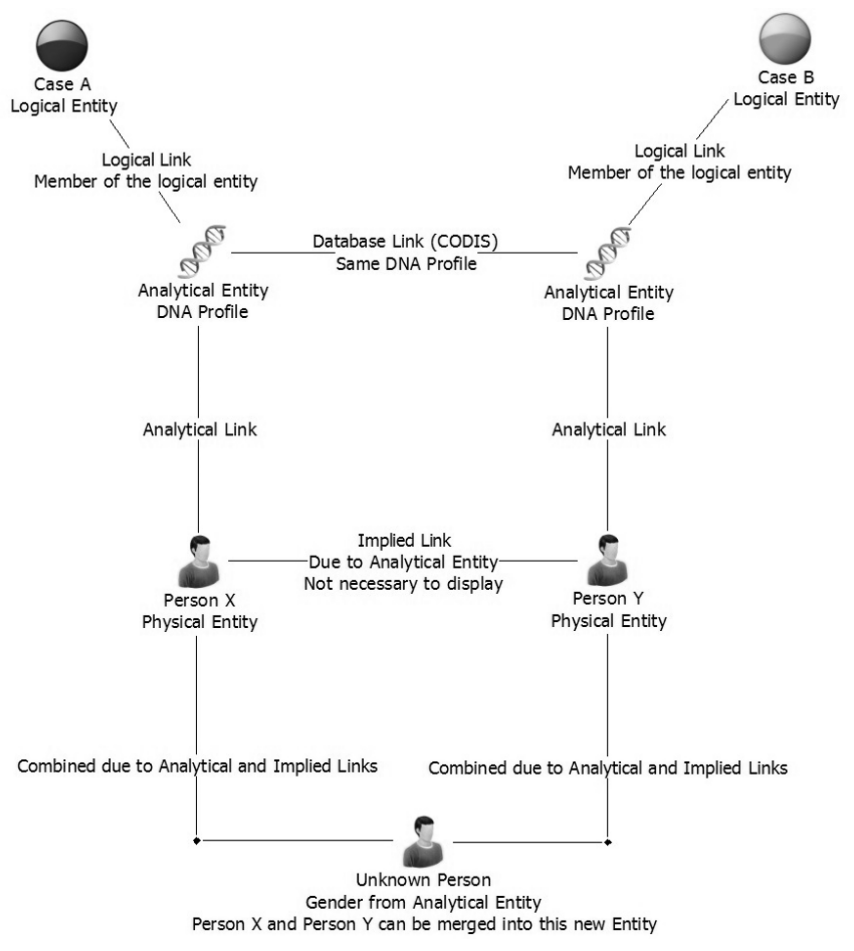

Figure 1.2: Critical linkage development between two cases for case assessment.

tification (NGI); State and local fingerprint databases; Combined DNA Index System (CODIS) or the National DNA Index System (NDIS); and the National Integrated Ballistic Information Network (NIBIN). Each of these serves great purpose to link different elements of a crime and also to store vast amounts of data. An investigator can search for comparison in the database of interest remotely anytime.

The Next Generation Identification system (NGI) is operated by the Federal Bureau of Investigation. The NGI system improved the efficiency and accuracy of biometric services to address evolving local, state, tribal, federal, national, and international criminal justice requirements. Contained within NGI is a national Rap Back service; the Interstate Photo System; fingerprint verification services; more complete and accurate identity records; and enhancements to the biometric identification repository. The Advanced Fingerprint Identification Technology (AFIT) system in NGI replaced the legacy Automated Fingerprint Identification System (AFIS) segment of the previously used IAFIS. The system provides automated fingerprint search capabilities, latent search capability, electronic image storage, and electronic exchange of fingerprints and responses [11]. This system hosts in excess of seventy million criminal fingerprints. NGI is a national fingerprint and criminal history system that responds to requests upon submission to help local, state, and federal agencies solve and prevent crime. This functions as an intelligence network because it 
allows for linkages to be drawn and can be remotely accumulated as well as searched. NGI also functions constantly as a growing database that assists in the adjudication of individuals attached to crimes. The investigator can enter in the fingerprint and with the use of software know as Universal Latent Workstation. This functions to ensure image capability as minutiae of fingerprints are marked and searched through the database. NGI and previously IAFIS are among the most prominent examples of an intelligence network and is a major asset to the closure of investigations.

Another prominent intelligence database used to assist in the adjudication of crime is the Combined DNA Index System (CODIS) or the National DNA Index System (NDIS). The NDIS contains over 12,113,810 offender profiles, 2,201,763 arrestee profiles, and 674,150 forensic profiles as of December 2015 [12]. There is a primary metric built into the system which measures the investigations that have been aided through the use of CODIS. The "Investigations Aided" metric counts the cases where the system has added value to the investigative process. As of December 2015, CODIS has produced over 315,410 hits assisting in more than 303,201 investigations [12]. These statistics empirically show the impact that intelligence databases and networks can have upon a criminal investigation. In the case of CODIS, an extracted DNA profile can be searched against the database. If a hit is determined, the profiles are consistent and the extracted profile is said to match the individual listed in the database. This can provide an individual who deposited DNA at the scene as a person of interest.

In addition to the intelligence databases above, the National Integrated Ballistic Information Network (NIBIN) serves as a resource for cartridge casing and bullet information. Developed by the ATF in 1999, NIBIN provides federal, state, and local agencies with an automated ballistic imaging system. This enables discovery of linkages between firearmsrelated violent crimes and the firearms used in those incidents [13]. This is accomplished through entry of data associated with the bullet or cartridge casing. The Integrated Ballistic Identification Systems (IBIS) technology takes digital images of cartridge cases from crime scenes or a crime gun test fires. IBIS compares those images against previous NIBIN entries. If a high-confidence candidate emerges, firearms examiners compare the original physical evidence microscopically to confirm the match. This is a NIBIN "hit," or the linking of two different investigations [13]. Since introduced NIBIN has been used to provide more than 68,000 NIBIN hits which led to confirmations. This is another example of the true performance metric of a forensic intelligence network; the successful arrest and prosecution of perpetrators involved in that crime and also the exclusion of suspected individuals from investigations.

All three of the above intelligence networks and databases are of great value. Each has the ability to create links between entities, be those individuals or objects, and the crime being searched. Linkages can guide an investigation and ultimately lead to correct outcomes in the prosecution of a case. These networks also all have the ability to provide exculpatory information regarding a person of interest. Linkage information based on the physical evidence is often at the forefront of the case when presented. The value exhibited by these networks is indicative and calls for proliferation of more networks which have this 
type of capability. Integration of such capabilities so that there is not distinctive networks seem to be a solution for case assessment and interpretation challenges. However, efficiency must be present for the network to be a viable resource.

\subsection{1 $\mathrm{ViCAP}^{\circledR}$}

An example of an intelligence network that has goals similar to that of this project is the Violent Criminal Apprehension Program $\left(\mathrm{ViCAP}^{\circledR}\right)$. It is a database which maintains the largest investigative repository of major violent crime cases in the United States [14]. It is designed to collect and analyze information about homicides, sexual assaults, missing persons, and other violent crimes involving unidentified human remains. This involves the entry of in-depth data on the case. This can include details on the victim(s), type of trauma, weapons used, information about the suspect and any composite images, crime scene specifics, vehicle descriptions, modus operandi, and more. Investigators can then search $\mathrm{ViCAP}^{\circledR}$ for cases similar to theirs and obtain results from anywhere in the United States. If any are found, investigators can read the details associated with that case reach out to the law enforcement agency point of contact for further discussion [14]. As this is happening there are FBI analysts who are tasked to review all incoming cases. This is to ensure the quality of the data. Additionally these analysts are inquire into certain cases, looking for similarities [14].

All of this seems like an innovative solution at the surface level, however there are major shortcomings associated with $\mathrm{ViCAP}^{\circledR}$. The system is rarely used. Only about 1,400 police agencies in the United States, out of roughly 18,000, participate in the system [15]. Among the violent crimes committed annually the system only receives reports from well under one percent of them. Its not even clear how many crimes the database has helped solve because the FBI does not release any statistics. In the 1990s a statistic was released however, it detailed that $\mathrm{ViCAP}^{\circledR}$ had only linked 33 crimes in 12 years of operation [15]. A review of the system by officers indicated that the system is confusing and cumbersome in use. It was noted that the entry of a single case would likely take an hour and results (hits) are rare while false positives are common. Many officers also added that the FBI fails to train on use of the system. The article also noted that training for ViCAP had dropped from a high of about 5,500 officers in 2012 to 1,200 in 2014 [15].

Effectively this appears to be a resource with a high amount of wasted potential with barely one percent of cases actually being entered into the system. The greater concept of $\operatorname{ViCAP}^{\circledR}$ is very parallel with that of this project in that there will be a narrowing of the gap between law enforcement agencies and forensic personnel altogether in the instance of case assessment and interpretation. The main complaints of $\mathrm{ViCAP}^{\circledR}$ were that the system required large amounts of data entry and was very troublesome to use. The application of different software to tackle the same problem has the potential to alleviate some of these issues. In order to be a viable and practical solution the software would have to be a more user friendly interface and would actually have to provide search-able results to the user. 


\subsection{IBM $^{\circledR}{ }^{\mathrm{i} 2}{ }^{\circledR}$ Analyst's Notebook $^{\circledR}$}

The intelligence network and model created from the research of this thesis will be completed through the utilization of IBM $^{\circledR}$ i ${ }^{\circledR}{ }^{\circledR}$ Analyst's Notebook ${ }^{\circledR}$ software. This is a software from IBM which is used for data analysis and investigation. This application is due to the effective intelligence analytical capabilities of the software. The software is a visual intelligence analysis environment that enables the user to quickly collate, analyze, and visualize data from numerous sources while reducing the time required to discover key information in complex data [16]. This is achieved through the software's ability to optimize the value of massive amounts of data and information. The application of this model utilizing the software would deliver timely, actionable intelligence to help identify, predict, prevent, and disrupt criminal activities based upon evidentiary value [16].

The true utility of this software will be exploited in development of the forensic intelligence model. The software will allow for the creation of a single cohesive and integrated network from distinct and contrasting data. The ability to search the network will allow for rapid identification of key individuals and patterns between the cases. Through the graphical interface the user will have an increased comprehension of the structure and hierarchy of incidents and the evidence attributed to these events. The interface also helps the user interpret the totality of the case information. Operational decision making will be also simpler as this network can be shared between individuals and agencies for crime linkages [16]. IBM $^{\circledR}$ i $2^{\circledR}$ Analyst's Notebook ${ }^{\circledR}$ shows utility in the application to this research and moreover the forensic science community.

The application of IBM ${ }^{\circledR}$ i2 ${ }^{\circledR}$ Analyst's Notebook ${ }^{\circledR}$ provides a range of methods to quickly breakdown the information associated with criminal activity. The program allows for data acquisition to be input in numerous ways for a broad range of data types. Structured data can be rapidly imported through the use of a wizard-style visual importer. An additional method to import data is through an intuitive drag and drop mode [17]. IBM ${ }^{\circledR}$ $\mathrm{i} 2{ }^{\circledR}$ Analyst's Notebook ${ }^{\circledR}$ includes manual data entry options that are designed to allow rapid chart item creation and editing. Users are able to choose from the wide-ranging array of icon types to visually represent items or events through the visual interface. This array has the capability to be expanded upon by the creation of templates which can be customized to any requirements the analyst may have. Another way the software can import data is through connection to and query of available data sources or repositories via extensibility options [17]. IBM ${ }^{\circledR}{ }^{\circledR} 2^{\circledR}$ Analyst Notebook ${ }^{\circledR}$ also offers the ability to import data in XML format. Style sheets can be created that are used in the import process to transform the data into the format that is required for IBM ${ }^{\circledR}{ }_{1} 2^{\circledR}$ Analyst's Notebook ${ }^{\circledR}$ [17]. In terms of extension, Analyst's Notebook ${ }^{\circledR}$ has capability with automated data acquisition products such as IBM ${ }^{\circledR}$ i2 iBridge $^{\circledR}$ which can link to a data source or repository and extract information into the software [17]. The numerous ways which data can be imported or input to the software exemplify its value to investigators. The customizability of the data entry methods allow for different agencies to employ this in a multitude of ways to suit the needs of the case file. For this research, import specification templates 
were created which enable the user to import criminal investigation data and casework files into the cohesive intelligence framework.

Furthermore, there are numerous ways to represent the details contained within a case file. Items can be represented as entities, links, events, time lines, or attributes in order to best represent the data to be analyzed. This helps drive the effective analysis and visualization of a wide range of investigative information. For example, an image (i.e. mug shots or CCTV imagery) can be stored pertaining to an entity. These images can then be displayed on the chart in place of an entitys visual icon or within the object itself [17]. Supplemental information or additional information from a different source can be added in the form of cards. The utility this multidimensional incorporation of data is that it allows the investigator to enter notes from interviews or statements. The network then allows for an entirely searchable digital case file instead of traditional notes on paper. Items can also be graded to record information such as source, reliability, and clearance level. Items imported from external data sources can also return the property information on those items in the form of data records. Data can be displayed as association, temporal, spatial, statistical, and spreadsheet views. Multiple views help to give a wider understanding of all the important who, why, what, when and where aspects of the case at hand and the overall association of the case within the network [17].

There are several other notable advantages of IBM ${ }^{\circledR} i 2^{\circledR}$ Analyst's Notebook ${ }^{\circledR}$. The software aids in identifying potential temporal trends such as activities that occur more at a particular time of day and day of week through the utilization of heat matrixes, detailed timeline views, and histogram visualizations. Additionally, IBM ${ }^{\circledR}$ i2 ${ }^{\circledR}$ Analyst's Notebook ${ }^{\circledR}$ can map information to a Google Earth ${ }^{\circledR}$ client or export selected chart data to a $\mathrm{kml} / \mathrm{kmz}$ file, a common mapping file format used by numerous mapping applications [17]. The software has another great feature where it can automatically find connecting networks. This helps to identify potential intermediaries between seemingly unconnected entities and highlight possible networks that connect multiple entities of interest. Additionally, there is a restriction put in place by the software where if data is being entered and it already exists in the system it merges the new input data with that existing and yields a notice for approval [17]. All of these features exist to aid an investigator with case assessment and interpretation.

Investigations can be comprised of several different dimensions. Figure 1.3 exemplifies the domains that can create problems within investigations. The right side of the figure is a representation of what is sought after through the use of an intelligence network; a single composite visualization. The comprehensive solution IBM ${ }^{\circledR} i 2^{\circledR}$ Analyst's Notebook ${ }^{\circledR}$ has for forensic intelligence networks exemplifies the wide range of possibilities and potential for the field. The multitude of possibilities makes the model customizable for agencies. Customizability alleviates the cumbersome nature of $\mathrm{ViCAP}^{\circledR}$ and provides an overall more viable option. 


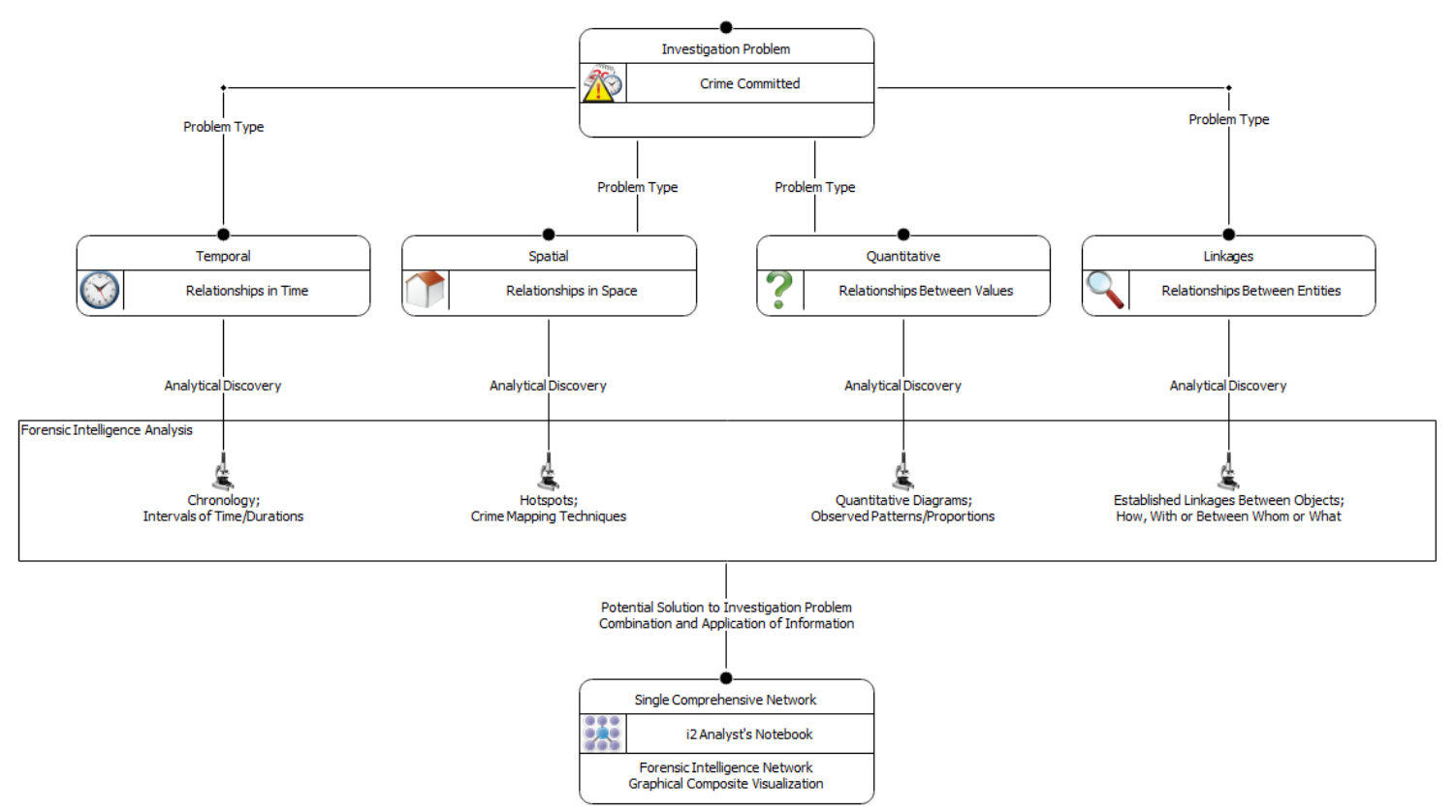

Figure 1.3: The dimensions of problems an investigation faces, IBM ${ }^{\circledR} i 2^{\circledR}$ Analyst's Notebook ${ }^{\circledR}$ functions to create the single composite visualization. Adapted from Rossy and Ribaux[18].

\section{$1.5 \quad \mathrm{R}^{\circledR}$ and RStudio ${ }^{\circledR}$}

Data entry, input, and transformation was accomplished through the use of $\mathrm{R}^{\circledR}$ and $\mathrm{R}$ Studio ${ }^{\circledR}$. $R^{\circledR}$ is a language and environment for statistical computing and graphics. $\mathrm{R}^{\circledR}$ provides a wide variety of statistical and graphical techniques. $\mathrm{R}^{\circledR}$ is an open source program which has the ability to develop code scripts to increase efficiency [19]. The utility of $\mathrm{R}^{\circledR}$ was extended through the use of RStudio ${ }^{\circledR}$. This is an integrated development environment (IDE) for $\mathrm{R}^{\circledR}$. It includes a console, syntax-highlighting editor that supports direct code execution, as well as numerous other tools [20]. RStudio ${ }^{\circledR}$ is also available in an open source form.

These two programs will allow for the extraction and transformation of case files for integration into IBM ${ }^{\circledR} \mathrm{i} 2{ }^{\circledR}$ Analyst's Notebook ${ }^{\circledR}$. A script of commands can also written and then executed which could extract vital information from the case file. This was done for extraction of information from databases. The information was then transformed and exported to a newly created file. The newly created file is then imported into IBM ${ }^{\circledR} i{ }^{\circledR}$ Analyst's Notebook ${ }^{\circledR}$ through a data import specification. An automated process saves 
the investigator time as there is no manual entry of the case details into the intelligence framework. Manual entry would then be supplemental with new details and be solely required upon need or conditions not set forth in the import specification model. Effectively

the features of $\mathrm{R}^{\circledR}$ allow for a script to be developed to integrate large scale amounts of data into the intelligence network through the simple file execution.

The utility of the script is also valuable for the transformation of data. As the data comes out of the database repository (i.e. AFIS) it may not be in a suitable format for an import specification. Transformation of the data is done for the user with the scripts developed for the import specification model.

\subsection{Application to the Criminal Justice System}

The current state of the United States criminal justice system is ineffective and disconnected in numerous regards. The current paradigm is reactive in nature for policing and investigations. Furthermore, there is a schism between forensic science, police, and attorneys. Forensic science is a rapid developing field which is often times underexploited, or simply not used to the fullest potential. The nature of investigations demand factual development that is holistic in scope to further the development of linkages between crimes or activities. Ludwig and Fraser completed a study which identified recurring themes in publications over a thirty-year period that encompasses the on-going debate on the effective use of forensic science. A review of thirty-six reports published (predominantly in England and Wales) since the 1980s, considered the use of forensic science in the investigation of volume crimes. They concluded that there is a call for further research to improve understanding and aid the development of effective working practices and policies in the criminal justice system. The themes identified included forensic knowledge and training of investigators, communication and information exchange between specialists and investigators, timeliness of forensic results, interagency relationships and deployment of crime scene examiner resources [21]. The drawn conclusions are based upon twenty one reports which emphasized limited forensic knowledge (the value of evidence and uncertainty of the capabilities of forensic science); twenty-one reports identified limited forensic training of investigators; twenty-eight reports identified poor communication, nineteen reports emphasized poor interagency collaboration and inadequate relationships; thirty reports commented on poor use and deployment of resources (particularly crime scene examiners); and twenty-two reports identified poor timeliness and slow turnaround- times from laboratories [21]. The research findings suggest that these factors continue to hinder the effective use of forensic science despite technological advances and this paper considers their potential causes.

A solution to close the gap between the several disciplines involved in investigations is the use of a forensic intelligence network. A network allows for more interaction between policing agencies, and even different shifts in the same department. An integrated network with several contributors allows for continual data entry to create links between cases that may appear unrelated. There could be links drawn between incidents that have the same 
modus operandi. The ability to search the network and automatic correlation between cases even allow for entering officers to draw conclusions that could be missed due to a lack of experience in the field. Additionally, this network serves as a constant briefing for all officers to the incidents of the area, even those that happened the shift prior. Overall the entire criminal justice system must begin some transcendence toward a more proactive system, forensic intelligence is the key to doing so. There is also a built in quality assurance element that provides transparency. It becomes harder to overlook details, which helps the investigator, but also aids the court with a comprehensive look into the investigation. A complete look forces accountability of the investigator to the investigation and proper procedure.

The forensic intelligence network proposed by this thesis would allow for complete case assessment to be conducted. Not only could collection techniques be developed through better decision making, but also the method and model itself could be evaluated because it is graphical and transparent in nature. The utility of a model/tool which develops and allows for decision making regarding its very usage is novel in scope. A concern of forensic intelligence networks is that a priori information regarding a case may lead to the introduction of bias to an investigation. In a collaborative framework, different kinds of visualizations integrating forensic case data can play a central role for supporting decisions. However, designing an informative chart that does not bias the reasoning process is not straightforward [18]. Using visualization as a catalyst for a collaborative approach integrating forensic data thus calls for better specifications. The usage of a network should not infringe upon the decision making by introducing bias more than that of experience. As people, our experiences and observations serve as the basis for the majority of our decision making regardless. The significance of an intelligence network is that it may introduce information which may challenge and help to evaluate those preconceived notions we hold.

\subsection{Previous Research and Literature Review}

\subsubsection{Background of Forensic Intelligence}

Commonly forensic science is referred to as the study of traces, which themselves are present as remnants of an activity, most often a criminal activity. Traces can be considered as the most basic "material or physical" information on crime. This definition opens towards new territories to be explored: once detected and collected, they will follow a complex set of intertwined processes that ultimately compose an entire information system. Evidence must be collated and interpreted in order to provide knowledge used to make decisions at various levels of security systems and criminal justice [22]. Also known is that the processing of a crime scene is the object of many decisions which depend on a variety of factors. These factors often compete against each other because this decision making process occurs generally within police organizations that are somewhat torn between a security and justice paradigm. "Crime scene treatment, to a large extent, predetermines the quality and quantity of information available for intelligence 
processes, investigation and ultimately for court evidence" [22]. Ribaux et. al. state that forensic intelligence and intelligence led policing are necessary for the punctual systematic analysis of numerical traces such as comparison of DNA, footwear impressions, earmarks, tool-marks, fingerprints, and other traces. These traces provide a "substantial help for detecting the activity of serial offenders and globally informing on the current criminal situation, mostly for dealing with high-volume crime" [22]. Therefore, forensic science should engage in three service streams: investigative, intelligence, and the courts. The investigative and intelligence streams naturally combat time and backlogs; there is generally a default to the court stream. Forensic intelligence modeling will provide forensic science facilities with tools to engage in the provision of forensic science intelligence as part of an overall criminal intelligence capability [4]. When a series is detected, partly by the use of the comparison of traces, their profile can be analyzed and lead to the identification of the offender. Conversely, when an individual is arrested in a certain context (for instance at the proximity of a criminal event), evaluation of the current criminal environment can help delineate the extent of his/her possible activity [22].

Environmental knowledge is critical to the integration and structure of intelligence [23]. Integrating of several components within an investigation will yield more knowledge regarding each crime scene investigation and can provide a priori information which will derive more informed decision making in the field. Significant is shown with how investigators interpret the case. This interpretation is done in the context of (1) the strategic environment, (2) the criminal environment, (3) the immediate environment and (4) the physical environment [23]. Integration of knowledge yields complete and a holistic approach to making the correct decisions for the case.

Numerous models for reform suggest the novel approach which fully integrates forensic science data into an intelligence network. Solid methodology for the analysis of serial crimes would be developed which also supports decision making in the deployment of resources, either by guiding proactive policing operations or helping the investigative process. Formalization has helped to derive a computerized system that efficiently supports the reasoning processes in the analysis of crime and this demand exploitation [24]. This includes a diverse range of vectors which when combined with broader geographic and demographic information, may develop links between different crimes which would build up better knowledge of the crimes/patterns at hand. The gathering starts with "soft" intelligence gained from tip-offs, undercover operations and contacts in the criminal underworld [25]. The notion of compounding analysis is vital to the success of intelligence networks. This is defined as every additional unit has the potential to increase the "reconstruction" of the overall picture, even though there remains the possibility that some data might not be used. Implementation of an intelligence network the suspects can be identified at a much earlier opportunity, allowing for the rapid interdiction and easier prosecution of crimes that might otherwise go unchecked [25]. This linkage of disparate pieces of forensic information allows analysts to make a bridge between crime scenes, suspects, modus operandi and time periods [4].

Research on forensic science should be prioritized, instead of research within forensic 


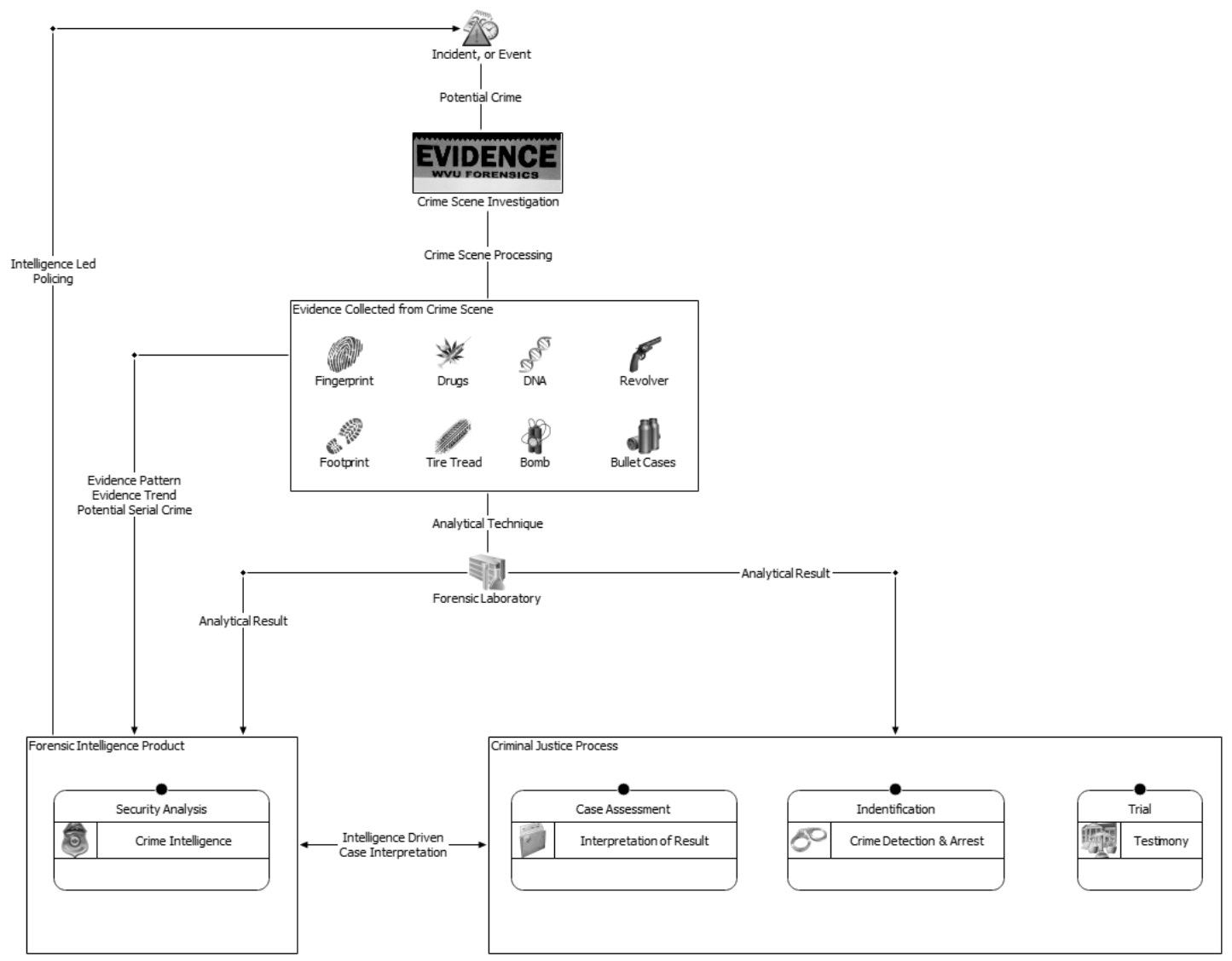

Figure 1.4: Role of forensic intelligence in the investigation and judicial processes. Risk analysis and forensic intelligence are integral to effective and knowledge driven forensic investigations.

science and the current justice paradigm. This includes developing and validating new tools and methods within the forensics paradigm promoted by the report as well as debating its nature. Research on such an entity utilizing fewer, more concise, fundamental pillars affords discipline and universality to its findings [26].

Forensic intelligence provides an avenue for the most critical part of an investigation: case based reasoning. This refers to when an investigator "tells a story, explains to a newcomer, or tackles a new situation, he systematically refers to previous items of experience. The fundamental reason is that few general models can be extracted in the field of crime investigation" [27]. This case based reasoning is so critical for the investigation because the integration of forensic case data can supplement information on the structure of criminality and give more insight either for operational or strategic decisions. Another 
useful function of the network is the potential that cases which are linked with forensic case data can also be compared to test hypothesis on how offenders activities transcend types of crimes (polymorphism) [28]. This is important because a systematic review was conducted which uncovered that the vast majority of events are linked through only one forensic link type (99.2 percent), further demonstrating the necessity to use all types of marks for a better detection of crime repetitions [28].

Overall there is great suggestion and support for the implementation of a model which is being proposed throughout the literature which attributes this idea as progressive in terms of the delegation of resources and decision making. The concept of a more integrated and informed police culture leads to more efficient and effective investigation from the very start. This then has a downstream effect on subsequent examination and analysis of evidence. All of this in combination with the potential to link to unsolved cases through a search-able network demonstrate the need for such a system.

The vitality of forensic intelligence models have been established in the literature $[2],[3],[5],[9],[24]$. The interconnectedness of investigative systems will greatly impact the criminal justice system and allow for an overall better approach to case management.

\subsubsection{Evidence Dynamics}

Evidence has a dynamic principle in that the value and relevance of that evidence can change throughout the progression of a case as the investigation continues. Evidence dynamics can also refer to the integrity of the physical evidence. However, "the value of physical evidence varies from type to type and case to case. In some investigations, its potential may never be fully appreciated" [29]. The term evidence dynamics is representative of any influence "that adds, changes, relocates, obscures, contaminates, or obliterates physical evidence regardless of intent. This creates a challenge for crime reconstructionists as they must consider and account for these factors in their interpretations" [30]. This stresses the need for the most objective and informed decisions. "We all make inferences daily, and we all collect, sift, evaluate, and then act upon evidence" [8]. The importance and call for more training of police in their recognition of potential evidence as information is required. The value of forensic evidence for police and prosecutors lies in its ability to interpret multiple physiological aspects of a crime scene and to link a particular suspect to it [8]. The most cognizant decision made is among the best things sought after in an investigation. Commonly it is something that cannot be completely taught and intelligence would serve as a tool by which all agents could make the best possible decisions.

Another function that an intelligence network could serve is the maintenance of evidence value. The assurance of accountability to the physical evidence is invaluable and can be tracked and displayed within a network. Also provided is a complete history for the evidence which can aid the investigator and account for the dynamic influences of evidence over the post discovery and collection phase [30].

An additional function that forensic intelligence networks can serve is through the teaching of officers the value evidence can have to their case. Horvath and Meesig present 
a review which reveals that most criminal cases do not involve the use of any physical evidence and that such evidence, even when available, is seldom seen by police detectives as having any intrinsic value. Detectives view physical evidence primarily to strengthen their position for the purpose of clearing cases by confession. No defendant would want to overcome the explanation required to nullify that in front of a jury. "Nevertheless, research shows that physical evidence improves clearances and convictions in burglary and robbery cases, which traditionally have low case resolution rates. Enhancement of the use and value of physical evidence to investigators, crime laboratory specialists, and others involved in criminal processing requires improved communication and collaborative efforts" [31]. An explanation regarding the utility of evidence could be of great value to police as a resource that trains recognition and subsequent collection of evidence.

\subsubsection{Case Assessment}

One of the most important parts of any investigation is decision-making. That decision making exists as the result of the assessment of the case as a whole. The interpretations, the thought process, the direction taken, and the logical process taken by the investigator are dependent upon the assessment of the case. "The drawing of rational and balanced inferences from observations, test results and measurements. This process, which we know as interpretation, is experiencing a steady period of evolution" [32]. Jackson and Jones introduce the concept of case assessment and interpretation through the development of a model with several recommended changes to the adversarial system. They demand an extension of the role played by forensic science in the criminal justice system since the true understanding of the field is lacked by key players and implementation of case assessment may validate how useful forensic science is. Their model for case assessment and interpretation consists of six steps and is as follows: (1) define the customer requirement; (2) assess how forensic science can help; (3) agree on a case examination strategy; (4) carry out case examination strategy; (5) interpret the results; (6) communicate [33]. They furthermore state that the manner in which forensic scientists interpreted their findings has remained largely unchanged for most of the twentieth century and today, "primarily relying on personal experience and personal opinion. In the sense that it was usually unclear to anyone else how the expert arrived at an opinion, such opinion could be hard to understand and to challenge" [33]. The arrival at conclusions appears to be a fundamental issue in which forensic science is perceived and used by all parties in the criminal justice system [1] [7]. The layer of transparency could be included through the presentation of an intelligence network, or a portion of one within a court room. This could serve as an instructional tool to the jury which would present all of the information in a graphical environment. This logical and robust presentation of information would also show any overstatements that have been made with regard to the evidence being presented.

Building upon the model above it is common that forensic work completed as an outcome does not properly consider the objectives of the customer. This means that there is solely limited value in measuring effectiveness of a forensic service [5]. This is partially 
due to the lack of knowledge regarding the field of forensic science. There are numerous opportunities to measure forensic effectiveness by linking forensic activity to crime outcomes achieved. The benefit achieved is that forensic contribution to crime resolution can be explored, especially at the summary level, to demonstrate the value forensic work adds to solving crime, and to aid decisions on allocation of scarce resources, using the basis of customer needs and outcomes achieved by applying differing forensic service levels. Initial analyses propose several forensic effectiveness measures and demonstrate the difficulty in obtaining complete and accurate data, as well as the need for data that can be used to validate assumptions [5]. This is key to obtaining the right result, and justice.

In a particular case much of the evidence will be interrelated, at minimum each piece of convergent evidence increases the likelihood of the truth of the other such pieces. "If one test of an inference is that the thesis with which it is consistent is, on holistic analysis, credible, then the whole case can be turned inside out and the truth of each piece of evidence comes to depend upon the credibility of the ultimate probandum rather than vice versa" [34]. If the evidence is not charted the result is not a true representation of the reasoning process. This may simply teach us that the inferential process is an extremely complicated one and that some compromises have to be made in setting it out on paper [34].

The interpretation of evidence will yield its overall utility and how it will fit and apply within an intelligence network. The interpretation of evidence is the most vital element to case assessment and decision making. Both of these are made easier, more efficient, and more consistent among different individuals by the utilization of an intelligence network. The case assessment and interpretation is the foundation for the direction of the case and how progression of an investigation extends. The completely search-able and graphical network serve as tools with which more sound judgment can be exhibited throughout all stages of the criminal justice system.

\subsubsection{Example of Case Assessment: The Yorkshire Ripper}

A case example is provided to illustrate the effectiveness of an analytical process as applied to an investigation. The following example is from Stuart S. Kind's "The Scientific Investigation of Crime", 1987 [35].

Contained within Table 1.1 is the information regarding the incident of numerous suspected Yorkshire Ripper attacks. The time, date, and location of the seventeen supposed Yorkshire Ripper cases were examined by the advisory team before the arrest of the assailant, Peter William Sutcliffe.

The team considered a map which the positions of the seventeen crimes were plotted. Each position was marked with a map pin and a piece of thread was tied to it. This was to consider "At which single location on the map could be placed an eighteenth pin, such that if we stretched the seventeen threads and tied each loose end to the eighteenth pin, the minimum total amount of thread would be used?" This is of value because any model of a real situation is a simplified concept, because models have proved their worth in many 


\begin{tabular}{|c|c|c|c|c|c|c|c|}
\hline Offence No. & Day & Date & Location & Clock Time & GMT & Offence & Victim \\
\hline 1 & Saturday & 5 July 1975 & Keighley & 0110 & 0010 & Assault & Anne Rogulskyj \\
\hline 2 & Friday & 15 August 1975 & Halifax & 2300 & 2200 & Assault & Olive Smelt \\
\hline 3 & Thursday & 30 October 1975 & Leeds & 0115 & 0115 & Murder & Wilma McCann \\
\hline 4 & Thursday & 20 November 1975 & Preston & 2220 & 2220 & Murder & Joan Harrison \\
\hline 5 & Tuesday & 20 January 1976 & Leeds & 1900 & 1900 & Murder & Emily Jackson \\
\hline 6 & Saturday & 5 February 1977 & Leeds & 2330 & 2330 & Murder & Irene Richardson \\
\hline 7 & Saturday & 23 April 1977 & Bradford & 2315 & 2215 & Murder & Patricia Atkinson \\
\hline 8 & Sunday & 26 June 1977 & Leeds & 0145 & 0045 & Murder & Jayne MacDonald \\
\hline 9 & Sunday & 10 July 1977 & Bradford & 0100 & 2400 & Assault & Maureen Long \\
\hline 10 & Saturday & l October 1977 & Manchester & 2130 & 2030 & Murder & Jean Jordan \\
\hline 11 & Wednesday & 14 December 1977 & Leeds & 2000 & 2000 & Assault & Marilyn Moore \\
\hline 12 & Saturday & 21 January 1978 & Bradford & 2130 & 2130 & Murder & Yvonne Pearson \\
\hline 13 & Tuesday & 31 January 1978 & Huddersfield & 2110 & 2110 & Murder & Elena Rytka \\
\hline 14 & Tuesday & 16 May 1978 & Manchester & 2200 & 2100 & Murder & Vera Millward \\
\hline 15 & Wednesday & 4 April 1979 & Halifax & 2330 & 2230 & Murder & Josephine Whitaker \\
\hline 16 & Sunday & 2 September 1979 & Bradford & 0215 & 0115 & Murder & Barbara Leach \\
\hline 17 & Monday & 17 November 1980 & Leeds & 2120 & 2120 & Murder & Jacqueline Hill \\
\hline
\end{tabular}

Table 1.1: Times : Victim Last Seen/Assaulted. Adapted from Kind[35].

other intellectual situations and because, in this specific instance, the model proved to be of value.

"A multitude of elements which could affect the situation were ignored. The method of pins and thread exemplify direct distances, and takes no cognizance of the actual nature of the routes available in the area. Are direct roads available or would communication have to be via minor roads? Do the routes available go through built up areas with heavy traffic or through relatively quiet country districts? What evidence is there that a criminal may be motivated by a desire to optimize his series crimes by choosing locations based, in any way, on his place of residence or work, whereas it is obvious that it is in his own best interest to confuse the issue as much as possible?"

In the seventeen cases cited the Ripper attacked his victims after sunset. This meant that during the summer months when days were longer the attacks tended to be later. If it were possible to allow for this effect of day length, for example by looking at the lapse of time from sunset until the time the crime was committed, would any pattern be discernible?

Obviously there were difficulties. In no case was the time of attack known with absolute precision and this uncertainty could render the value of any such examination doubtful. However the reasons for making an attempt to discern pattern in the timing of the attacks are just the same as those given above in relation to the center of gravity studies.

By plotting the crimes in this fashion it became immediately apparent that there was a marked and progressive tendency for the crimes to be committed later in the day during the summer months. This in itself is unremarkable. Next sought was a determination of any patterns present regarding this timing. This was carried out with "line of best fit" through the scattered points.

Simply that, having rather crudely allowed for day length on our graph, the Ripper 
crimes which were committed later than the average time tended to be in Leeds and Bradford. This was hardly a result which could have been produced convincingly in the witness box as court evidence. However, it is at least low-grade evidence which, combined with other low-grade evidence, might help to point the investigator in the right direction.

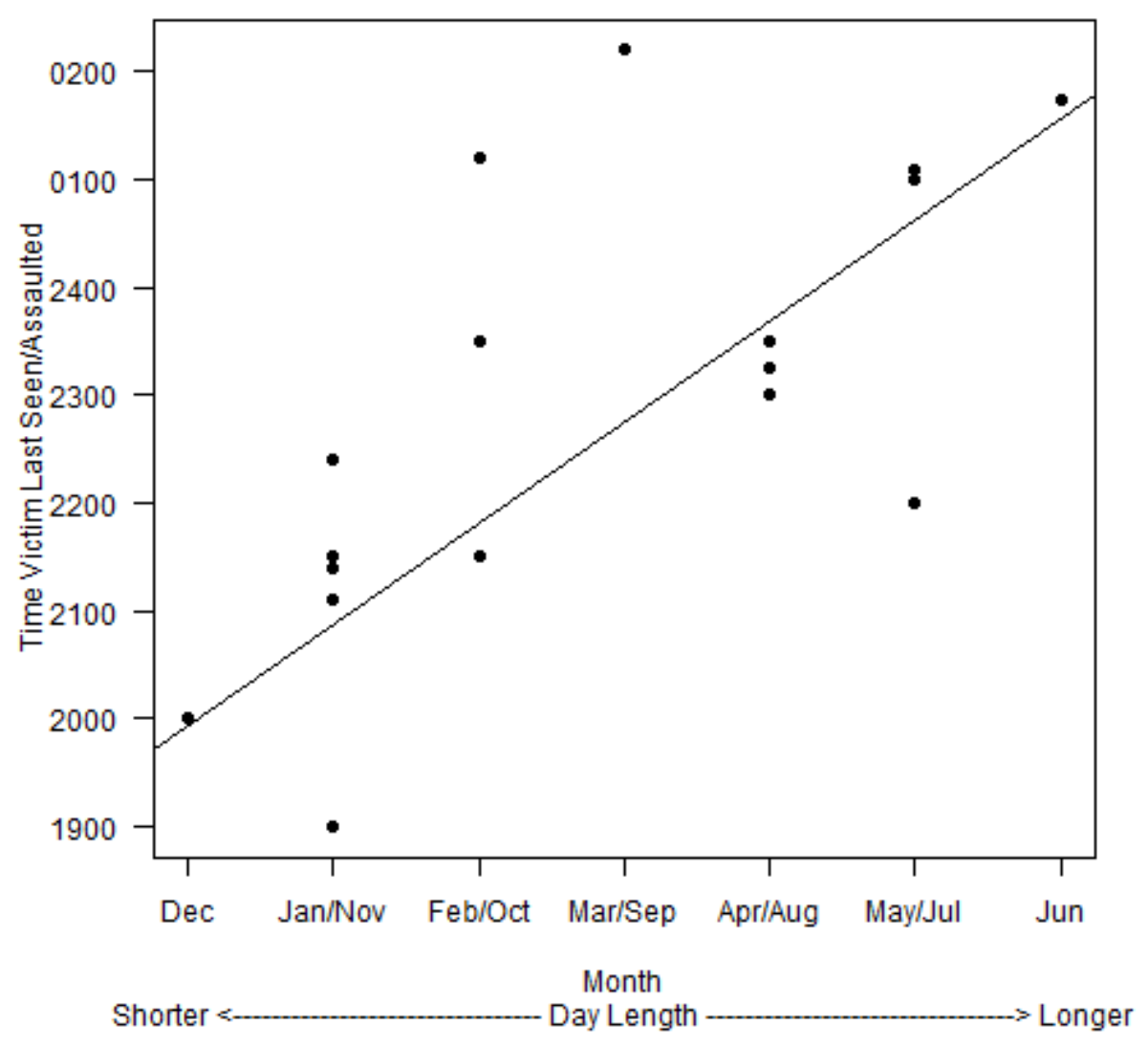

Figure 1.5: The data from Table 1.1 plotted as clock time (ordinate) and day length (abscissa). It is instructive to rework the data in the form of a simple rank order after sunset, particularly in the light of the special status of attack No. 4 of Table 1.1. This was the only one of the seventeen attacks to which Peter William Sutcliffe did not plead guilty. Adapted from Kind[35]. 


\section{Test Scenario}

In order to show the viability of this thesis project a model forensic intelligence network was created in a preliminary study. This setup is representative of the secure network that would exist in investigating agencies. The small scale network was developed to show the ability of IBM ${ }^{\circledR} \mathrm{i} 2{ }^{\circledR}$ Analyst's Notebook ${ }^{\circledR}$ to function in an investigative system. The additional purpose of this setup was to attempt development of an intelligence network by several individuals concurrently. The network consisted of four computers or work stations. The application was found to be usable on several different computers on the network, however it was not possible to work concurrently on the same file. Upon further investigation, the Premium version of IBM ${ }^{\circledR} \mathrm{i} 2{ }^{\circledR}$ Analyst's Notebook ${ }^{\circledR}$ is required to work in the same file at the same time. Further investigation of multiple-user integration was not completed beyond this point due to use of the base version of the software.

Utilizing IBM ${ }^{\circledR} i 2^{\circledR}$ Analyst's Notebook ${ }^{\circledR}$ a forensic intelligence network was created. Criminal case information was provided in the form of several different cases by Dr. Keith Morris during the FIS 501: Foundations of Criminalistics course at West Virginia University. The case data was manually entered into the software and a network was generated as a result. This network is a graphical representation of twenty-eight total cases and the connections between them. These connections are comprised of links several drawn from hits in CODIS and NIBIN among other sources. Individuals involved, evidence tags, descriptions, dates, times, and any available data were entered and were found to be entirely search-able. The network also contains identification information such as complete DNA profiles and firearm identification information in the form of IBIS results. The DNA profile is entered based upon the thirteen CODIS locus allele calls in order without any spaces. The details of entities are exhibited through attributes to a firearm. Attributes associated with that entity are: the manufacturer, model, caliber, and serial number. Instances allow for details to be input regarding an object, event, link, or anything present in the network. The links between the cases serve as the true utility of this research and how the network is beneficial to proper investigation technique.

The completed network is visible in Figure 2.1. Overall this network was used as a preliminary study as a proof of concept for this thesis project. An example of how a case appears is visible in Figure 2.2. Additionally, Figure 2.3 provides a larger image of what case linkage appears like within IBM ${ }^{\circledR}$ i $2{ }^{\circledR}$ Analyst's Notebook ${ }^{\circledR}$. Shown in the network are numerous linkages that have been drawn between the separate cases. These cases are linked through several factors however DNA and firearm analysis of collected evidence 
were the main contributors to those linkages within this test scenario. The layout of this network helps to understand the relationship between cases and the totality of evidence that was collected throughout the investigations. 


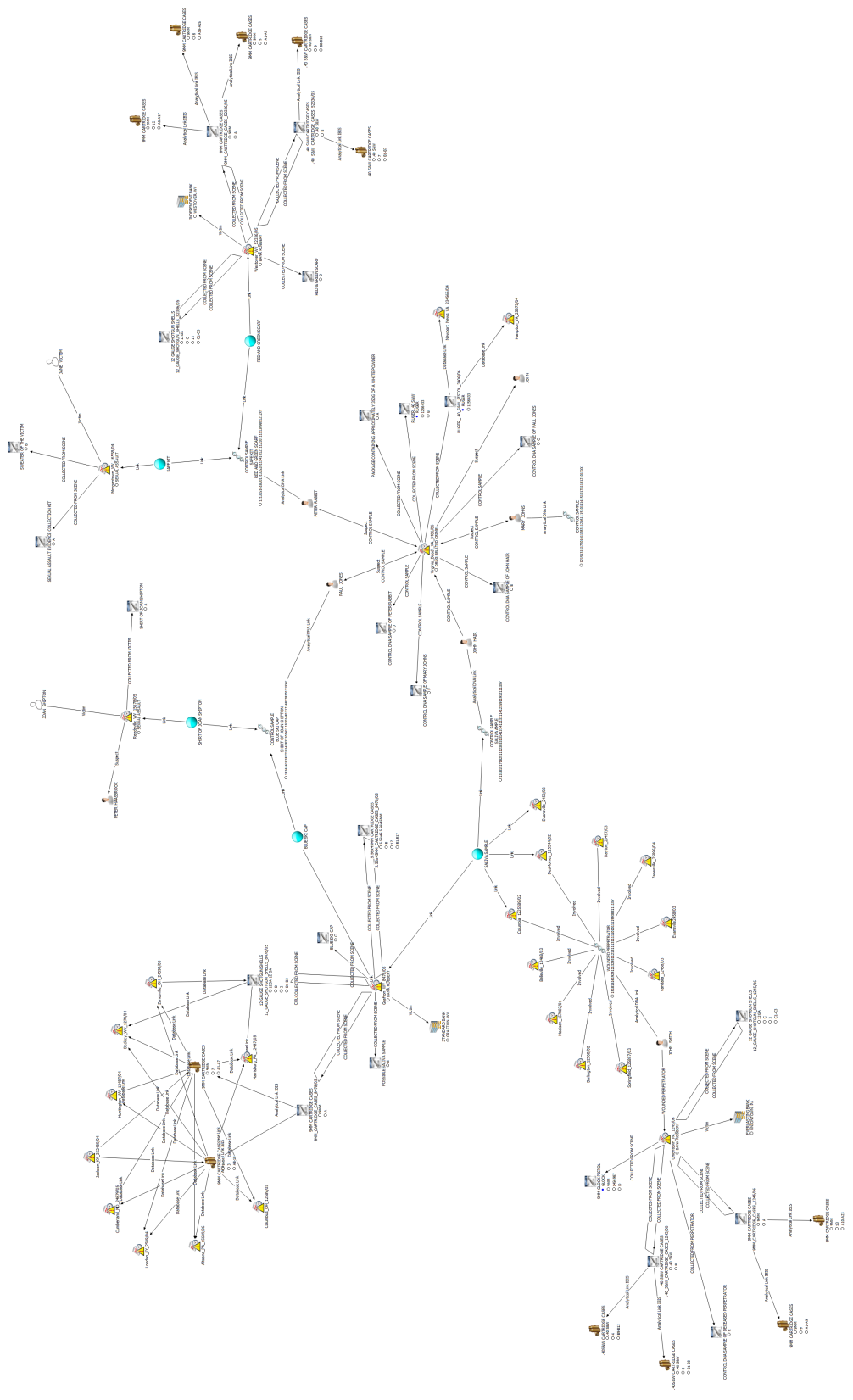

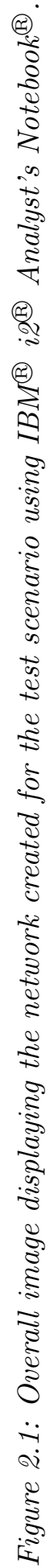




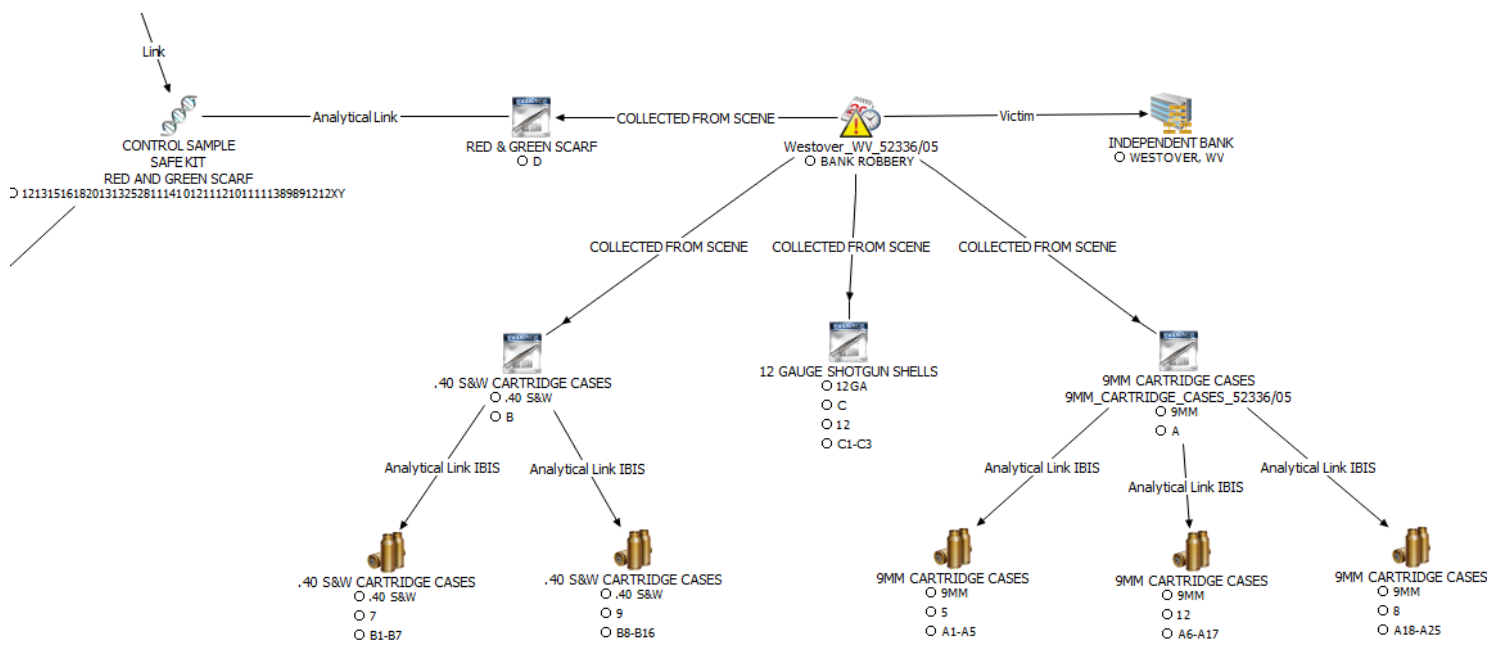

Figure 2.2: This is a representation of a single case that has been entered into IBM ${ }^{\circledR} i 2^{\circledR}$ Analyst's Notebook ${ }^{\circledR}$. 


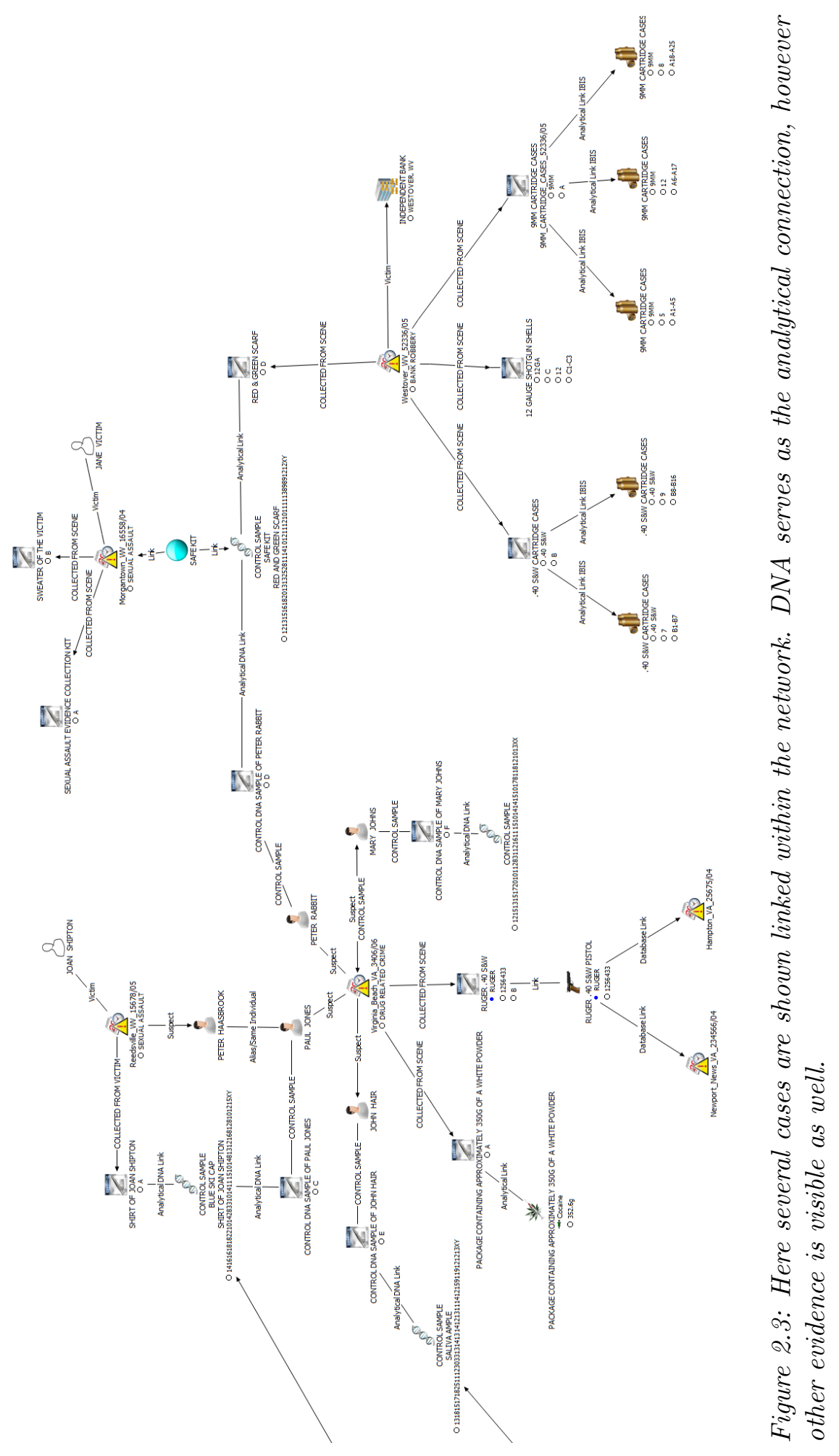




\section{Complete Utilization of Forensic Evidence Through Incorporation in Forensic Intelligence Networks}




\title{
Complete Utilization of Forensic Evidence Through Integration into Forensic Intelligence Networks
}

\author{
Jamie S. Spaulding ${ }^{\mathrm{a}, *}$, Keith B. Morris ${ }^{\mathrm{a}}$ \\ ${ }^{a}$ Department of Forensic and Investigative Science, West Virginia University, P.O. Box 6121, \\ Morgantown, WV 26506, United States
}

\begin{abstract}
The nature of forensic investigations are succumb to the current paradigm within the criminal justice system. A contemporary model is needed which moves from a single case to a multi-case approach for case assessment and interpretation of criminal cases. Forensic intelligence frameworks provide a solution through integration of criminal case information into a large scale graphical and analytical network. Utilization of closed or adjudicated cases within such a framework enables the investigator to access potentially forgotten information in order to solve the case at hand. An import specification model was developed which incorporates the information relevant to the incident and the evidence recovered as a product of the investigation. The model demonstrates the effectiveness of incorporating information through linkage development that could be missed with reliance on memory. Additionally, import specifications provide a consistent approach to integration of cases into the network. Application of the framework aids in harnessing inter and intra-case linkages for a shift in the forensic landscape from a case-by-case approach to a multi-case global focus. The intelligence network furthers case assessment and interpretation through the visualization and linkage development of the given case with other entities in the network (environment of other criminal activity). The product of forensic intelligence yields the ability to conduct crime analysis which enables the identification, prediction, prevention, and disruption of criminal activity while informing operational decision making.
\end{abstract}

Keywords: Forensic, Intelligence, Database, Analyst's Notebook, Case assessment

\section{Introduction}

Forensic science serves as an analytical tool for criminal investigations through evaluation of evidence. Forensic evidence is generally circumstantial in nature meaning that it is evidence that can lead to inferences about fact. For example, a fingerprint or DNA sample can put suspect at a scene, but lacks the ability to prove guilt. However, this in no manner weakens forensic evidence. Through the integration of evidence associated with a

\footnotetext{
*Corresponding Author

Email address: jspauldi@mix.wvu.edu (Jamie S. Spaulding)
} 
criminal investigation, linkages can be drawn both between the evidence and with other entities. In the context of an investigation an entity is any object with a distinct and independent existence such as a person, weapon, or vehicle [1]. As with any object, there are characteristics of the object; these are referred to as attributes. An example would be a firearm (entity) with the following attributes: manufacturer, caliber, serial number, etc.... When considered, there is a vast amount of information relevant to a given investigation. Within the investigative community this information is being far underutilized for closure of criminal cases. After a case has been adjudicated the evidence and information ceases to be useful. The case has an incredible probability of ending up in a cabinet or shelf for storage until destroyed. The only remaining significance is through the investigators memory or for appellate purposes.

Downstream of the case being closed there could be significant use for the case. For example, it is widely known that the United States has the highest levels of recidivism in the world. Within three years of release, about two-thirds (67.8 percent) of released prisoners are rearrested. Within five years of release, about three-quarters (76.6 percent) of released prisoners are rearrested. Of those prisoners who were rearrested, more than half (56.7 percent) are arrested by the end of the first year [2]. The closed case in the cabinet may be useful considering this context. Criminals may go to prison and gain an education with respect to crime but old tendencies may persist. The individual may commit a similar crime, do so in the same area, or have a similar modus operandi as the prior case that had been long forgotten. The information contained within the previous case may be of value in determining the perpetrator of the new crime, regardless of who it may be.

The true utility of forensic science lies in intelligence-led policing, “... in other words as information to further direct ongoing criminal investigations and disruptions, rather than as props in the dramaturgy of a criminal trial" [3, p. 780]. Intelligence-led policing strategies are also known as forensic intelligence. Forensic intelligence is defined as "the accurate, timely and useful product of logically processing (analysis of) forensic case data (information) for investigation and/or intelligence purposes" [4, p. 172]. This definition indicates that forensic information supports other investigations through the collection, collation, interpretation, and dissemination of information. Potential implications are to revisit each step of the process to gain a complete intelligence product. In Ireland, a 2007 report concluded that "[t]he work of a forensic laboratory does not only concern evidence for the courts but should also give impulses to the investigation. The findings of the laboratory can often give valuable information that can assist the investigation or can be used as intelligence" [5, p. 12]. The true intelligence comes from the analytical processes applied to the information known as crime analysis. Crime analysis is the "qualitative and quantitative study of crime and law enforcement information in combination with socio-demographic and spatial factors to apprehend criminals, prevent crime, reduce disorder, and evaluate organizational procedures" [6, p. 13]. Santos [7] also adds that these outcomes are achieved through five different types of crime analysis:

- Intelligence analysis: the study of criminal activity to assist investigative personnel in linking people, events, and property. 
- Crime investigative analysis: the study of serial criminals, victims, and/or crime scenes as well as societal influences to develop patterns that will assist in linking together and solving current serial criminal activity.

- Tactical crime analysis: the study of characteristics such as how, when, and where the activity has occurred to develop trends to identify leads/suspects and clear cases.

- Strategic crime analysis: the study of crime information integrated with socio-demographic and spatial factors to determine patterns of activity and evaluate responses and procedures.

- Administrative crime analysis: presentation of findings/concerns from crime analysis to inform law enforcement, city government, and citizens of legal, political, and practical concerns.

This project is concerned with all five types of crime analysis above. The model developed for this project includes both a mechanism for development and the resultant intelligence network structure. Utilization of the case information is critical in the development of linkages between articles of evidence and moreover crimes.

\section{Rationale}

Crimes are solved through the assessment of linkages drawn between an incident, articles of evidence, and accused. This is referred to as case assessment and interpretation which is primarily achieved through personal experience and expert opinion. A case with more uncovered or stronger linkages generally has a much easier assessment by the investigator. But, what about cases that have fewer pieces of evidence or have gone cold? A repository of cases may alleviate the lack of information.

\subsection{Utility of forensic intelligence systems}

There are numerous advantages to developing a digital repository of case information. Firstly, the repository would consist of information from all of the agencys cases. Furthermore, this concept could be expanded to be multi-jurisdictional or exist between agencies. With the information collated, case assessment of a given case can take place within a global and historical context. Secondly, a repository or database of prior cases enables investigators access to cases outside of their own experience and gives a reference for recidivists as mentioned above. Digital case files can be utilized to create connections and develop linkages with the case at hand. Having the database as a tool is a better method that sheer reliance on investigators memory of prior cases. Thirdly, an extension of the prior point is that using the network in conjunction with the reports for the case may serve as a tool for trial preparation. The network may also be useful within the context of a trial as an illustration to the

jury as a testimonial aid. Finally, the intelligence network could be utilized in the briefing for the start of a new police shift. The investigators and officers could get a graphical look at the cases that have occurred and determine potential leads to follow up. 
All of the reasons listed above help to change the current paradigm that forensic science and law enforcement are trapped in. Forensic intelligence is a viable approach to create a proactive environment instead of the reactive system currently in place. A graphical network collated with all of the data enables the many different types of crime analysis presented above. Advancements in crime analysis enable a predictive element to allocation of resources and effort in crime prevention. The necessary advancement for the field is the complete utilization of resources within an agency, including prior case information.

\subsection{Need within the forensic community}

There is a profound need within the forensic community to adopt a more effective method for case assessment within investigations. Several points within the Presidents Council of Advisors on Science and Technology (PCAST) report illustrate that forensic science still has room for improvement. In the PCAST report, the committee highlights that "reviews of trial transcripts have found that expert witnesses have often overstated the probative value of their evidence, going far beyond what the relevant science can justify" [8, p. 29]. As indicated above, graphical intelligence systems within a courtroom may alleviate the investigators ability to over-state the significance of the evidence. This can be accomplished through grades associated with the links signifying how strong the connection is between entities. The report also added that investigations including forensic practice have problems stemming from the lack of a strong 'quality culture,' "specifically, dozens of investigations of crime laboratoriesprimarily at the state and local levelhave revealed repeated failures concerning the handling and processing of evidence and incorrect interpretation of forensic analysis results." [8, p.33]. A more intuitive and effective intelligence analysis environment which enables the user to quickly collate, analyze, and visualize data from numerous sources appears to be a viable solution. Another advantage is potential reduction in time for the discovery of key information within the case. The network would also allow for a new quality assurance method in the form of administrative review. With entities and linkages displayed in a graphical format, a supervisor could complete a review of the network and ensure that the case assessment and the interpretations made are valid.

The need for a higher level of case assessment is furthermore driven by the numerous diverse types of criminal patterns that exist. The International Association of Crime Analysts (IACA) defines a crime pattern as two or more crimes that are treated as a single unit of investigative analysis and meet the following criteria: (1) share at least one point of similarity (crime type, offender/victim behavior, type of victim or target, type of property targeted, or location) which creates a distinction from other crimes of the time period; (2) the victim and offender are strangers; and (3) the crimes occur within a limited time frame [7]. Additionally, the IACA gives numerous types of observable crime patterns:

- Series: A group of similar crimes thought to be committed by the same individual or group of individuals acting in concert.

- Spree: A specific type of series characterized by high frequency of criminal activity within a brief time frame; activity appears almost continuous. 
- Hot prey: A group of crimes involving victims who share similar physical characteristics and/or engage in similar behavior.

- Hot product: A group of crimes in which a unique type of property is targeted for theft.

- Hot spot: A group of similar crimes committed by one or more individuals at locations within close proximity to one another.

- Hot place: A group of similar crimes committed by one or more individuals at the same location.

- Hot setting: A group of similar crimes committed by one or more individuals that are primarily related by the type of place where crimes occurred.

Identifying the type of pattern is important because appropriate police responses will vary depending on the nature of the pattern. For example, tactical responses to hot spot or hot place patterns would focus less on identification and more on deterrence efforts such as directed patrol, whereas a series or spree would benefit from suspect identification methods. Understanding the type of pattern enables investigators and administrators to best use resources in response. Intelligence network analysis serves to uncover links that could possibly be overlooked by investigators. An added benefit of intelligence analysis is the potential to close more cases. For example, without linkage of cases in the same pattern, an individual may be implicated or convicted for a crime when in fact that individual should have been convicted of the entire series of crime. The true benefit is a higher percentage of closed case which provides closure to victims and increases the effectiveness of an agency. Identification of patterns and development of linkages is substantial need within the investigative community to ensure the complete use of all resources for effective criminal investigations.

\section{Materials and Methods}

To show that forensic intelligence analysis is a suitable option for criminal case information, a database of cases was created. The cases and information that comprised the database were adjudicated cases beyond the statute of limitation and were received from a police agency. The information was extracted from the case files into Microsoft Excel spreadsheets.

\section{1. $I B M^{\circledR} i{ }^{\circledR}$ Analyst's Notebook ${ }^{\circledR}$}

IBM $^{\circledR}$ i $2^{\circledR}$ Analyst's Notebook ${ }^{\circledR}$ was utilized for the development of the intelligence network associated with this project. Analyst's Notebook ${ }^{\circledR}$ is a software from IBM ${ }^{\circledR}$ used for data analysis and investigation. The software is a visual intelligence analysis environment that enables the user to quickly gather, organize, analyze, and visualize data from several sources. In this model, the sources are the different criminal cases within the database. The implementation of this model utilizing the software delivers timely, actionable intelligence 
based upon evidentiary value to help identify, predict, prevent, and disrupt criminal activities. A single cohesive and integrated network was developed from the totality of case data contained within the repository.

Analyst's Notebook ${ }^{\circledR}$ was selected as a suitable platform for creating an intelligence model due to the variety of entities that are built into the program. Among the numerous panels of entities built into the program, there are sections which contain icons for crime, cyber-crime, locations, and weapons. Figure 1 provides an example of the entity options for different evidence types.

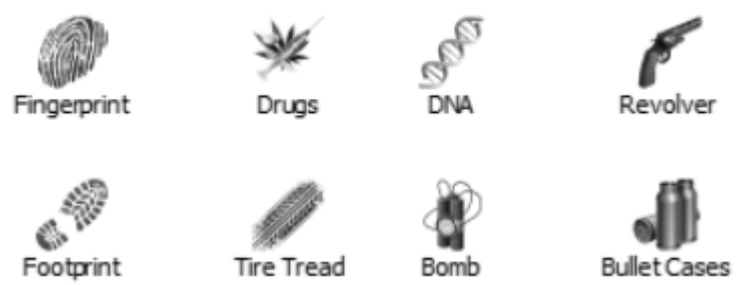

Figure 1: Image captured from $\operatorname{IBM}^{\circledR}{ }^{\circledR} 2^{\circledR}{ }^{\circledR}$ Analyst's Notebook ${ }^{\circledR}$ showing the built in entity options for articles of evidence.

Another advantage of utilizing IBM ${ }^{\circledR} \mathrm{i} 2{ }^{\circledR}$ Analyst's Notebook ${ }^{\circledR}$ is that the variety of entities allows for a multitude of possibilities. The large number of icons allows for a designation of a given entity when creating the network so that there is less ambiguity amongst users. This means that an icon can be used consistently as a representation of an entity in the network and there is no indecision as to what should be used.

\section{Generation of a forensic intelligence network}

In order to develop an intelligence network that can accommodate and accurately depict the case at hand, import specifications were created to translate the spreadsheets of case information. An import specification defines how Analyst's Notebook ${ }^{\circledR}$ converts a text or spreadsheet file into chart items (including entities, attributes, and instances) to be analyzed and added to the network. The import specification serves as a mechanism to incorporate the information into the network consistently. The model created during this project consists of three distinct import specifications.

\subsection{Import Specifications}

The created import specifications are a two step process. Firstly, two import specifications were created to incorporate the criminal case information (e.g. case description, potential suspects, victims). One of the specifications was created to be utilized for criminal cases in which the victim was an individual. The second specification was created to incorporate the information of criminal cases in which the victim was an organization or business. The distinction between these import specifications was that the entity depicting 
the victim changed icons to obtain a more effective representation of the victim type. The design of the import specification is shown in Figure 2.

As an example the case shown in Figure 2 has four potential suspects and two victims involved. Each individual has an underlaying unique identity, however the name visible in the network is as follows: "First_Middle_Last_Suffix". The victims are represented as a silhouette consisting of a black outline. Suspects or persons of interest are presented as a generic icon for an individual. The difference in icon is solely to aid the user in differentiating persons involved in the case. Below the icons are the attributes associated with the given entity. The following are attributes shown for an individual in the network: date of birth, race/ethnicity, social security number, and gender. Also shown are the links between the incident icon and the entities, these are shown as "(same as Type)" in Figure 2. This means that the link type corresponds to the designation as a potential suspect, a victim, or someone involved; that title is displayed on the graphical network. This is the shell by which IBM ${ }^{\circledR}$ i $2{ }^{\circledR}$ Analyst's Notebook ${ }^{\circledR}$ interprets the spreadsheet information for import. As the information is imported, the software populates these fields (entity names, attributes, cards) based upon columns in the spreadsheet which have been assigned. Simply filling out the spreadsheet with information of the case and running the import specification builds the network automatically.

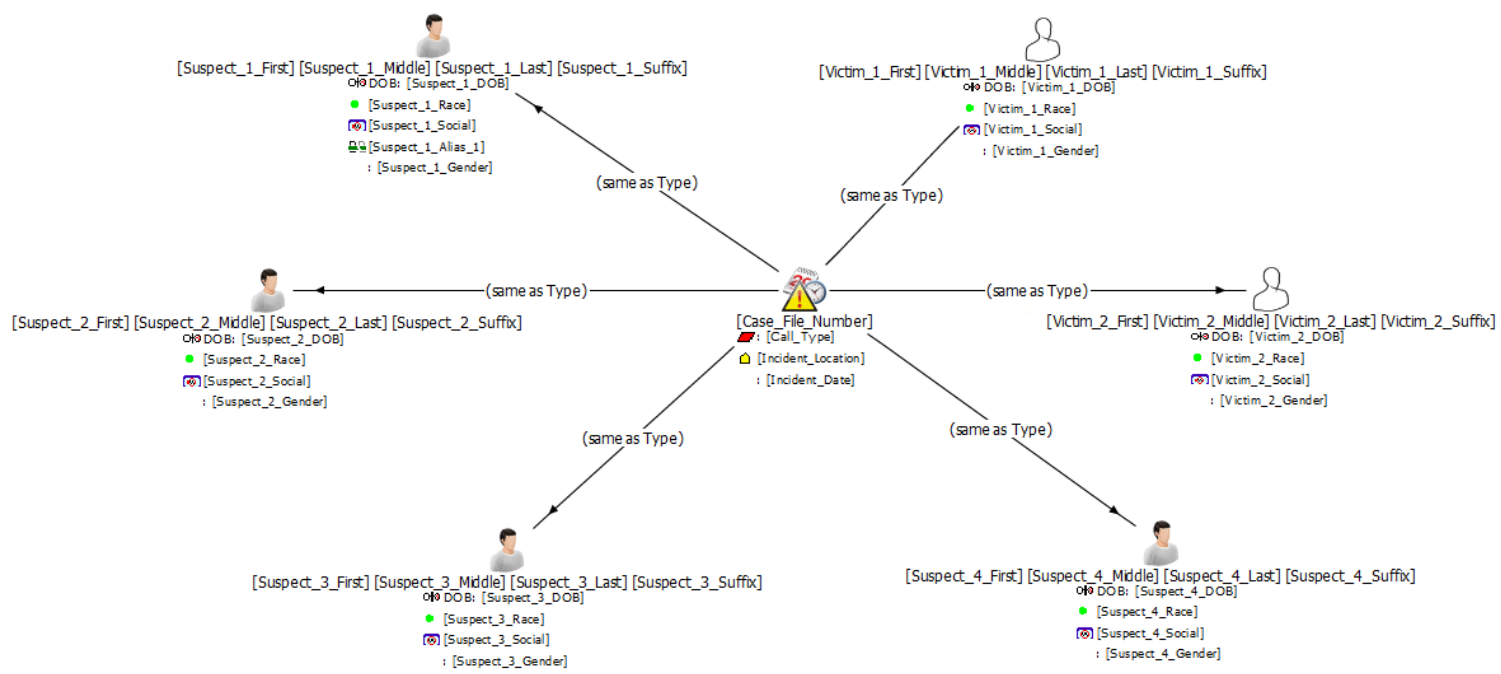

Figure 2: Image captured of the import specification for a case with persons as victims. Shown is the linkage of each individual to the case file. 
Finally, the third import specification was developed to add evidence collected on scene or associated with the case into the network. The evidence was automatically linked to the given case. Attributes were also assigned to the entity (if available) and included: evidence tag number, manufacturer, model number, and serial number. The link between the entity and the case was labeled with the role that the entity played in the case (e.g. collected from scene, stolen, recovered from suspect, etc.).

After the import specifications are run, the case(s) is/are imported into the network. An example of a case imported using the above import specifications is shown in Figure 3. This case involves an armed robbery of John NA Smith where three articles were stolen from his person. There is no limit to the amount of evidence or individuals that can be associated with a case and the import specifications developed through this project make an user friendly mechanism to incorporate case data into an intelligence network for analysis and linkage development. Please reference Appendix $A$ and Appendix $B$ for complete images of the developed network.

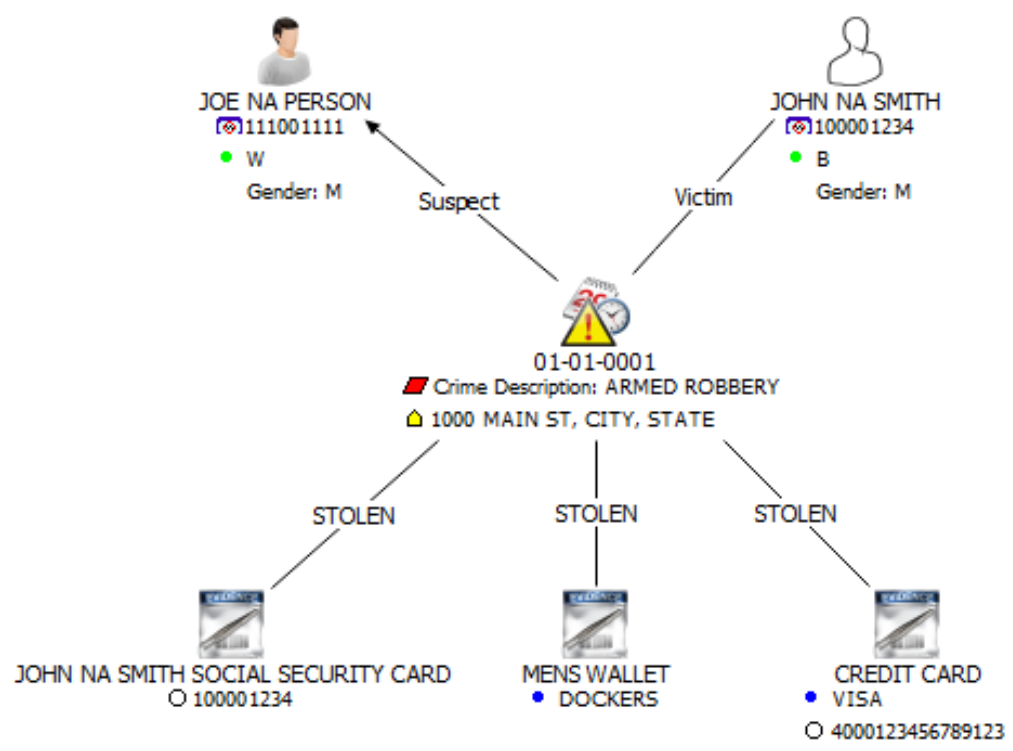

Figure 3: Image captured of the import specification for a case with individuals as the victims. Shown is the linkage of each individual to the incident. 


\subsection{Network design for consistency}

In order for an intelligence network to function properly there must be consistency throughout the network to sustain a searchable nature. This allows for a uniform search method that can be used within the network. Furthermore consistent entry is necessary for the linkage of entities. Therefore, there must be a standard method for case entry into the network. Beneath each entity is an identity. This identity must be unique to that particular entity. For individuals, 'First_Middle_Last_Suffix_SocialSecurityNumber' was used as a unique identity. Such an identity allows for the network to identify the person by name or SSN if needed. This becomes applicable if a witness claims to have seen John Smith near the scene at the time of incident, a search can be made in that case for John Smith which encompasses all notes and entities. Articles of evidence were assigned an identity of 'Case\#_Article_Tag\#'.

A standard form of network development may seem tedious, redundant, and difficult to achieve. However, it is critical for the software to automatically draw connections or links through identification of entities already in the network. The design of the import specification model aimed to alleviate this through an Microsoft Excel ${ }^{\circledR}$ spreadsheet that automatically populates fields and a list of requirements for the investigator using the system. Among the requirements are: all fields must be in capital letters (IBM ${ }^{\circledR} \mathrm{i} 2{ }^{\circledR}$ Analyst's Notebook $^{\circledR}$ is case sensitive); no spaces (instead underscores), no dashes or spaces for social security numbers (e.g. 123456789), and attention to correct spelling. A standard method for data entry into the system is also ideal as it helps to achieve a consistent result amongst different users. Additionally, the standardized method ensures that the system functions optimally and prevents the development of false links. For entities that are in the network there must be a constant update of that file to ensure network continuity and accuracy. This notion extends to the input of the date and time of all events. Accurate time and date information allows for the software to yield a chronology if necessary or create heat maps at given times if desired. The chronology allows the user to see an event frame of the scenario if desired.

\section{Case assessment for criminal investigations}

Several avenues of case assessment and interpretation are available through the application of this model. "The drawing of rational and balanced inferences from observations, test results and measurements. This process, which we know as interpretation, is experiencing a steady period of evolution" [9, p. 152]. The manner in which forensic scientists interpret their findings has remained largely unchanged for most of the twentieth century and today. Forensic scientists and investigators in general "primarily rely on personal experience and personal opinion. In the sense that it was usually unclear to anyone else how the expert arrived at an opinion, such opinion could be hard to understand and to challenge. In addition to this lack of transparency" [10, p. 2]. Suggested is a need for a more apparent, repeatable, and objective method to assess the criminal case. The developed intelligence

network model is useful in accommodating such need. The utility of an import specification is that the mechanism is fixed and the information is merely added into the spreadsheets. 
Any additional changes within the network can be tracked to develop a history of actions for reproducibility purposes. If evidence associated with a case is not charted, the result is not a true representation of the reasoning process carried out by the investigator. Representing the reasoning process is of the utmost importance because the inferential process is a complicated one [11]. The intelligence network approach also lends for assessment within propositions of crime level; source, activity, and offense. "Science is about understanding; an essential element of understanding the place of the scientist in a criminal justice system is that of defining the propositions he/she can meaningfully address in a given framework of circumstances" [12, p. 10]. A scientist cannot speculate on the truth of a proposition without the consideration of at least one alternative proposition. A more holistic view of evidence within the suggested intelligence framework may provide insight to conclusions drawn. To draw inferences about higher level propositions (e.g. offense), the scientist needs to be given information which leads to 'a framework of circumstances' [13]. Communication or interaction between scientist, investigator, and defense team may facilitate the greatest assistance to the court. This interaction between parties and sharing of information may be well served with the intelligence model.

The interpretation of evidence demonstrates the overall utility of the intelligence network model. The interpretation of evidence is the most vital element to case assessment and decision making. A more informed and analytical methodology seeks to prevent tunnel vision for an investigator and provide a rationale for the direction of the investigation. Both case assessment and decision making are made easier, more efficient, and more consistent with the utilization of an intelligence network. The completely searchable and graphical network serves as a tool with which more sound judgment can be exhibited throughout all stages of the criminal justice system. Furthermore, IBM ${ }^{\circledR}{ }^{i} 2^{\circledR}$ Analyst's Notebook ${ }^{\circledR}$ has numerous built in features for further analysis of criminal information.

Event frames offer an alternative representation of entities and can serve to assess events which occurred throughout the course of the incident(s) in question. An event frame is an entity representation that emphasizes date and time information. An event frame is often used in conjunction with theme lines [1]. Event frames provide a different presentation of events that can be useful in case analysis. Events are given a date and time to form a chronological flow of events for the duration of incident(s). A potential use for this could be as an aid to the trier of fact. If permitted into evidence it would serve as a flow chart of the actions and events that were presented by the attorney. Additionally, there is great potential to use event frames in the training of investigators by introducing the concept of step-wise case assessment for the interpretation of the events. An example event frame is given in two parts: Figure 4 shows the events prior to police intervention and Figure 5 outlines the events that led to incident prevention. The case example given is represents an attempted bank robbery scenario. 


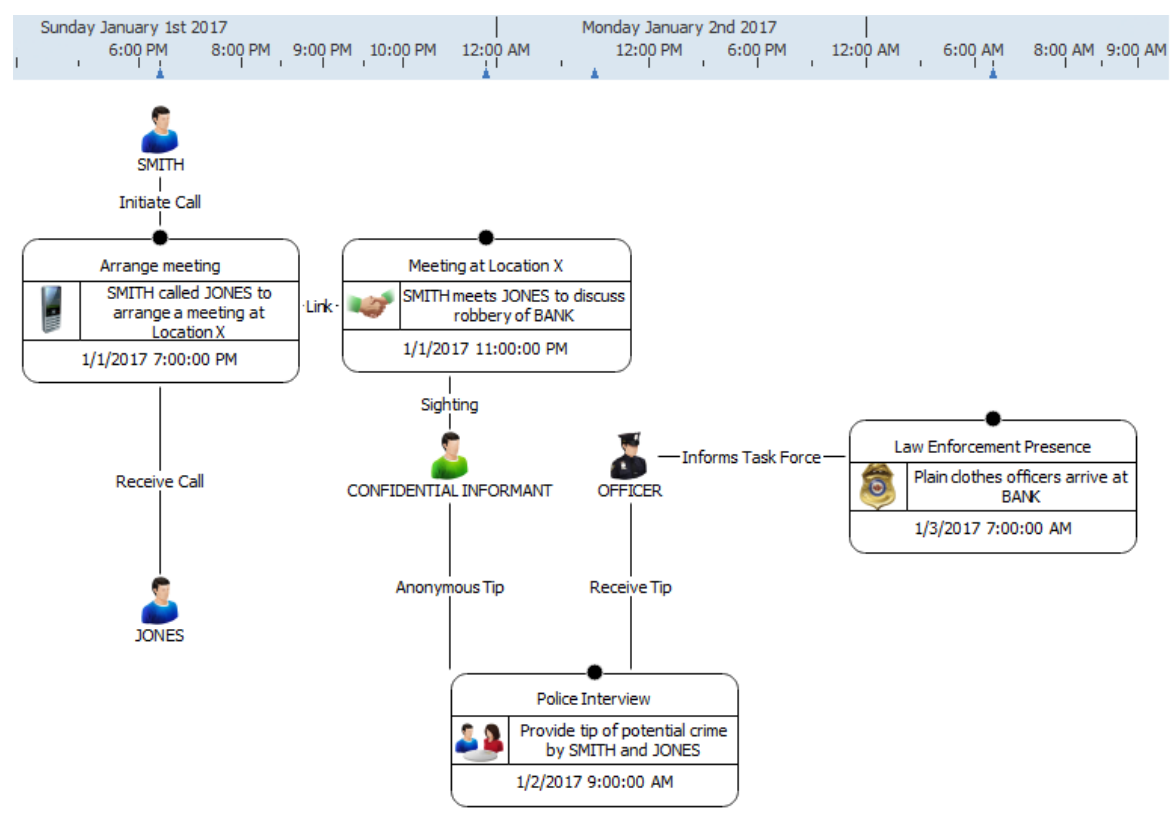

Figure 4: Image captured of an example event frame depicting the events that transpired prior to police intervention.

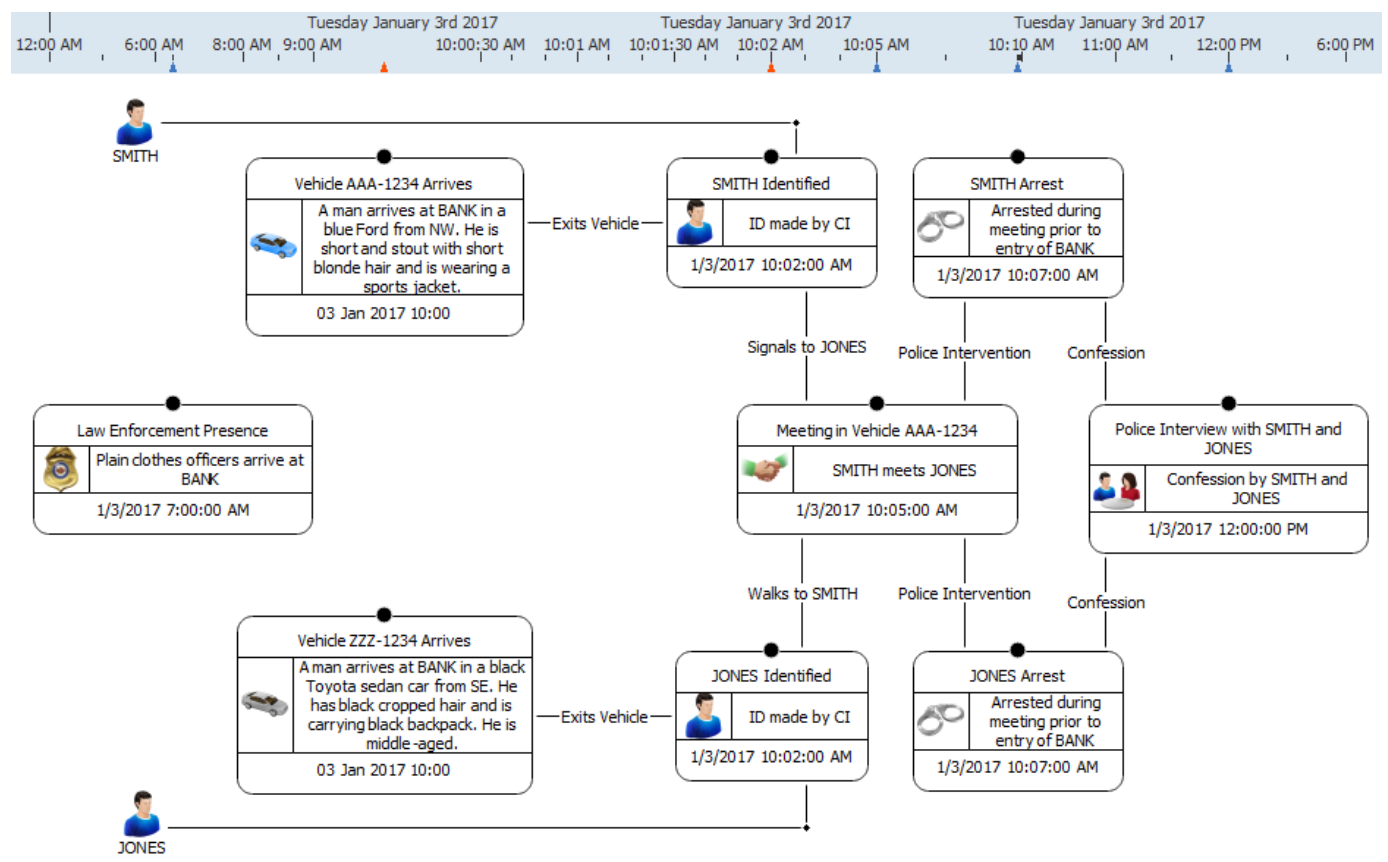

Figure 5: Image captured of the example event frame depicting the events that took place during incident prevention and arrest. 


\subsection{Integration of information}

The integration of criminal investigation information and systematic exploitation is essential to produce knowledge which will better serve each respective investigation. "The fundamental principle of forensic intelligence is that, instead of treating each case individually with the aim of assisting the court (i.e., evidential focus), a multi-case focus and more holistic approach based on the study of crime phenomena is followed" [14, p. 44]. Attempts to compile and utilize the information currently exist at the federal level in the form of fusion centers. The concept of a fusion center is to connect the dots through information from disparate sources to construct an overall picture of an environment and improve an agencys awareness of real and potential threats [15]. Fusion centers have an underlying process of fusing, or integrating, information from a variety of sources in order to identify, track, and prevent multi-jurisdictional crime problems. A strength of fusion centers is that they are a centralized hub enabling and promoting contact between law enforcement and public safety agencies which commonly experience separation [15]. Multiple agencies are collocated into a single facility and information is shared between them which appears to be an necessary improvement in communication. The shortcoming of this process is that not every case undergoes this analytical process and the process exists above a single agency. The implications of the model presented within this paper seek to resolve this shortcoming by introducing the potential at any level of agency.

In order for the model to be effective the process must begin at the crime scene. A model with beginnings at the scene demands that investigators have specific training related to crime scene assessment/investigation and the provision of relevant and contemporary case information (e.g., modus operandi, time of day, and type of goods targeted). Insurance that proper procedures and protocols are followed is vital to enabling a multi-case rather than a single case focus [16]. Also important is the consideration of evidence on scene such as fingerprints, DNA, tool impressions, etc.... If integrated into the network, forensic evidence will significantly impact the volume and value of information gathered with a more accurate representation of the scene. The crime scene investigator plays an essential role to the information that is collected for integration into the network. However, the investigator receives an intelligence product in the form of knowledge regarding local crime trends and types. Such a priori information makes it easier for the investigator to detect and discern similarities or differences in the crimes they attend.

Timeliness is a fundamental and recurring premise throughout forensic intelligence. Information becomes stagnant and less useful if not entered and processed rapidly. To enable rapidity in the process Bruenisholz, et. al. suggests the potential for IT systems at the crime scene for data entry and the swift transmission of data to 'home base' to enable rapid assessment and comparison [16]. This step may not be entirely possible or wise (compromise to scene integrity) but the notion serves as a reinforcement that time is of the essence for any investigation. The information of the incident or details of the evidence can be relayed back to the agency while on scene for immediate incorporation into the network. This could provide the investigator with real-time intelligence at the scene. An advantage of this is that the investigator could be more informed as to the decisions made on potential evidence articles to collect so that nothing is left behind. 


\subsection{Evaluation of network and system}

Major scale contribution of information is without question ideal for the decision making process. Value from forensic case data and forensic intelligence is maximized if it is a consolidated, multidisciplinary product [16]. The true value of the information is the product that can be given to administration for informed operational decision making. As outlined in Section 1 administrative crime analysis uses the findings from crime analysis to inform operational concerns. Establishment of a committee to review the intelligence product is key to incorporation of the model and refinement of the network structure to accommodate needs. This is critical because the import specification model proposed serves to bring prior case information to use. Evaluation of new case information and adjustments may be of necessary for the agency.

\section{Discussion}

Forensic intelligence systems are a viable option to the collation of criminal case data as a means to provide a more effective and efficient service. "A fundamental component of building law enforcement capacity involves enhancing understanding of how criminal intelligence works and how practically to develop, share, and use it" [16, p. 21]. Developments within criminality demand investigators remain current with pattern. This provides several benefits: crime disruption and prevention; time and cost efficiency; early identification of suspects; more effective use of forensic analytical results; threat assessments, situation reports, and risk assessments; and better understanding of the criminal activity to inform policing and security actions [17].

The import specification model developed in this project integrates closed cases into an intelligence structure for potential use to aid future investigations. The model was created as a method to better assess criminal events and add an analytical component to investigations. Intelligence provides knowledge with the purpose of closing cases and evolving current investigation techniques. Downstream implications of the model seek to provide a better product for the criminal justice system and improve case flow.

In the creation of the intelligence network utilizing the import specifications developed a linkage was uncovered. Two separate cases were found to be linked through both individuals and evidence articles. In one of the cases two perpetrators were accused of larceny. The individuals stole a wallet from a person and were identified by the accused in the report. A later incident of fraud was reported with the two individuals having used a credit card alleged to be in the wallet of the prior incident. The development of the linkage through both the individuals and article of evidence shows promise for the intelligence model proposed by this work. Figure 6 is an excerpt of the linkage developed between the two cases.

\subsection{Decision making}

A benefit of the applied intelligence model is the information/knowledge that can be used to make more informed decisions. Utilization of case information may uncover linkages with prior cases that have already been closed. There is also the potential to link unsolved cases that have similarities, reevaluation may determine that the cases are in fact related and 


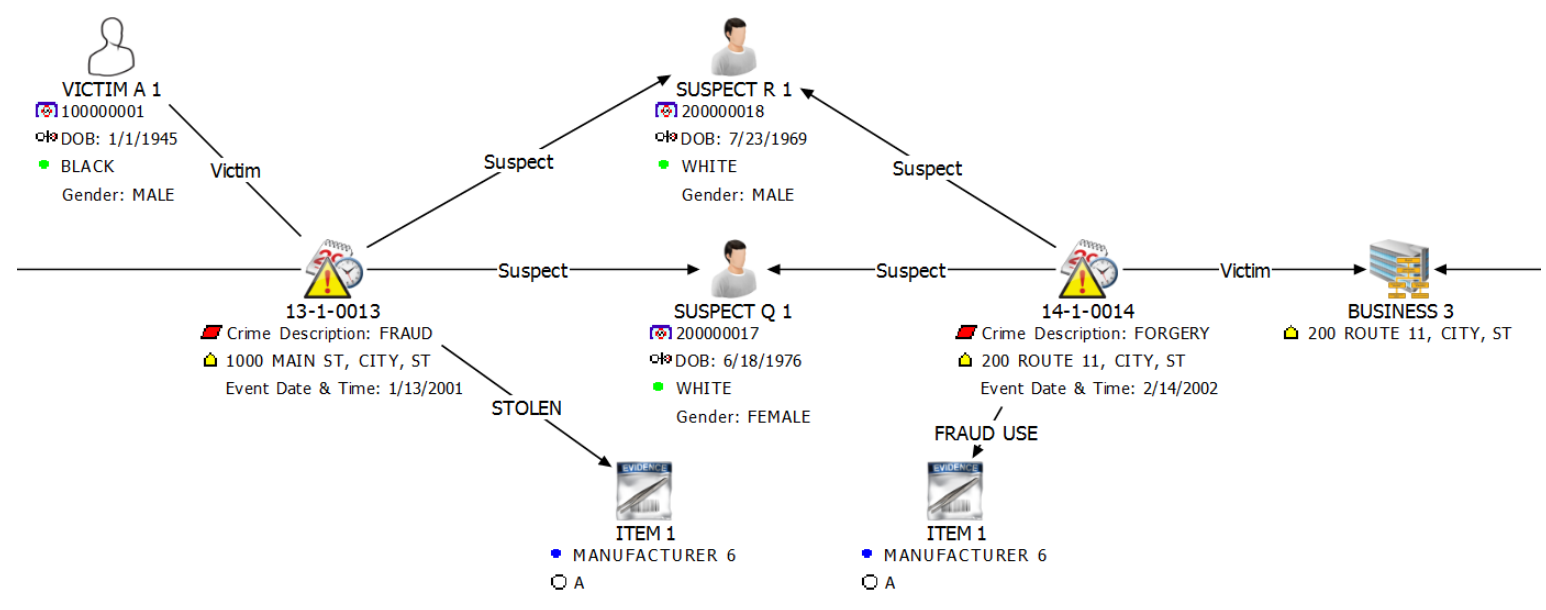

Figure 6: Example of a linkage that was developed in the network between two suspects and two cases.

information from each may stimulate a lead for the investigation. Linkages may also form that would point to unexpected cases for additional information. Currently there is a reliance on an investigator's memory to recall prior cases for similarities. The intelligence network model seeks to integrate the information and alleviate this reliance. Uncovering patterns or trends provide as much information to an investigator early in an investigation to make better decisions. This concept is merely a graphical representation of what we currently do in making decisions. Each additional developed linkage merely serves to enhance the decision that has been made.

\subsection{Organizational Structure}

Another benefit of intelligence networks for forensic science and investigations is the inherent organization that the network provides. The data is imported and is then clustered around a central point (incident or logical entity) as members of that entity. Outward the entities (individuals or article of evidence) potentially link elsewhere. Grades of the links allow the investigator to express their beliefs regarding the strength of a given link. All of the collation serves to graphically represent the logical assessment of the case.

An example of knowledge driven policing and operational decision making is summarized in Figure 7. The example represents a hot spot of several incidents that occurred at organization that was provided in the received criminal case files. The network provides a graphical look at the amount of reported incidents which is useful because as this increases clustering is evident. Another benefit is the attribute of each incident shown. Quickly an investigator can observe any provided detail on screen. In this case the crimes were generally an expected type for the location; fraud and larceny. The other cases of embezzlement and forgery may be an alert to an investigator if a pattern were to develop. Also shown for each case are the links to other entities. If several cases of the type arose they may be related 
and not isolated incidents.

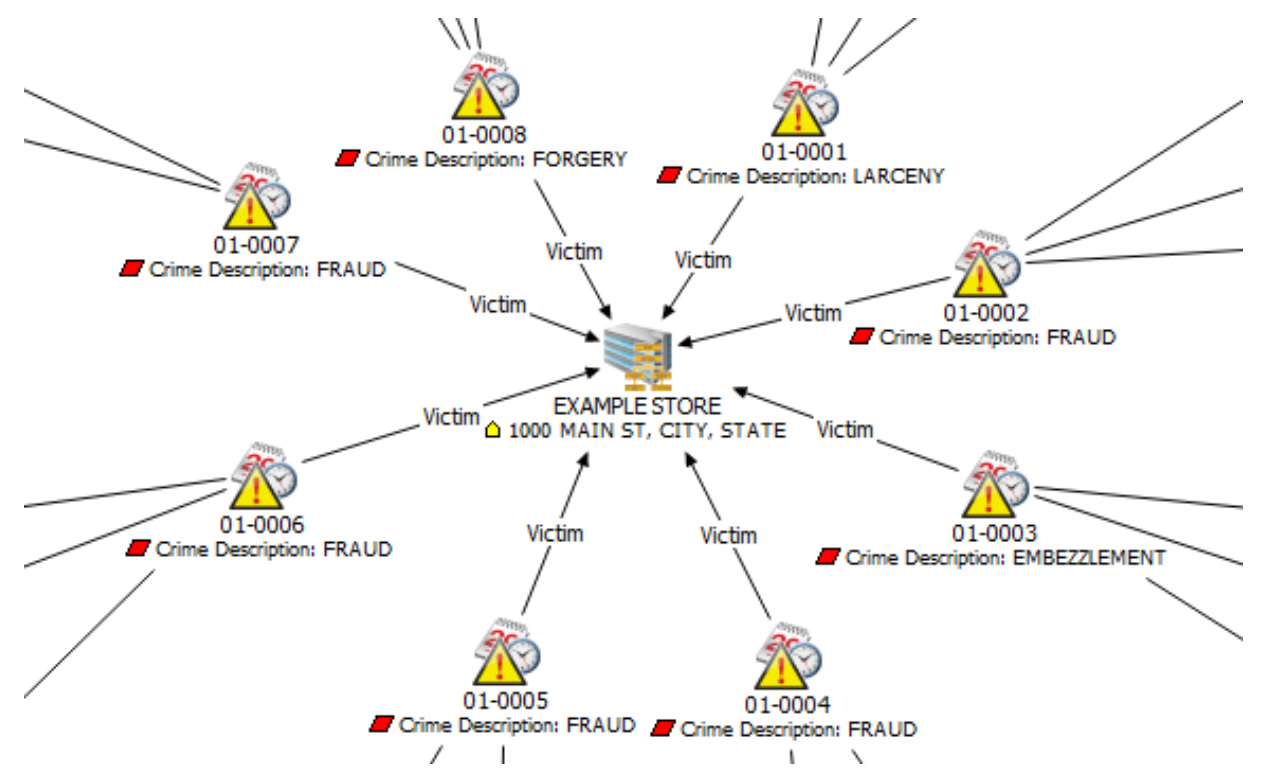

Figure 7: Example hot spot shown at an organization with several reported incidents.

Hot spot analysis with the intelligence framework may yield new a priori information for an agency. The information may suggest that criminal tendencies are changing or that the individual involved may not be a regular customer. Overall the intelligence network seems to provide a more organized structure for information within agencies. IBM ${ }^{\circledR}$ i2 ${ }^{\circledR}$ Analyst's Notebook $^{\circledR}$ also features the ability to link with satellite imagery for cluster plotting of data as an alternate visualization of activity.

Articles of evidence were also incorporated through the import specifications associated with this model. The utility is that the evidence is presented associated with the case and linkage grades can be added signifying the strength associated between the entities. The presence of evidence as the network expanded led to large clusters around individual cases. This is a problem at surface observation of the network. However, arrangement features in the software aided visualization of case. The searchable nature of the network also helps overcome the clutter. The true utility is that any component of the case file is accessible by search; a major improvement over the traditional method.

\subsection{Limitations}

The import specification model developed through the project is succumb to a few limiting factors. The import specifications were developed using provided adjudicated case files. The information received was limited by what was kept on record by the agency. Additionally, access to examinations/analysis of articles of evidence were not provided. These factors inhibit the production of an import specification that is refined and immediately applicable 
to all agencies. Follow up refinement of the import specification using complete data will alleviate these concerns.

Another limitation of forensic intelligence in general is the fundamental reliance on recidivism or criminal repetition. An important consideration is that the linkages are primarily developed through detection of common elements/entities. The model presented would function with great efficiency in localized areas where a low number of offenders engage in the majority of criminal activity. If this is true the targeting of police actions on a specific prolific group has the potential to drastically reduce the number of offenses and substantially influence the general level of criminality. However, linkage development will still occur in any environment if two entities of the same identity are introduced.

A final concern exists in the legal policy and procedures that govern the application of information sharing necessary for forensic intelligence. Before an agency invests resources in the development of forensic intelligence systems, integrity needs to be established with attention paid to the governance and legitimacy of the system [18]. Domestic law enforcement agencies serve as producers, consumers, and administrators of forensic information/intelligence and are expected to expand their technological capacity to gather and disseminate forensic information and intelligence. With political expectations to expand traditional parameters restraining law enforcement information sharing are increasingly inadequate. Oversight management of the information flows are critical to the development of standard operating procedures. Another concern is that the citizens lack the ability to know of, understand, and challenge exchanges of their data [18]. Additional legal issues pertaining to forensic intelligence systems are: ownership of data; storage of information and destruction requirements legality of the intended use of forensic intelligence; evidentiary validity of data in court; human rights and privacy; oversight bodies; and information sharing [18]. No single approach can be made to overcome the legal challenges suggested, and a jurisdiction by jurisdiction approach would be necessary for implementation.

\section{Conclusions}

Implementation of a forensic intelligence framework requires a lot of planning, adaptation, and a shift in focus away from traditional case assessment. New emphasis must be placed on crime prevention and disruption of crime along with the traditional focus on the court. A shift from a single case focus to a multi-case focus using forensic intelligence systems appears to be a viable method to increase effectiveness and efficiency of investigative work/strategy.

The model presented in this article exhibits the effectiveness of import specifications in introducing case information into a forensic intelligence structure. The inclusion of case files in the network enables circumstances of the closed incidents to remain available for linkage development. Expansion of the network will provide a higher opportunity to link cases. The import specifications allow for integration of this information with ease. Refinement and adjustment of the model to accommodate the information gathered by a particular agency

is a necessary step prior to usage. The intelligence structure also provides value through a graphical depiction of incidents within the perspective of all agency cases. Totality of case 
information from the investigation and the analysis process will provide contemporary case assessment within a multi-case approach. The general model will assist in developing a more uniform approach and nomenclature across the forensic and investigative science community. 


\section{Appendix A. Complete Network}

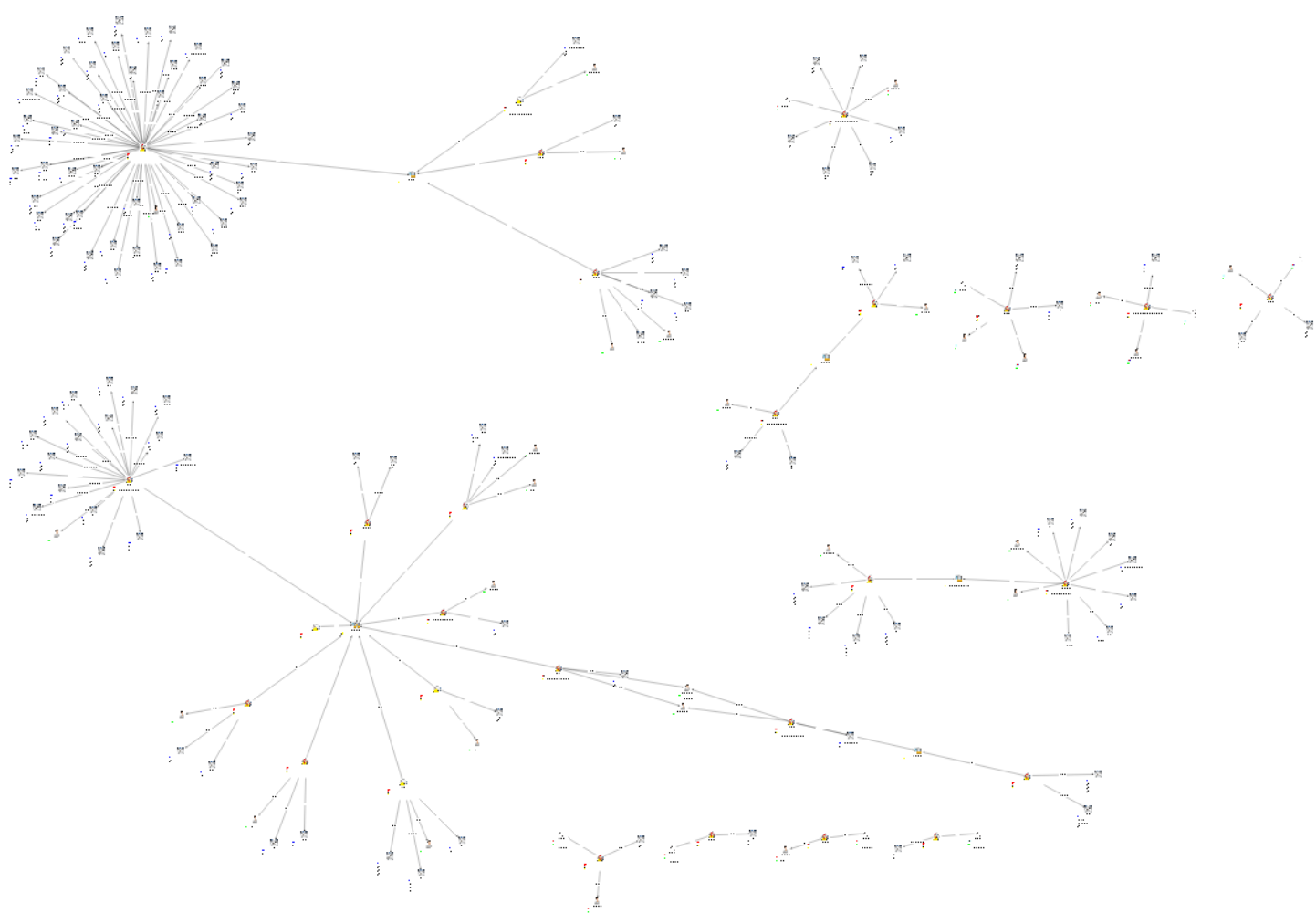

Figure A.8: Complete network developed from the twenty six criminal cases. 


\section{Appendix B. Network of Cases (Evidence Removed)}

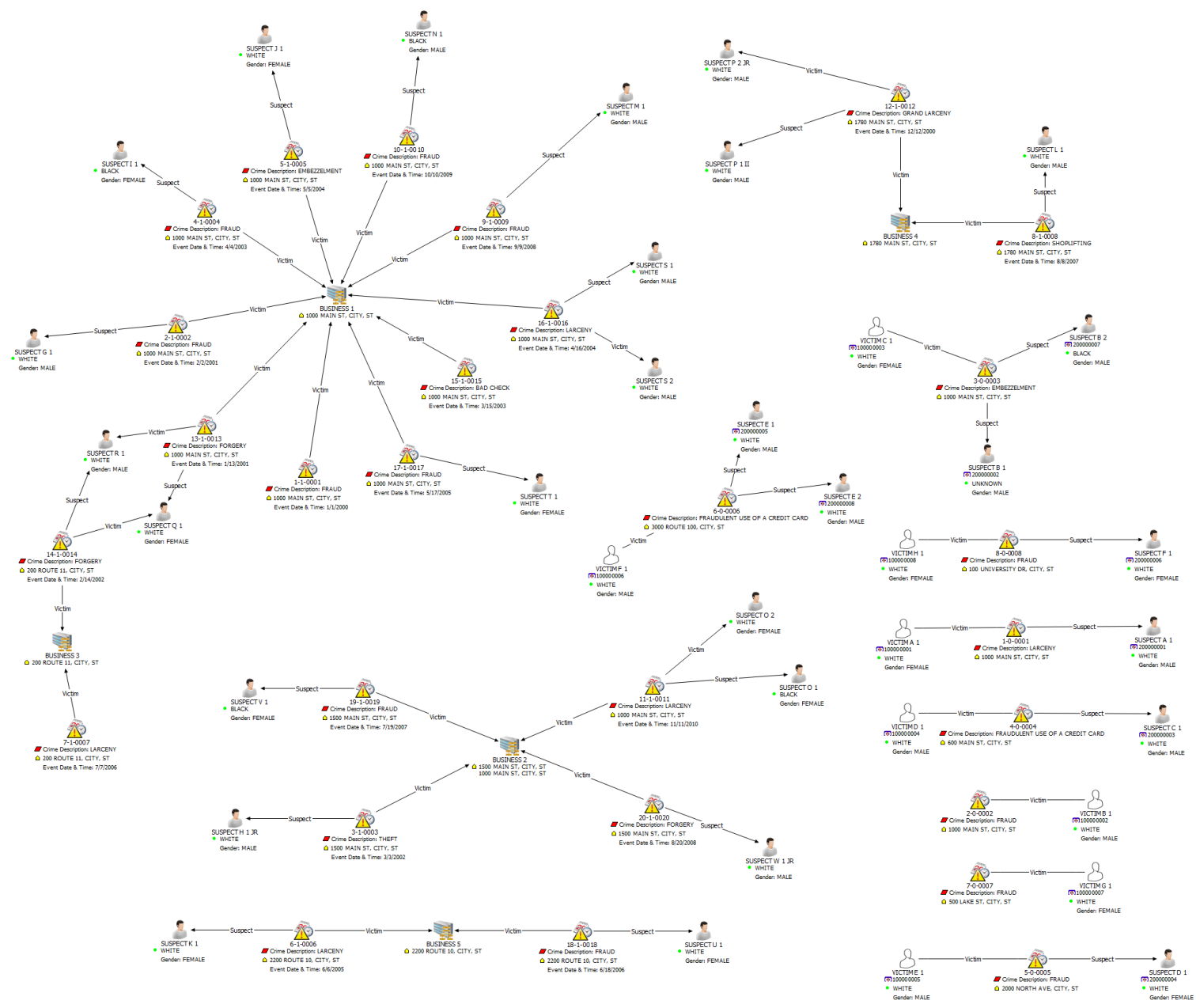

Figure B.9: Complete network developed from the twenty six received criminal cases shown in Appendix A with articles of evidence removed. 


\section{Appendix C. Clustered Case}

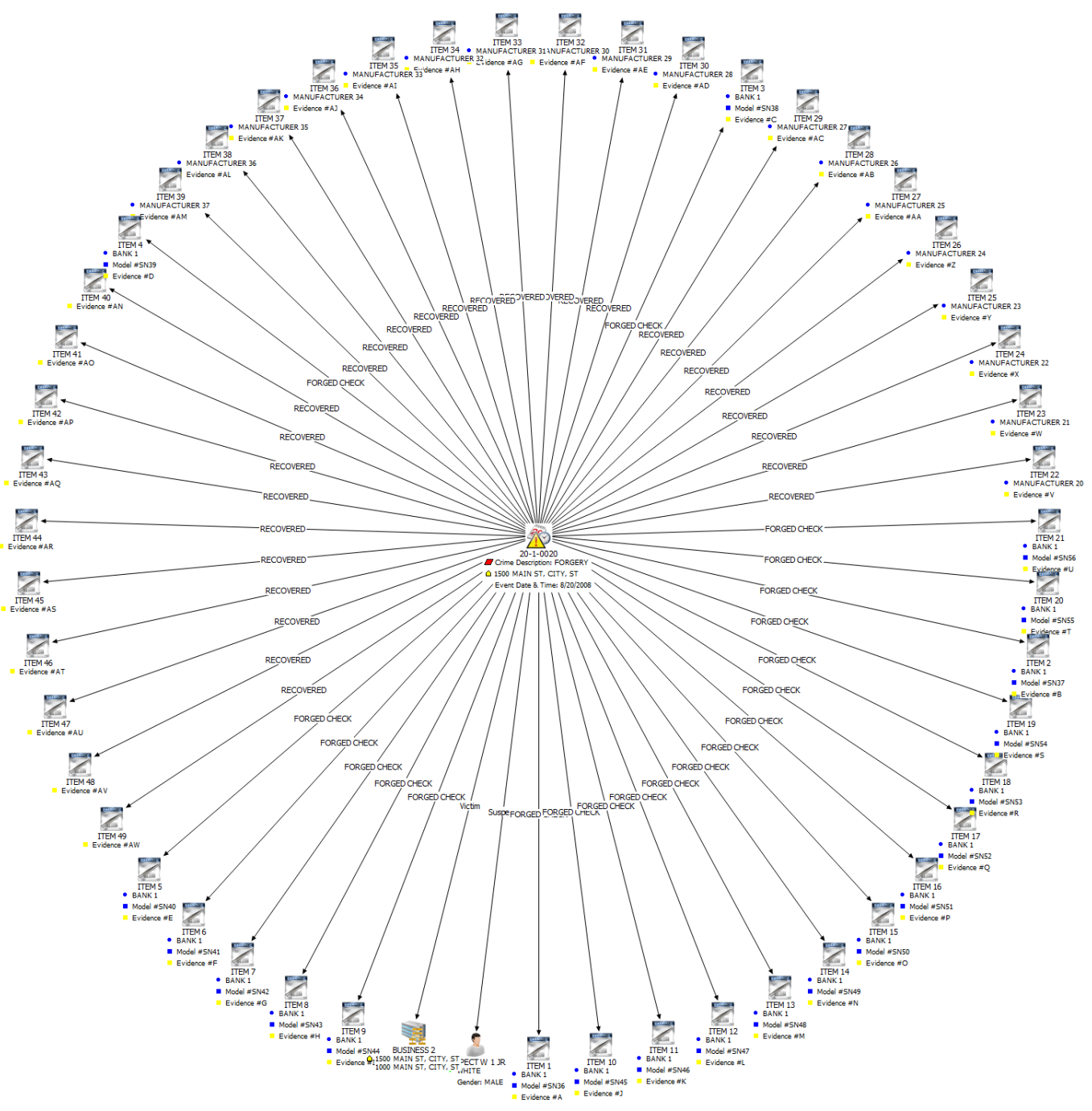

Figure C.10: Example of an individual case with 49 total pieces of evidence (21 were forged checks used to pay for remainder of items). 


\section{Appendix D. Import Specification for Crimes Against Organizations}

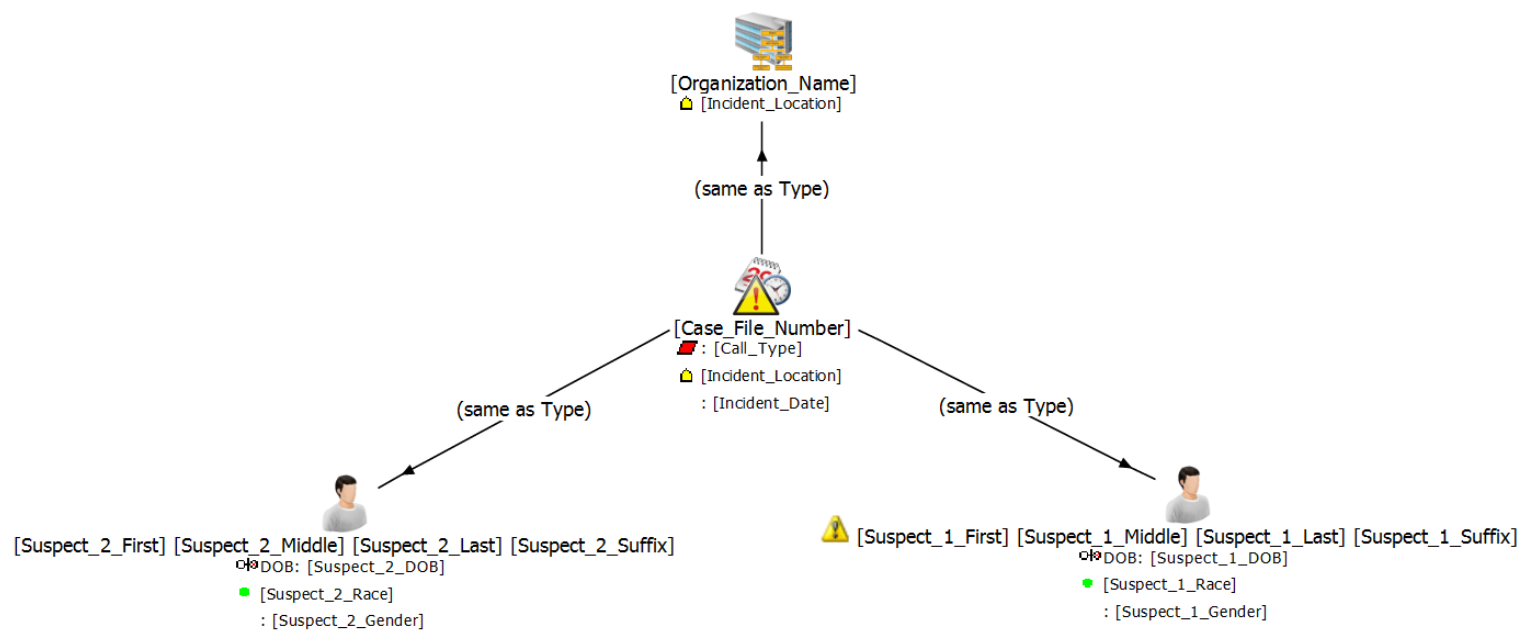

Figure D.11: An image of the import specification design for inclusion of crimes in which the victim is an organization or business. Image captured from IBM ${ }^{\circledR} \mathrm{i} 2{ }^{\circledR}$ Analyst's Notebook ${ }^{\circledR}$. 


\section{Appendix E. Import Specification for Inclusion of Evidence}

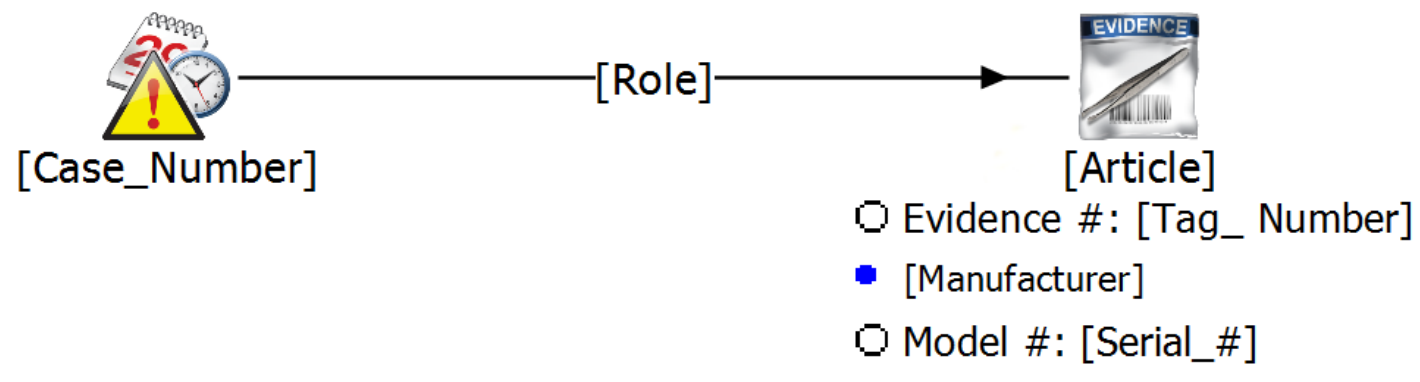

Figure E.12: An image of the import specification design for inclusion of articles of evidence relevant to the incident of interest. Image captured from IBM ${ }^{\circledR}{ }^{\circledR} 2^{\circledR}$ Analyst's Notebook ${ }^{\circledR}$. 


\section{References}

[1] i2 Limited, i2 Analyst's Notebook User Guide (2009).

[2] M. Durose, A. Cooper, H. Snyder, Recidivism of prisoners released in 30 states in 2005: Patterns from 2005 to 2010, U.S. Department of Justice, Office of Justice Programs, Bureau of Justice Statistics.

[3] R. Williams, Policing and Forensic Science, 2nd Edition, Willan, 2008, Ch. 28, pp. 760-793.

[4] O. Ribaux, S. J. Walsh, P. Margot, The contribution of forensic science to crime analysis and investigation: Forensic intelligence, Forensic Science International 156 (23) (2006) 171 - 181.

[5] I. Kopp, Review of resource needs in the forensic science laboratory and the wider scientific context in ireland.

[6] J. Strickland, Introduction to crime analysis and mapping, Lulu, Inc., 2014.

[7] R. B. Santos, Crime analysis with crime mapping, 4th Edition, SAGE Publications, Inc., 2017.

[8] Presidents Council of Advisors on Science and Technology, Forensic science in criminal courts: Ensuring scientific validity of feature-comparison methods, Executive Office of the Presidents Council of Advisors on Science and Technology (2016).

[9] R. Cook, I. Evett, G. Jackson, P. Jones, J. Lambert, A model for case assessment and interpretation, Science and Justice 38 (3) (1998) 151-156.

[10] G. Jackson, P. J. Jones, Case assessment and interpretation, Wiley Encyclopedia of Forensic Science.

[11] B. Robertson, John Henry Wigmore and Arthur Allan Thomas: An Example of Wigmorian Analysis, Victoria University of Wellington Law Review.

[12] I. Evett, G. Jackson, J. Lambert, More on the hierarchy of propositions: exploring the distinction between explanations and propositions, Science \& Justice 40 (1) (2000) 3 - 10.

[13] R. Cook, I. Evett, G. Jackson, P. Jones, J. Lambert, A hierarchy of propositions: deciding which level to address in casework, Science \& Justice 38 (4) (1998) $231-239$.

[14] S. Baechler, M. Morelato, O. Ribaux, A. Beavis, M. Tahtouh, K. P. Kirkbride, P. Esseiva, P. Margot, C. Roux, Forensic intelligence framework. Part II: Study of the main generic building blocks and challenges through the examples of illicit drugs and false identity documents monitoring, Forensic Science International 250 (2015) 4452. doi:10.1016/j.forsciint.2015.02.021.

[15] R. G. Joyal, State Fusion Centers Their Effectiveness in Information Sharing and Intelligence Analysis, LFB Scholarly Publishing LLC, 2012.

[16] E. Bruenisholz, S. Prakash, A. Ross, M. Morelato, T. O’Malley, M. A. Raymond, O. Ribaux, C. P. Roux, S. Walsh, The intelligent use of forensic data: An introduction to the principles, Forensic Science Policy \& Management: An International Journal 7 (1-2) (2016) 21-29.

[17] M. Morelato, S. Baechler, O. Ribaux, A. Beavis, M. Tahtouh, P. Kirkbride, C. Roux, P. Margot, Forensic intelligence framework - Part I: Induction of a transversal model by comparing illicit drugs and false identity documents monitoring, Forensic Science International 236 (2014) 181 - 190.

[18] C. McCartney, Forensic data exchange: ensuring integrity., Australian Journal of Forensic Sciences 47 (1) (2015) $36-48$. 


\section{Integration of AFIS, CODIS, and IBIS Data to Forensic Intelligence Networks for Real-Time Case Assessment}




\title{
Integration of AFIS, CODIS, and IBIS Data to Forensic Intelligence Networks for Real-Time Case Assessment
}

\author{
Jamie S. Spaulding ${ }^{\mathrm{a}, *}$, Keith B. Morris ${ }^{\mathrm{a}}$ \\ ${ }^{a}$ Department of Forensic and Investigative Science, West Virginia University, P.O. Box 6121, \\ Morgantown, WV 26506, United States
}

\begin{abstract}
Forensic analysis is traditionally applied to support the investigative process from the crime scene to the trial on a case-by-case basis. The isolated single case approach does not fully exploit the potential of forensic case data. Introduction of forensic case data to an intelligence framework enables an analytical assessment preventing missed linkages within the case. Additionally, information generated through the analytical process conducted on recovered evidence can be integrated to the network for a contemporary case assessment model.

A three step import specification model is proposed for integration of forensic case information into an intelligence framework. Firstly, inclusion of information relevant to the incident itself (date, time, location, persons involved) is added to the network. Next evidence gathered through investigation is added to the case information as distinct entities. Finally, any analytical result or database search can be charted to potentially link the article of evidence to individuals or other cases in the network. This step-wise approach integrates information in a rapid and consistent manner. Extraction of information directly from the databases was used to streamline the process of incorporating forensic results into an intelligence framework. Interpretation of the incident can occur within a global perspective of all agency cases. The multi-case approach offered by the proposed model has the potential to assist in developing a more uniform approach and nomenclature across the forensic and investigative science community.
\end{abstract}

Keywords: Forensic, Intelligence, Analyst's Notebook, AFIS, CODIS, IBIS

\section{Introduction}

Forensic science is defined as "the application of scientific or technical practices to the recognition, collection, analysis, and interpretation of evidence for criminal and civil law or regulatory issues" $[1$, p. 1]. By nature, forensic science is diverse and encompasses numerous different disciplines or scientific domains to solve matters in question within a legal forum. The application of science is utilized to provide insight for the trier of fact through inference

\footnotetext{
*Corresponding Author

Email address: jspauldi@mix.wvu.edu (Jamie S. Spaulding)
} 
development or analytical result. However, forensic science can be further utilized through the application of a forensic intelligence framework. Forensic intelligence is "the accurate, timely, and useful product of logically processing forensic case data for investigation and/or intelligence purposes" [2, p. 172]. Embracing the philosophy of forensic intelligence heightens the potential of evidence/features to detect relationships between pieces of evidence and to support inference of a likely common source. The integrative process of forensic intelligence assists the investigator with the critical decision making process. Uninformed decisions have a significant influence and affect the direction of the downstream investigation which can lead to an unsolved case or implication of an innocent individual. Accurate decision making can be reinforced by linkages or relationships uncovered within a case. Analysis of evidence can also create linkages between cases leading to more effective case closure.

In order for the effective utilization of a forensic intelligence framework, the decision making and reasoning process must be considered. A distinction has been proposed in forensic science between evaluative and investigative forms of reasoning [3]. For forensic evaluation "prescriptive evaluative style, arguments, and experience are postulated as expressible in terms of probabilities, in an essentially deductive framework" [4, p. 3]. This means that observations are gathered and interpreted in order to advise propositions expressing the view of the defense against the view of the prosecutor. "In this perspective, the provision of expert opinions (probabilities) is integrated into formal rules isolating the deductive contribution of forensic experts (the likelihood ratio) in a globally inductive process (Bayesian formalism)" $[4$, p. 3]. The above evaluative perspective is contrasted with the logical processes that take place during the course of the investigation. This reasoning process is completed by compiling a variety of sources of data, and knowledge regarding the incident in question. This collation of information translates into criminal intelligence through reliance on experience of previous similar cases or recognition that a typical situation is central to interpreting a given scene. The distinction between evaluation and investigation reasoning processes is key in understanding that the forensic intelligence framework and model must be two-fold. Initially, a mechanism needs to exist for integration of investigative information into the framework (Chapter 3). Once this information is assessed within the context of a multi-case environment, follow-up analysis is necessary. Finally, integration of analytical results are required for a framework capable of comprehensive case assessment and interpretation. Ribaux et. al. suggest a 'bottom-up approach' for assessing the diverse value of forensic science by critically evaluating existing forensic investigative processes; recommending identification databases as a starting point [4].

\section{Background}

Forensic identification databases serve as an ideal starting point for a step forward since the databases illustrate a turn from evaluative to investigative domains. Forensic intelligence systems and databases serve as repositories of information which can be searched and collated to form links between the case at hand and others in the repository. The databases have undergone unprecedented growth over the last two decades [5]. Among the most notable intelligence databases are the Next Generation Identification (NGI); State and local 
fingerprint databases; Combined DNA Index System (CODIS) or the National DNA Index System (NDIS); and the National Integrated Ballistic Information Network (NIBIN). Each of these serves to link different elements of a crime and store vast amounts of data. An investigator can search for comparison in the database of interest remotely anytime.

The Next Generation Identification system (NGI) is operated by the Federal Bureau of Investigation. The NGI system improved the efficiency and accuracy of biometric services to address evolving local, state, tribal, federal, national, and international criminal justice requirements. Contained within NGI is a national 'Rap Back' service; the Interstate Photo System; fingerprint verification services; identity records; and enhancements to the biometric identification repository. The Advanced Fingerprint Identification Technology (AFIT) system within NGI replaced the legacy Automated Fingerprint Identification System (AFIS) segment of the previously used IAFIS. The system provides automated fingerprint search capabilities, latent search capability, electronic image storage, and electronic exchange of fingerprints and responses [6]. This system hosts in excess of seventy million criminal fingerprints available for search.

Another prominent intelligence database used to assist in the adjudication of crime is the Combined DNA Index System (CODIS) or the National DNA Index System (NDIS). The NDIS contains over 12,854,420 offender profiles, 2,708,809 arrestee profiles, and 772,613 forensic profiles as of April 2017 [7]. There is a primary metric built into the system which measures the investigations that have been aided through the use of CODIS. The "Investigations Aided" metric counts the cases where the system has added value to the investigative process. In the case of CODIS, an extracted DNA profile can be searched against the database. If a hit is determined, the profiles are consistent and the extracted profile is said to match the individual listed in the database. This can provide information to link an individual who deposited DNA at the scene as a person of interest.

In addition to the intelligence databases above, the National Integrated Ballistic Information Network (NIBIN) serves as a resource for cartridge casing and bullet information. NIBIN provides federal, state, and local agencies with an automated ballistic imaging system. The Integrated Ballistic Identification System (IBIS) technology takes digital images of cartridge cases from crime scenes or a firearm test fires. IBIS compares those images against previous NIBIN entries. If a high-confidence candidate emerges, firearms examiners compare the original physical evidence microscopically to confirm the match. This is a NIBIN "hit," or the linking of two different investigations [8].

All three of the above intelligence databases have the ability to create links between entities, be those individuals or objects, and the crime being searched. Linkages can guide an investigation and ultimately lead to correct outcomes in the prosecution of a case. These networks all have the ability to provide exculpatory information regarding a person of interest as well. However, there are limitations to consider with all of the above databases. First, all evidence, even that which is "subtle to interpret (e.g. low-quality DNA profiles), should be recognized as only contributing to the most direct, and the least creative, elementary species of hypothesis generation in investigation, i.e. at source level" [4, p. 5]. Secondly, the lack of integration between forensic identification databases and the other components of the justice system responsible for following up on results is perhaps the biggest weakness, in 
that desirable outcomes have not been clearly defined or carefully researched [9]. A lasting concern is how the databases are evaluated. The databases, forensic science, and the criminal justice process is considered on a case-by-case approach, in terms of obtaining the greatest number of hits or matches in a function of efforts and costs related to the collection and analysis of evidence [4]. Ribaux et. al. also add:

Forensic investigators tend to reason in terms of solving a potential serial problem, while studies remain focused on the chance to extract a profile from the nature of a single trace, on a case-by-case approach, and on searching for hits in databases, whatever their relevancy. [4, p. 5]

Instead of this disconnect involving the criminal justice system, a streamlined approach is necessary. The exploitation of collected forensic evidence regularly contributes to solve investigations and should be fully utilized in a global analytical environment. There are findings that the evidence is used much more throughout the course of the investigation than it is during court proceedings [4]. The forensic investigation must be considered both as an information process and as a rationalization for problem solving. Forensic intelligence frameworks are a suitable platform for the consideration and assessment of evidence articles. The outcome may strengthen the decision making process and overall conclusions reached regarding the articles of evidence.

\section{Rationale}

Crimes are solved through the assessment of linkages drawn between an incident, evidence, and persons involved. This is referred to as case assessment and interpretation which is primarily achieved through personal experience and expert opinion [10]. Interpreting given evidence entails the drawing of rational and balanced inferences from observations, test results, and measurements. Currently, this interpretation is done in isolation based upon a single case approach lacking consideration of the greater environment and landscape [11]. Integration of forensic intelligence systems and databases into a single cohesive framework is an optimal strategy to improve the current case assessment process and manage the schism that exists between science and law enforcement.

\subsection{Singular Utility of forensic intelligence systems and databases}

The application of science is utilized to provide insight for the trier of fact by "uncovering the actions or happenings of an event... by way of (1) identification (categorization), (2) individualization, (3) association, and (4) reconstruction" $[12$, p. 36]. That is the ultimate goal of forensic science. Forensic databases draw linkages between individuals, evidence, and/or cases which greatly aid this purpose. An extension of linkage development can be achieved through the implementation of a forensic intelligence system. Forensic intelligence plays a new role in forensic science through its extension of its case-by-case approach into

a more phenomenological and proactive approach [13]. This is a great innovation to the nature of investigations because the current paradigm restricts the field to a reactive nature. 
The impact that forensic databases have on the landscape of investigations cannot be understated. There is a continual processing of service requests undertaken by these systems in hopes for assistance with criminal cases. The following statistics currently show the use of the forensic databases mentioned above in Section 2. Through April 2017, the NGI system has received an average of 204,957 daily receipts (including Tenprint Rap Sheet Search) and has processed on average 204,898 of those requests each day [6]. As of April 2017, CODIS has produced over 373,099 hits assisting in more than 358,069 investigations since introduction [7]. Since the program began in 1999 through March 2016, NIBIN has amassed approximately 2.8 million images of ballistic evidence and has yielded more than 74,000 NIBIN hits which have later been confirmed by examiners. [8]. These statistics show the contribution the systems have made to forensic investigations and the promise that information has for a contemporary case assessment model.

A forensic intelligence framework has several implications to improving the field of forensic science. The intelligence based product of the framework will serve immediate purpose by providing investigators a priori knowledge that will assist their decision making processes. For example, similar shoe impressions at a series of burglaries may be indicative of a common offender or serial crime. With more proactive intelligence-led policing methods being utilized, a timely intelligence product is becoming more necessary and a forensic intelligence framework can play a pivotal role and must therefore be placed at the heart of any new model [14]. Forensic evidence has great potential to detect relationships and linkages between pieces of evidence as shown by the NGI, CODIS, and NIBIN systems. Through incorporating a systematic profiling approach, the forensic intelligence process is able to further uncover links, patterns, and trends to support decision making by investigators. Strategic, operational, and tactical levels will all be greatly impacted through a shift to forensic intelligence based models due to support with context and decision making [2]. The intelligence product also provides support and information to administrators for operational decision making. Presentation of findings from crime analysis will better inform all parties of potential legal, political, and practical concerns. Forensic intelligence implementation offers a shift from a single case focus to a multi-case approach which may increase effectiveness and efficiency of investigative work/strategy.

\subsection{Gap between science and law enforcement}

A substantial communication gap exists between scientists and law enforcement/legal personnel within investigations. A lack of communication cannot foster ideal case assessment and interpretation practice within an investigation that considers the totality of evidence and result. Many efforts have been made to express what distinguishes the forensic scientist from the investigator instead of considering the commonalities between the two. According to this vision, the best use of forensic science is in the integrated support it provides to investigations. Indeed, failures have been "recognized as occurring from a lack of communication, rather than to collusion with law enforcement" [15, p. 146]. An additional disconnect occasionally occurs between forensic science laboratories and police. Investigators have restricted the opportunity to monitor the status of their case analysis which limits the ability to inform laboratories when analysis of a submitted sample is no longer required 
[11]. Implementation of forensic scientists participating in the investigation requires a move away from the coordination and cooperation efforts which exist at many agencies toward a collaboration between parties. Collaboration is a process "through which parties who see different aspects of a problem can constructively explore their differences and search for solutions that go beyond their own limited vision of what is possible" [16, p. 5]. Collaboration is a method for solving shared problems, can be used to help organizations join forces, pool information, and mutually benefit. This approach is critical as organizations become increasingly interdependent and undergo rapid change both internally and externally. Supportive teamwork and cooperative relationships between investigators and scientists, while maintaining scientific and investigative integrity are lacking. Furthermore, methods of how to share investigative approaches between partners are still lacking [15].

Communication of forensic findings is limited in standard practice which yields corresponding limitations in interpretation of the results of forensic analyses [12]. Throughout the investigative community there remains a great variability in crime scene investigation practices. Persistent concerns of variability and proper training at the crime scene can contribute to the difficulties of drawing accurate conclusions once evidence is subjected to forensic laboratory methods [12]. Forensic intelligence provides a potential solution through increasing collaboration between all parties and could consist of a more intuitive and effective intelligence analysis environment which enables the user to quickly collate, analyze, and visualize data from numerous sources. A graphical environment within an analytical framework would enable the parties to remotely contribute and assess the context of the incident in question. The network could be shared between law enforcement officials, even among different agencies; forensic scientists, both in the lab and in the field; and attorneys, at both trial and appellate levels. Compilation of such vast information seeks to reduce the occurrence of mistakes. Furthermore, access by these parties would greatly reduce the time required to discover key information in complex data. Investigators would be able to better structure and transparently express how the information is processed within the context of the surrounding cases and information bringing forward a holistic and shared view on information, gathered from different sources, in a common memory [15].

\subsection{Enabling real-time case assessment}

With communication barriers in place there is no place for comprehensive assessment of criminal cases. The trouble with this barrier is a breakdown in complete consideration of all facts, entities involved, and strength of conclusions prior to trial. This is referred to as linkage blindness [15]. Forensic intelligence frameworks exist as a solution to this problem. Consistent and timely input of information allows for administrative support to the investigator if a problem were to arise. The framework also demands a consistency which alleviates variation in experience or standard operating procedure. As the information is uncovered or provided it can immediately be imported into the system which allows for case assessment and interpretation in real time. The assessment will take place in the context of all other cases the agency has within the network. Linkage development will occur upon import and the system will allow for the investigator to have rapid feedback. The assessment process can begin at the crime scene if desired. Information could be relayed from the scene 
to the agency where it can be incorporated. Resulting linkages in the early stages of the investigation may provide an investigator at the crime scene information to aid their decision making process and the downstream investigation.

\subsection{Impact on the criminal justice system and process}

Implementation of a forensic intelligence framework within investigative work will have several benefits to the criminal justice system currently in place. Implementation of an import based intelligence model will streamline the process and reduce down time. The process will become faster and more efficient because several agents can collaborate and introduce information at the same time. Once the information is introduced the assessment begins. Analytical processes are conducted automatically preventing linkage blindness. A multiple level contribution to a network encompassing case information, persons involved, articles of evidence, and analytical results will propagate linkages. Another advantage is that the current reactive system will adopt a substantially more proactive approach. Information/intelligence is available for more effective assessment of the case (by investigators and triers of fact), consideration of persons/evidence within multi-case environment, and informed policy decision making. Another benefit of the model is the avenues of communication that open between all levels of the investigation. A concern of bias by the position of the case in the network can be eliminated through the usage of administrative liaisons with the laboratory analysts prior to their conducting the analysis.

A collaborative process and informed investigative community are the results of implementing forensic intelligence frameworks. The process fosters and aids case assessment and interpretation within a larger landscape. Intelligence products can be used by all parties for improving technique, policy, and training efforts. The network can also be used in conjunction with reports to better prepare for trial. The network may also be useful within the trial as an illustration to the jury aiding testimony. A forensic intelligence framework may provide a beneficial change to the landscape of forensic science and allows for information integration at all steps of the investigative process.

\section{Materials and Methods}

A forensic intelligence network was developed which incorporated information from several database forms. The network was used to visualize articles of evidence and the information gathered about a case, the analytical results of the evidence, and link cases with one another. This was accomplished through the import of case information in series to simulate the course of the investigation. Resulting was an intelligence network that encompassed the incident; individuals and evidence involved; and analytical results of the evidence from databases linked within the graphical environment.

\section{1. $I B M^{\circledR} i 2^{\circledR}$ Analyst's Notebook ${ }^{\circledR}$}

The intelligence network and import specifications developed were created using IBM $^{\circledR}$ i2 ${ }^{\circledR}$ Analyst's Notebook ${ }^{\circledR}$. Analyst's Notebook ${ }^{\circledR}$ is a software from IBM ${ }^{\circledR}$ intended for data analysis and investigation. Data analysis is facilitated using multiple analysis views 
including association, temporal, spatial, and statistical views to identify relationships between entities within the network [17]. The import model developed created and refined provides an intuitive mechanism for incorporation of criminal cases and all involved entities. The software automatically links two entities of the same identity and allows for a variable linkage grade (strength of link). Visualization of the case and entities within the network are completed using several style and organizational functions within the software.

\subsection{Case information}

Case information was generated and entered into the template of a local police agency. The template used was obtained from the agency in order to ensure that the model accurately represented the information in current forms and gathered by police. A total of fifty-one criminal cases were generated for the model. The generated data was then entered into Microsoft Excel ${ }^{\circledR}$ spreadsheets. The information entered into the spreadsheet regarding the incident was: location; date and time; type (e.g. burglary); organization/business involved; and victim/suspect(s) or person(s) involved and identifying information (name, social security no., date of birth, sex, ethnicity, etc.). Another file contained all of the evidence collected or involved in the incident and identifying information (manufacturer, quantity, serial number, etc.) about the evidence. Finally, files were generated or extracted to represent and simulate the results of the analysis conducted on the articles of evidence previously mentioned.

Software, systems and databases were used in order to accurately incorporate the results of the analysis. The following systems were used in the model: AFIX Tracker ${ }^{\circledR}$ for fingerprints; the Integrated Ballistics Identification System ${ }^{\circledR}$ (IBIS) for firearm related evidence; and a simulated DNA database. For fingerprint evidence, known tenprints were added to the biographical database within AFIX Tracker ${ }^{\circledR}$ with an identity matching individual(s) involved in the incidents of the network; both victims and suspects. Latent fingerprints were also added to the case file to represent evidence from the scene. A search for the latents was then performed within the program and identifications were assigned. Firearm evidence (cartridge cases and firearms) was added to the cases from information that was already in the IBIS ${ }^{\circledR}$ system and database. Evidence collected in connection with the simulated case was assigned to generate a match from the system. A database of DNA profiles was generated using $\mathrm{R}^{\circledR}$ and profiles were assigned to individuals within the network.

\subsection{1. $R^{\circledR}$ and RStudio ${ }^{\circledR}$}

$\mathrm{R}^{\circledR}$ is an open source program with an integrated suite of software facilities for data manipulation, calculation, and graphical display $[18]$. $\mathrm{R}^{\circledR}$ was utilized through RStudio ${ }^{\circledR}$. RStudio ${ }^{\circledR}$ is an integrated development environment (IDE) for $\mathrm{R}^{\circledR}$. It includes a console, syntax-highlighting editor that supports direct code execution, as well as several other tools [19]. RStudio ${ }^{\circledR}$ is also available in an open source form. RStudio was used for the extraction of information from databases as well as transforming and adding identities to database search results. Elaboration will take place in Section 5.1. 
Table 1: The table shows the number of cases entered into each database. The databases were searched and results were integrated directly into the intelligence network.

\begin{tabular}{|c|c|}
\hline Database & Total Cases \\
\hline AFIX & 10 \\
\hline DNA & 12 \\
\hline IBIS & 10 \\
\hline AFIX \& DNA & 5 \\
\hline AFIX \& IBIS & 5 \\
\hline DNA \& IBIS & 4 \\
\hline AFIX, DNA, \& IBIS & 6 \\
\hline
\end{tabular}

\subsubsection{Breakdown by case type}

The cases used to build the import specification model contained articles of evidence that had a simulated positive analytical result and database search. This was done to show the integration of a result into the intelligence network. Table 1 shows the total number of cases that were used and the respective database the cases were entered into and searched.

The three databases were chosen for this intelligence network as they signified a major portion of forensic casework. Integration of the information would be beneficial to the greater criminal justice system as a connection between the database search result and intelligence network interface was achieved. The methodology could be further applied to other systems or databases for adaptation to implementing the model.

\section{Generation of a forensic intelligence network}

An import specification model was used to develop an intelligence network that can accommodate and accurately depict criminal cases. An import specification is used to define how Analyst's Notebook ${ }^{\circledR}$ interprets a file and charts the information (including entities, attributes, and instances) into the analytical environment. Import specifications in this model are a step-wise mechanism to incorporate the case information into the network. The import specifications model created entails three distinct steps. The first step consists of two import specifications which were created which incorporate the criminal case information (e.g. case description, potential suspects, victims); one for personal victims and one for organizational/incorporated victims. The second step is the integration of pieces designated as evidence. These two steps are outlined in greater detail in Chapter 3. With the first two steps completed, the intelligence network contains icons which represent all entities associated with the incident. Links were also created automatically to the given case. Attributes were also entered of entities. These steps are followed up with the integration of information gained from the database search result in order to represent the analytical linkages in the intelligence framework.

\subsection{Information extraction from databases}

RStudio ${ }^{\circledR}$ was used for several portions of the research to facilitate the development of files to be imported into IBM ${ }^{\circledR}$ i2 ${ }^{\circledR}$ Analyst's Notebook ${ }^{\circledR}$. Firstly, the package 'ran- 
domNames' within $\mathrm{R}^{\circledR}$ was used to generate random names, genders, and ethnicities for individuals to be imported within the network. Date of birth and social security numbers were also generated using a random number generator in $\mathrm{R}^{\circledR}$ and a master file of individuals was exported. A unique DNA profile was generated for each identity as well. The code used the National Institute of Standards and Technology (NIST) established frequencies [20] to generate accurate allele call frequencies and unique DNA profiles. The code used to generate the DNA profiles is shown in Appendix G. Next, information such as searches, biographical details, results, and latent cases were extracted from the AFIX Tracker ${ }^{\circledR}$ registry. AFIX Tracker ${ }^{\circledR}$ operates using a Microsoft Access ${ }^{\circledR}$ file which was accessed and information was extracted through a channel and transformed into a .csv file. After transformation unique identities were generated for the articles of evidence and the individuals to match the format of the import specification and intelligence network. The code developed to extract this information is shown in Appendix $H$. Additionally, the script of commands used to extract the information from AFIX Tracker ${ }^{\circledR}$ was made executable for automation of extracting the information [21]. RStudio ${ }^{\circledR}$ was also used to generate identities for the data that had been exported from IBIS ${ }^{\circledR}$ in spreadsheets as above.

\subsection{Transformation of data into import specifications}

The development of a complete intelligence network model began with creation of simulated criminal cases. Each of the created cases contains the following items: incident number, location, date/time, incident type, investigating officer, and victim/suspect(s) biographical information. The case types were designed to accommodate the breakdown shown in Table 1. The case type was selected to allow for likely pieces of evidence. Examples of the case types are: burglary (fingerprints); shooting incident (firearms); sexual assault (DNA); and others (e.g. auto theft, narcotics, robbery, unidentified body, and more). The variety was intended to represent several incidents encountered in casework. Special attention was given to ensure accuracy within the cases. For example, a case type of sexual assault has results of analysis and database results designed to show multiple profiles detected, or at minimum the female profile from collection. An example of an incident involving a sexual assault with multiple DNA contributors is given in Appendix $C$. The case shows both male and female DNA profiles being developed; one matching the victim, the other matching a person of interest labeled as suspect. Overlap of evidence types was used to show possibilities within casework; six cases were generated possessing evidence which utilized results from all three databases. Evidence associated with the case was intended to facilitate processing. Examples of evidence for the evidence types are: cans/bottles/objects or lifts from the scene (fingerprints); cartridge cases or firearms collected (firearms); and sexual assault forensic examination (SAFE) kits or swabs of stains (DNA). Evidence was simulated in submission to a lab where results were entered into the respective database. In a few cases, no results were returned.

Furthering the model in the previous work (Chapter 3) was accomplished through integration of these database results. The extraction of the information was done using the

methods outlined in Section 5.1. The third step of importing the database and analytical results was accomplished through the use of four import specifications. Each database had 
its own import specification to incorporate information, except IBIS ${ }^{\circledR}$ which used two. Two import specifications were necessary for IBIS ${ }^{\circledR}$ because one is used in the event of recovering a firearm whereas the other is suitable for cartridge case or ballistic identification. These import specifications create an icon representing the analytical result (e.g. developed fingerprint) and create links to both the evidence associated with it and with other entities associated with the evidence (e.g. individuals, cases). For example, a detected fingerprint was linked to the individual responsible for deposition. This is shown in Figure 1. IBM ${ }^{\circledR}$ i2 ${ }^{\circledR}$ Analyst's Notebook ${ }^{\circledR}$ then automatically associates that individual identity with every other occurrence in the intelligence network.

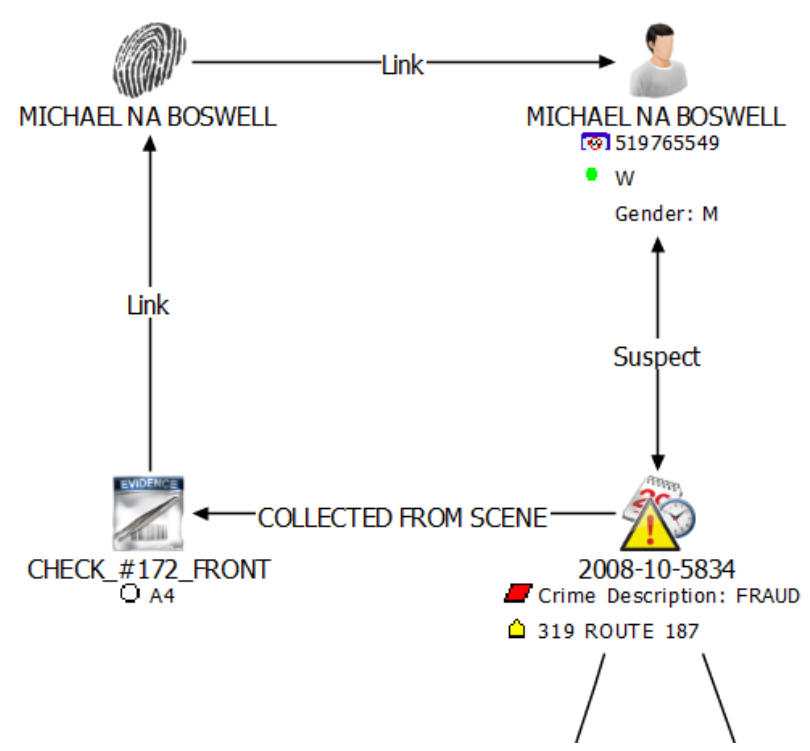

Figure 1: Image captured from IBM ${ }^{\circledR} \mathrm{i} 2^{\circledR}$ Analyst's Notebook ${ }^{\circledR}$ showing a fraud incident with a recovered fingerprint from a check. The fingerprint belongs to a Michael Boswell subject who is linked to the case as a suspect.

\subsection{Evaluation of network}

Evaluation of the import specification model and intelligence network was done through assessment of a few key features. The design and simulation of criminal incidents and case files allowed for knowledge of ground truth. The knowledge of incidents allowed for determination of whether or not appropriate links exist and associations were made. This assessment was completed to ensure all appropriate links were developed on a single given case. This was followed by import of the remaining cases to ensure no fault was found with the cases. Use of a general import specifications and mass import of all cases at the same time as well as individually into the network showed effectiveness. No issues were detected in either import sequence. General import specifications mean that multiple 
incident/case types are imported with a single specification. Articles of evidence were found to be appropriately linked to results and duplicate links were not detected. Analytical results were linked to the expected individuals, other evidence, and other cases by IBM ${ }^{\circledR}$ i2 ${ }^{\circledR}$ Analyst's Notebook ${ }^{\circledR}$ within the charted intelligence network. Entities with the same identities were merged leading to links being drawn between cases yielding a functioning network.

Value from forensic case data and forensic intelligence is maximized if it is a consolidated, multidisciplinary product [11]. This was apparent in linkages drawn between cases using the model. This is of utility to the investigator as linkages may uncover leads within the network and also to administrations as well. Evaluation during implementation and ongoing evaluation of the system are necessary for agencies considering the model proposed. Informed operational decision making can be achieved through use of the resultant intelligence product [22]. Establishment of a review process for the intelligence product is critical for incorporation of the model, refinement of the network structure to accommodate needs, and insurance that the information is accurately incorporated/represented. This is possible through supervisory or administrative review similarly to the CODIS system administration currently in place [23]. Evaluation of new case information and adjustments may be necessary for the agency to effectively utilize the information within their current system.

\subsubsection{Integration of information}

The effect of a system which integrates large-scale amounts of information allows for more accurate case assessment and interpretation of incidents. An investigator can visualize the entirety of the incident in question within the graphical network environment. The expanded model allows for assessment to include database results seamlessly. All information associated with the case is shown with the databases and linkages can be graded by the investigator/analyst. Reference Appendix A, Appendix B, and Appendix $C$ for examples of case representation within the network. The network also shows the amount of support for their conclusion such as the evidence and linkages for each case. The position within global environment of the network can also be relevant or of use for interpretation of the incident. Further evaluation of the import specification model would take implementation and use within investigations to evaluate the outcomes of the process and effectiveness of linkage.

A potential limitation of implementing the model is collaboration and information sharing with the databases. An avenue for the sharing of the information would need to be established. Rossy et. al. [24] recommend remote access to Laboratory Information Management Systems (LIMS) for investigators as it would add efficiency to the forensic and investigative processes. Legal restrictions may pose a challenge to the development of a comprehensive intelligence framework as proposed and the associated crime intelligence database. Numerous works $[4],[5],[11],[14],[24]$ cite IT systems and global data integration as a critical factor for the real utility of forensic intelligence. 


\section{Discussion}

An effective and efficient investigative service can be achieved through a contemporary model of case assessment and interpretation using a forensic intelligence framework. Developing a comprehensive understanding and outlook on criminal activity is critical to developing and applying police capability. Advantages of such action are more effective interpretation and use of forensic analytical results, resource distribution, and informed policing and security actions.

The three step import specification model developed in this project combines closed and new cases into an environment intended to aid future investigations through linkage development. The model was created to add an analytical assessment to investigations using all case information. Introduction of the model will provide a better product and streamline the criminal justice system in order to reduce court backlog. Case assessment using the totality of case information may uncover linkages with other cases. Follow up using the information of the cases in conjunction may provide enough information to solve both cases. There is also the potential to link cold cases in the network through similarities or stimulate a lead to refocus the investigation. Direct linkage from IBM ${ }^{\circledR} \mathrm{i} 2^{\circledR}$ Analyst's Notebook ${ }^{\circledR}$ facilitates immediate association and recognition of linkages. Appendix A shows the totality of the network created for this work. An example of a singular case is shown in Figure 2. In this case; DNA, fingerprint, and firearm evidence is combined and shown in IBM ${ }^{\circledR}$ i2 ${ }^{\circledR}$ Analyst's Notebook ${ }^{\circledR}$. For the fingerprint evidence a series of fingerprints were lifted from the outside of the rear master bedroom window (Evidence C1-C3). Two latent fingerprints were also processed and developed from a coin holder (Evidence D) collected from the scene. All five of these fingerprints were identified as being left by a 'Ricardo $\mathrm{Na}$ Gomez' subject. Additionally, a touch DNA swab was collected from the scene and a DNA profile was developed which matched the Gomez subject. The final piece of evidence collected from the scene was a cartridge case which was identified as being fired a Ruger ${ }^{\circledR}$ handgun as shown. Note that the database search revealed that the firearm was associated with a different incident which was also charted. The utility of the proposed intelligence model is the presentation and linkage development capability exhibited in Figure 2. There are several pieces of evidence linking the primary suspect to the incident with suspicion to an associated incident.

The four import specifications within the final import step are intended to develop linkages which explain the relationships between the evidence and incidents. Use in combination allows for charting of several pieces of evidence and the analysis as shown in Figure 2. The party seeking to add to the network simply places the information in the spreadsheet and runs the import specification. The final step of import specification model imports database results and overlays them with the previous incident and evidence due to matching identities. The import specifications are shown in Appendix D, Appendix E, and Appendix $F$. The import specification for cases involving DNA database results (Appendix $D$ ) shows several linkages internal to the case in conjunction to external links. The incident is linked to the 'Subject_Object' which is the evidence collected to the scene. The article of evidence has an analytical link with the DNA profile that was developed. The DNA profile is 


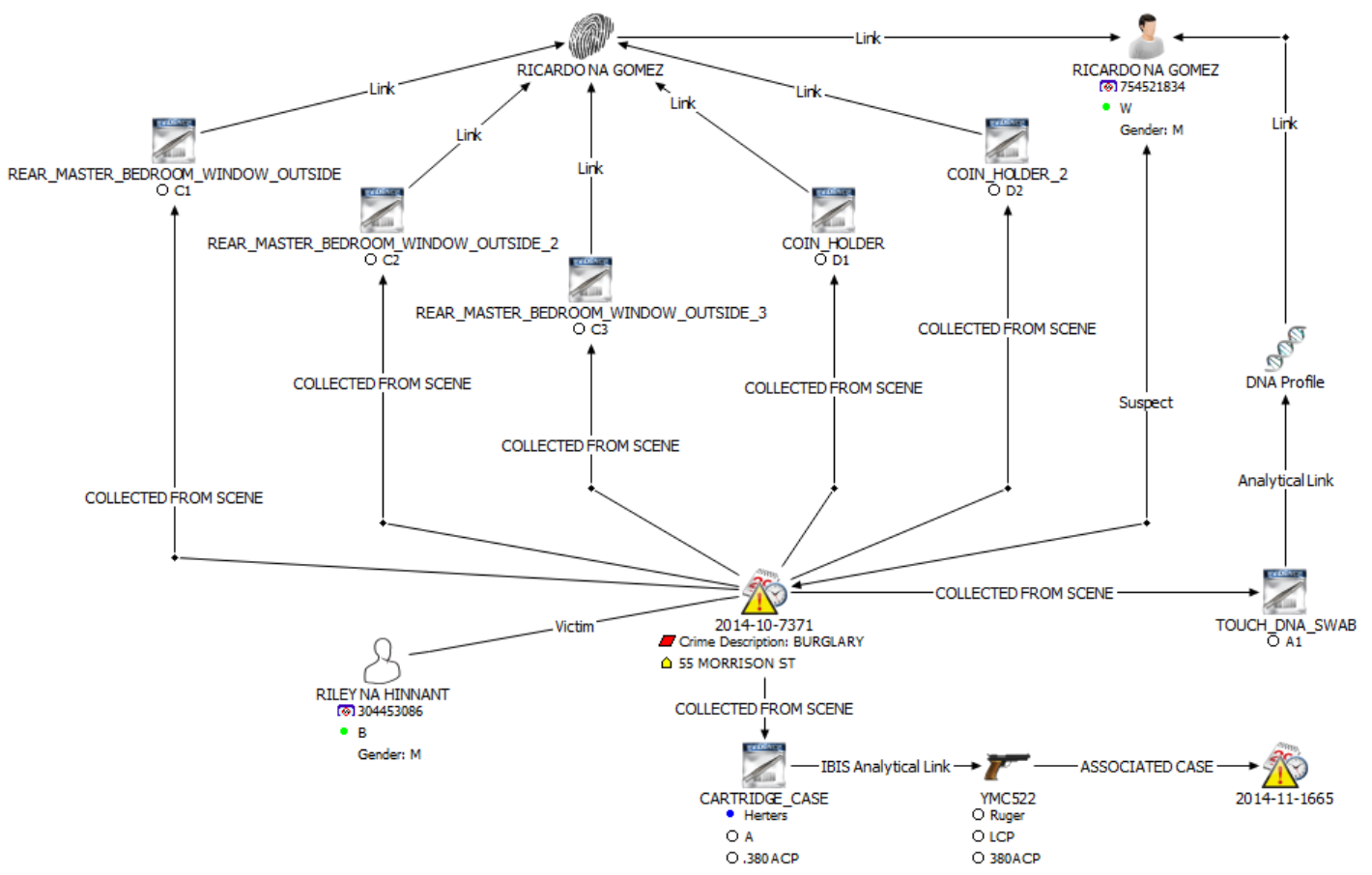

Figure 2: Image captured from IBM ${ }^{\circledR} \mathrm{i} 2^{\circledR}$ Analyst's Notebook ${ }^{\circledR}$ showing a burglary incident with several articles of evidence. The database search has also linked this case to another incident through the involvement of a particular firearm.

linked to the individual whom the DNA profile belongs. Finally, the import specification shows the individual has the potential to match with twenty other cases (associated from database such as NDIS). The software automatically draws linkages based upon the information entered into the spreadsheet. The fingerprint/AFIX Tracker ${ }^{\circledR}$ import specification is shown as Appendix E. In this import specification the incident is charted and verified using the latent case number and the evidence is charted using the latent location information entered into the database. These identities must match the identities as entered during the first two import specifications (case information and evidence) into IBM ${ }^{\circledR}$ i2 ${ }^{\circledR}$ Analyst's Notebook ${ }^{\circledR}$. A linkage between the latent location on a piece of evidence to the incident is also overlaid. Next the fingerprint developed is linked to the article of evidence on which it was detected. The individual is then linked to the fingerprint as shown by the analysis. Finally, the individual is linked to the case and their role can be changed to be associated/involved/suspect/victim. The import specification links the person to the case associated and the fingerprint result. This enables a future entry to link the given case to the individual and fingerprint and subsequently associate the two incidents. Next, the firearms/IBIS ${ }^{\circledR}$ import specifications are shown in Appendix F. Both import specifications show the incident and article of evidence labeled as 'CaseID_Sample' and the evidence item name. Next the recovered firearm import specification associates the article of evidence with 
a firearm known as 'IdentifierGun_Sample' which how IBIS ${ }^{\circledR}$ labels the sample of interest. This is then linked with a case in the database. A dotted or uncertain implied link associates the case in the database as having a potential link with the current incident. The recovered cartridge case import specification is also shown in Appendix $F$. In addition to the incident and evidence, a cartridge case is added and linked to the collected article of evidence outlining the details given by the examiner. This cartridge case icon is then linked (IBIS Analytical Link) to a firearm that was either matched by the examiner or given by database search. The firearm is then linked to any associated cases given by the database. Again, a dotted or uncertain implied link associates the case in the database as having a potential link with the current incident.

The import specifications are useful in the integration of information into the intelligence network. The process moves quickly and provides great information through the charting and linking of entities within the network. The graphical representation of the case is useful for decision making and contributes to the production of a better forensic product.

\subsection{Decision making}

A better product is necessary because several limitations exist within casework such as the decision making processes. Research indicates a large diversity in evidence collected (in type, numbers, rapidity and relevancy), by crime scene investigators belonging to the same units [25]. It appears that experience in decision making takes precedence over standard operating procedures. Investigators draw many parallels with police officers and are often one in the same. Both are reactive in nature, responding to calls for service, and respond to crimes which can occur repetitively [4]. Knowledge of crime-related problems or criminal activity can assist investigators plan and execute accordingly due to the potential of intelligence to provide guidance on recognition of highly informative evidence or patterns. Furthermore, the intelligence network serves as a check of objectivity for investigators discretion because linkages may exist which would hinder tunnel vision or suggest other avenues for the course of the investigation.

\subsection{Organizational Structure}

Organization is key to accurate visualization of an incident. A case is shown as a cluster of all entities after it has been imported. Links connect the various entities to the cases and with each other. Graphical charting of the incidents, especially in the company of other incidents in the area, helps assess the circumstances of the case. IBM ${ }^{\circledR} \mathrm{i} 2{ }^{\circledR}$ Analyst's Notebook ${ }^{\circledR}$ also allows for event frames to be created. An event frame is a representation that emphasizes chronology of events within an incident. This enhances the assessment of the case through graphical charting and consideration of the actions/events that transpired throughout the course of the incident in question. An additional potential use for event frames could be to aid the trier of fact as an exhibit. Organizational structure is also key to effective analytical efforts directed to detect pervasive series in crime, determination of the root causes of these incidents, coordination of a response to the problem, and assessment of the chosen line of action [4]. 


\subsection{Facilitating a working relationship}

Collaboration is critical to advancing the system currently in place and fostering an effective criminal justice system. Adopting problem-oriented or intelligence-led policing offers the possibility to enhance value of forensic operations, while preserving privacy. "Thinking more systematically about the substrate on which crime and disorder develop will necessarily augment priority given to forensically link entities and events to decipher crime and disorder concentrations" [4, p. 11]. Development of a working relationship only seeks to induce cooperation in solving complex investigations. Contribution from several disciplines in a coordinated effort to investigate criminal activity is the fundamental philosophy of forensic science. Exploitation of all parties through a working relationship should bring forth a more informed effort and focus attention on solving crime. The first barrier in achieving this is the current lack of communication between the parties involved.

\subsubsection{Impact on communication}

Communication is critical to a collaborative process and informed investigative community. Better decision making is shown as a component of the forensic intelligence model. The demand of consistency for entities in the network and for import of evidence will fuel a channel of communication between agents contributing. A single nomenclature would be an improvement for the field of forensic science and would be parallel with the current progres-

sion of the field. Recently, the Presidents Council of Advisors on Science and Technology (PCAST) called upon the field of forensic science to develop a "standardization of terminology used in reporting and testifying about the results of forensic sciences" [26, p. 35]. Closure of the gap between scientists and law enforcement as indicated in Section 3.2 is a necessity for complex investigations moving into new areas such as digital evidence. Communication and coordinated efforts are going to be critical as the criminal justice system detects and tackles new forms of criminal activity.

\section{Conclusion}

A paradigm shift is necessary to meet the growing information and intelligence needs of investigatory work. A new model encompassing a forensic intelligence framework has been developed as a solution to reduce linkage blindness and enhance the analytical nature of criminal investigations. The proposed model combines a three-step import specification sequence that guides incorporation of information into the network. Subsequently; strategic, tactical, and operational efforts/actions generate information to drive informed investigations through link, pattern, and trend discovery. Forensic outcomes have a great potential to detect crime series and the implementation of a forensic intelligence framework fully exploits that potential with a shift away from traditional case assessment.

The model presented in this article exhibits the effectiveness of import specifications in introducing case information, articles of evidence, and analytical results into a forensic intelligence structure. Forensic intelligence serves to enable a contemporary case assessment methodology through the inclusion of all information related to and uncovered throughout 
a criminal investigation. Interpretation and presentation of crime can exist within the network which enables assessment within the landscape of crime in the network. The import specifications developed allow for a consistency between case information integration in a user friendly package. Refinement of the model may be necessary to accommodate potential information as necessary. Graphical depiction of incidents within a global perspective of all agency case adds value to the case assessment and interpretation. The multi-case approach offered by the proposed model has great potential to assist in developing a more uniform approach and nomenclature across the forensic and investigative science community. 


\section{Appendix A. Complete Network}

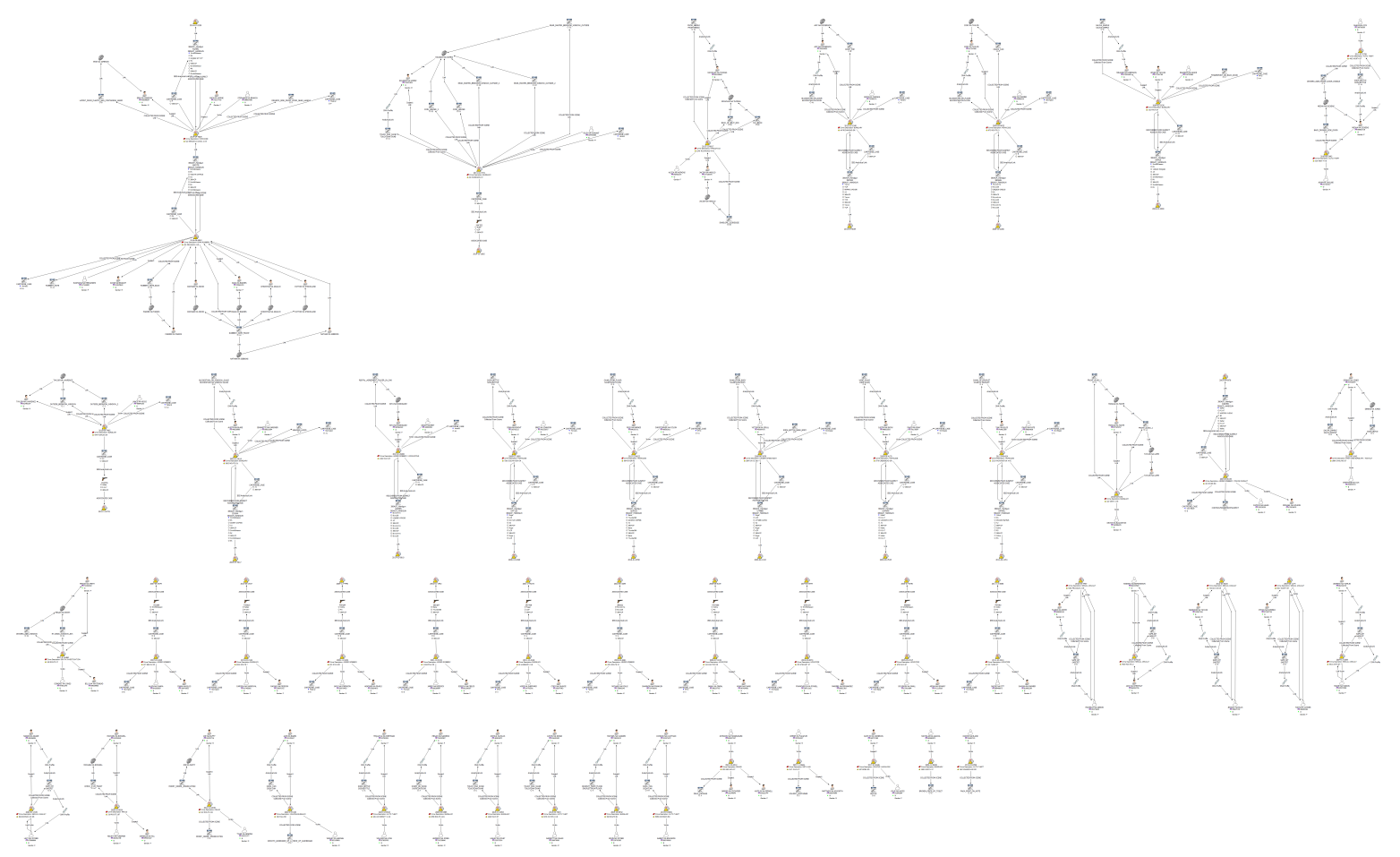

Figure A.3: Complete network developed from the fifty one simulated criminal cases. 


\section{Appendix B. Fingerprint Case Example}

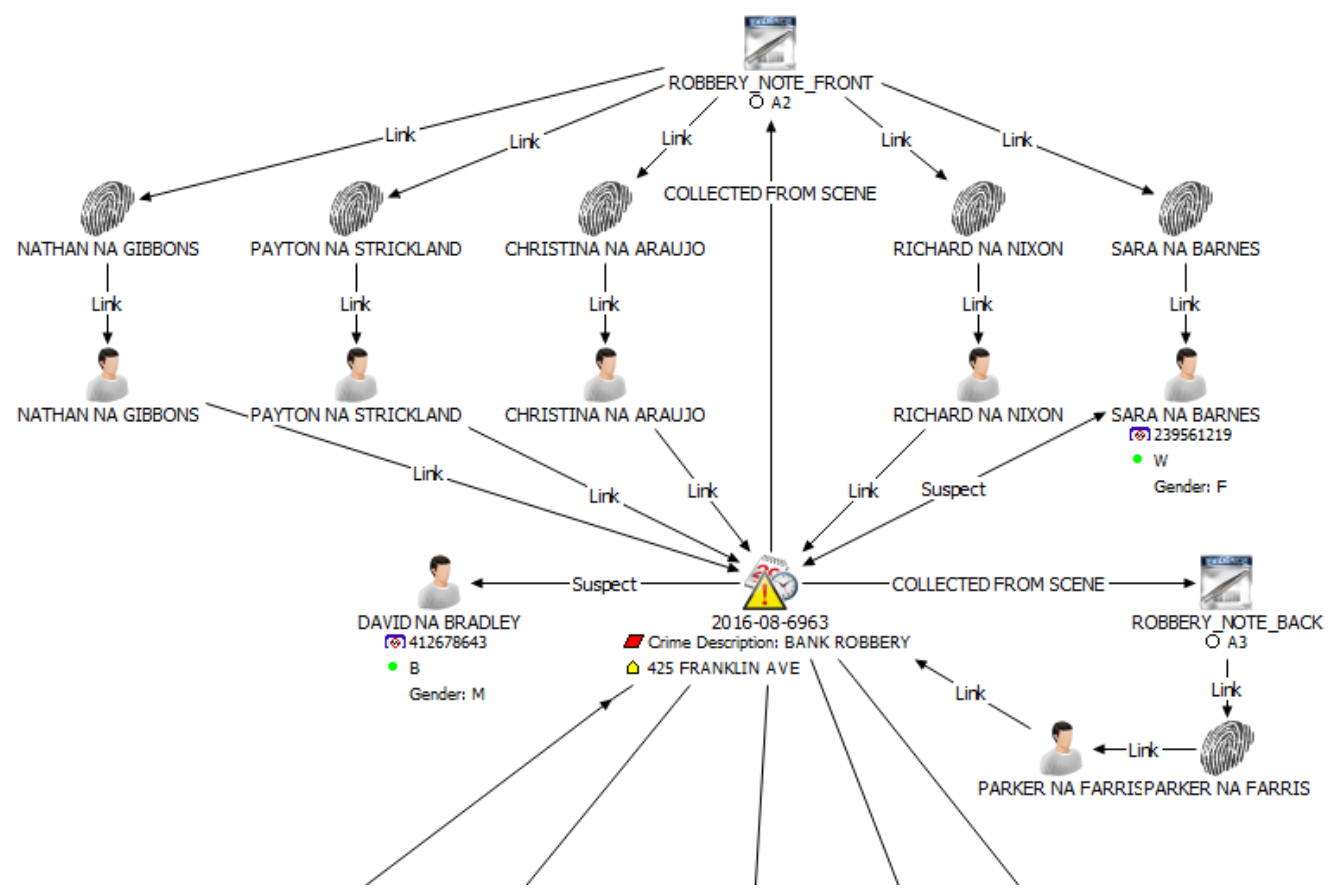

Figure B.4: A case example where the evidence was searched for latent prints. Several fingerprints were discovered and developed where a search of the database revealed six different contributors to the fingerprints on the front and back of a robbery note. 


\section{Appendix C. SAFE Kit Case Example}

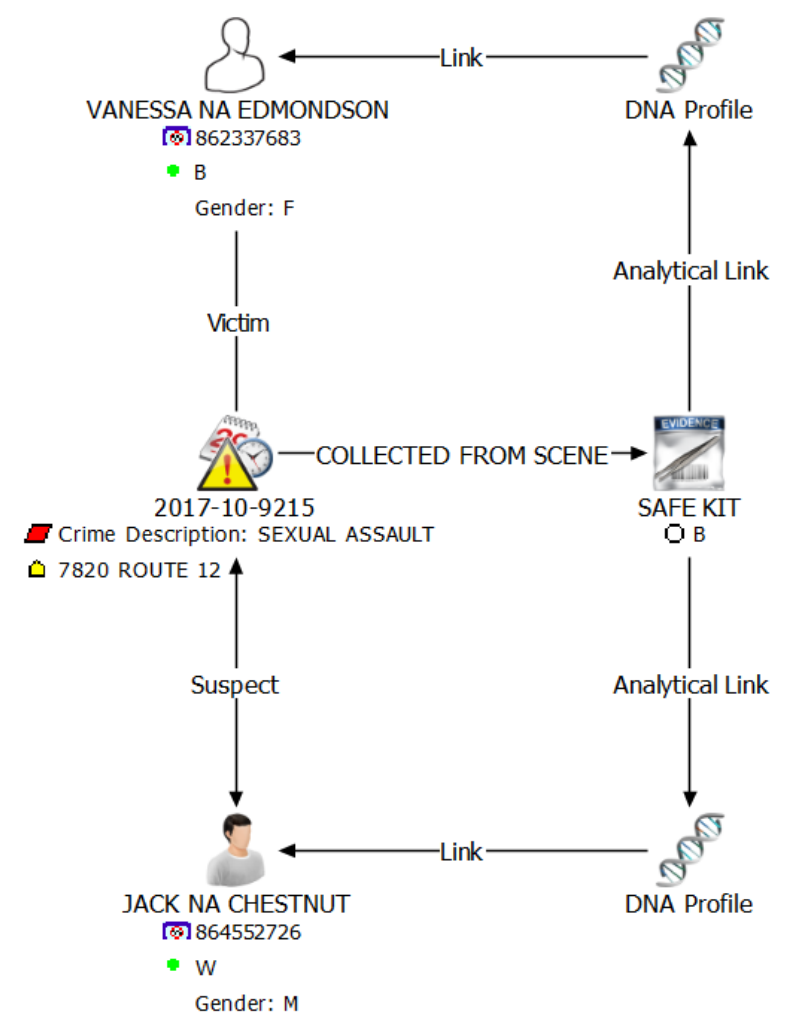

Figure C.5: Case example where two profiles were developed through examination of a SAFE kit. One profile was that of the victim and the other belong to a male subject in the database who then became a suspect for the case. 


\section{Appendix D. Import Specification for Cases with DNA Database Results}

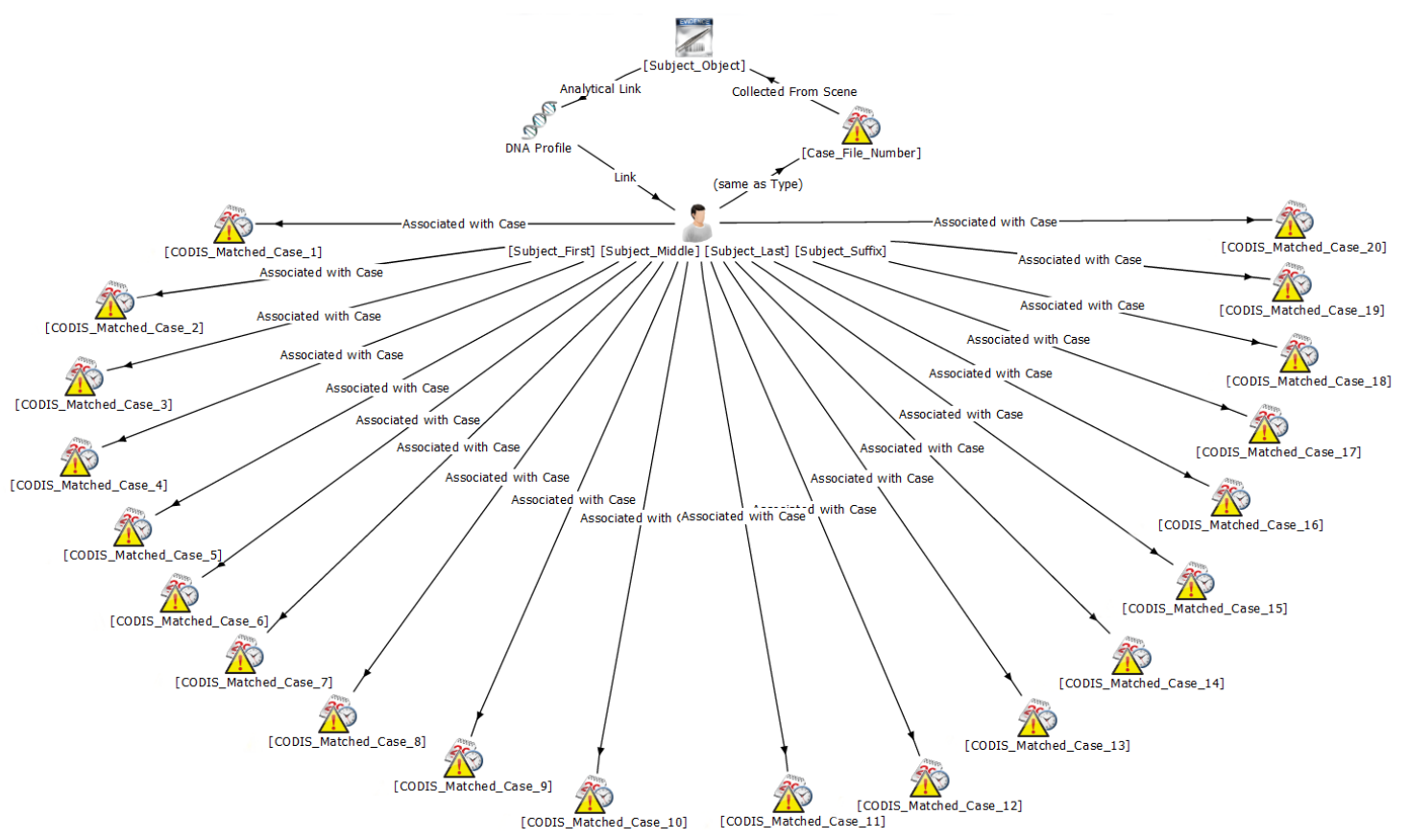

Figure D.6: Shown is the import specification design for inclusion of DNA analytical results. The image was captured from IBM ${ }^{\circledR} \mathrm{i} 2{ }^{\circledR}$ Analyst's Notebook ${ }^{\circledR}$ and shows linkage potential of up to twenty other incidents. 


\section{Appendix E. Import Specification for Cases with Fingerprint Evidence: AFIX Tracker $^{\circledR}$}

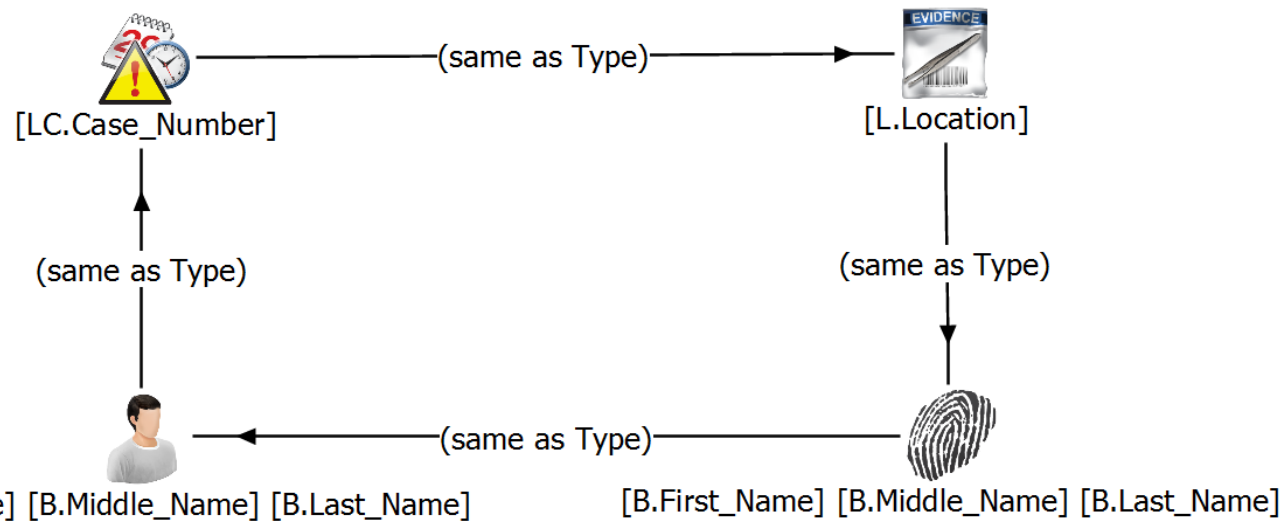

Figure E.7: Shown is the import specification design for inclusion of fingerprint analytical results. The image was captured from IBM ${ }^{\circledR} \mathrm{i} 2{ }^{\circledR}$ Analyst's Notebook ${ }^{\circledR}$ and shows the linkage of the latent location on a piece of evidence to the incident, the fingerprint developed to the evidence, the individual to the fingerprint, and finally the individual to the case as involved This import specification was designed for use with AFIX Tracker ${ }^{\circledR}$. 


\section{Appendix F. Import Specifications for Cases with Firearms Evidence: IBIS ${ }^{\circledR}$}

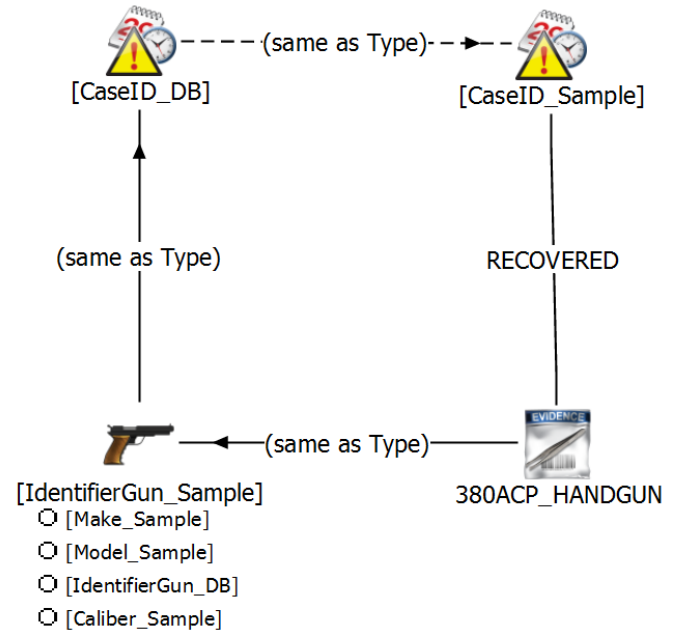

Recovered Firearm Import Specification

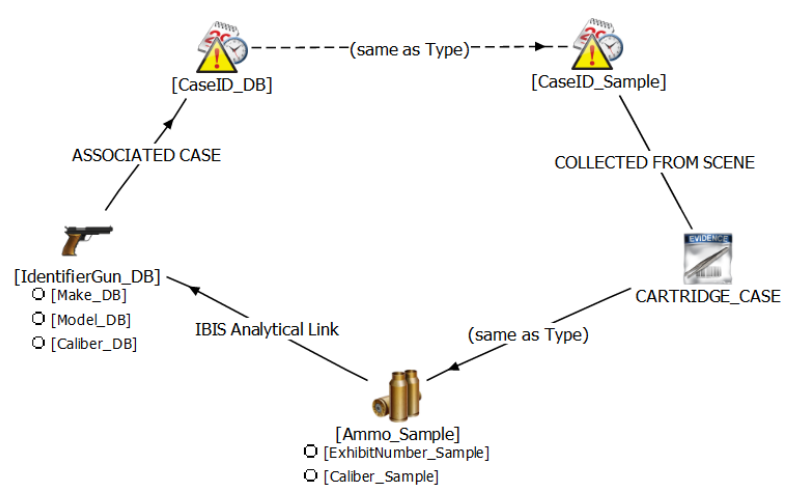

Recovered Cartridge Case Import Specification

Figure F.8: Shown is the import specification design for inclusion of firearm evidence results. The image was captured from IBM ${ }^{\circledR} i 2^{\circledR}$ Analyst's Notebook ${ }^{\circledR}$ and shows linkages developed for both a recovered firearm and a recovered cartridge case. 
Appendix G. $R^{\circledR}$ Script for Simulating a DNA Database 


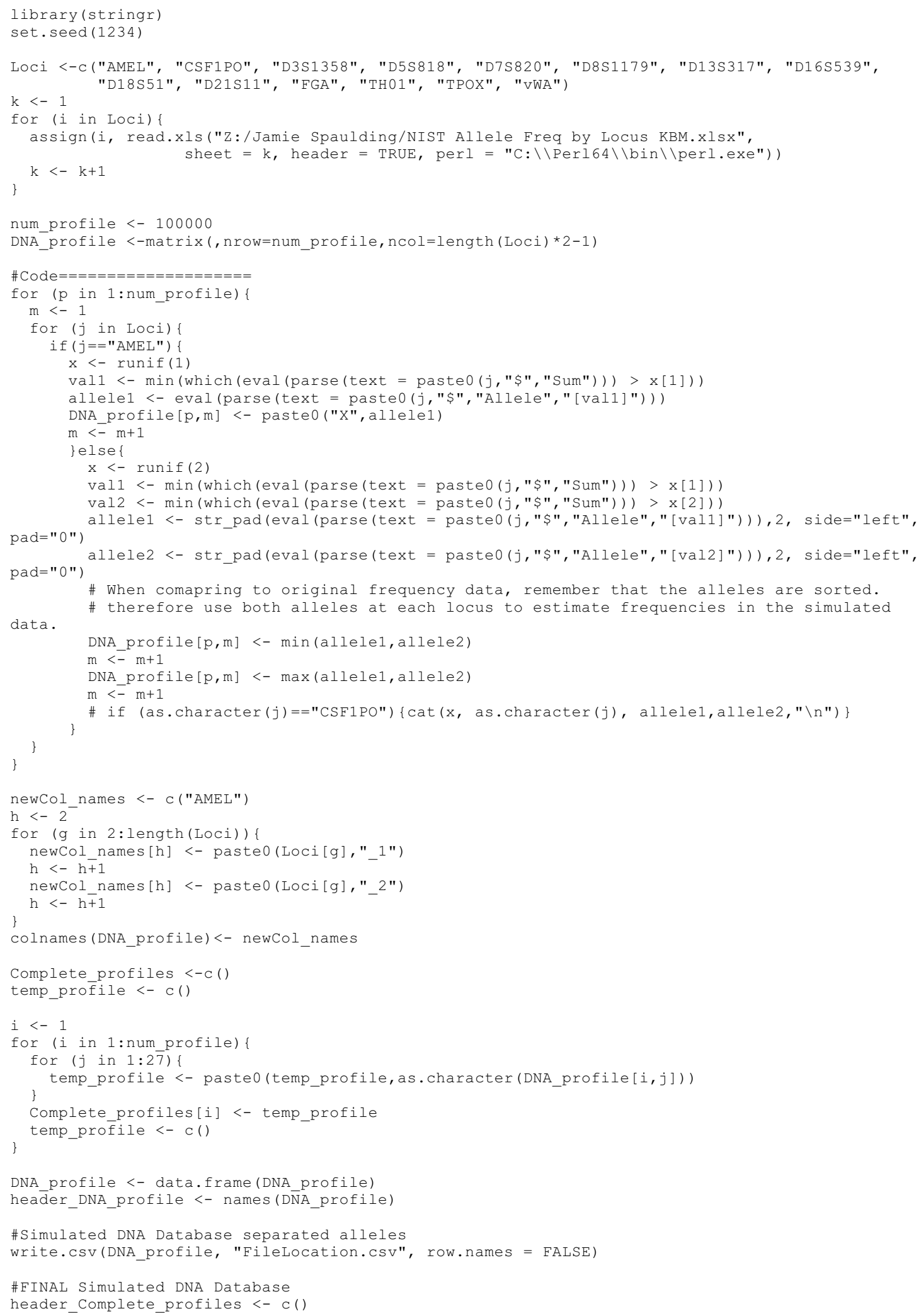


for (m in 1:length(header DNA profile)) \{

header_Complete_profiles $<-$ paste0 (header_Complete_profiles, header_DNA_profile[m])

Complete_profiles[1]<- header_Complete_profiles

write.csv(Complete_profiles, "FileLocation.csv", row.names = FALSE) 
Appendix $H \cdot R^{\circledR}$ Script for Extracting Information from AFIX Tracker ${ }^{\circledR}$ 


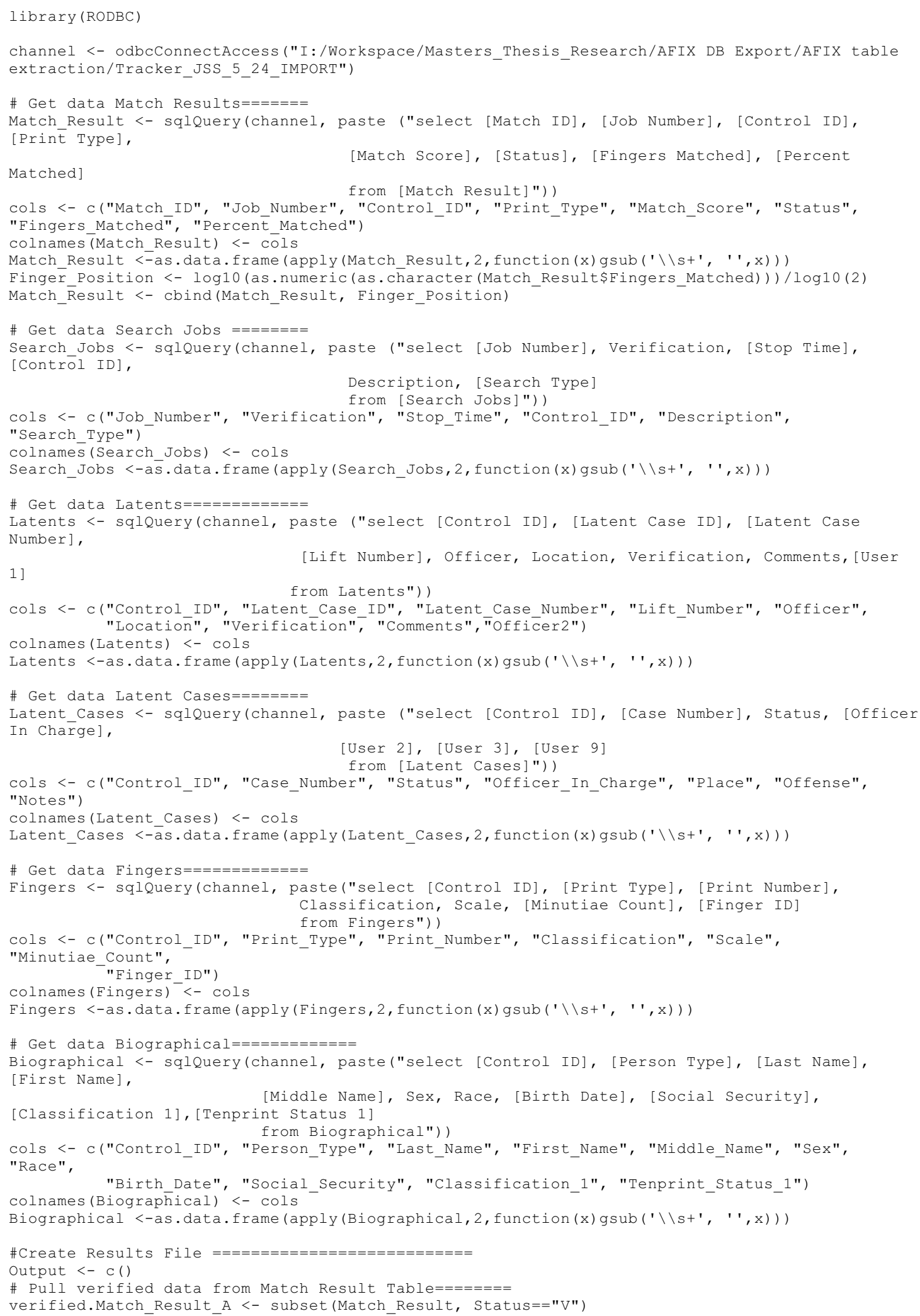




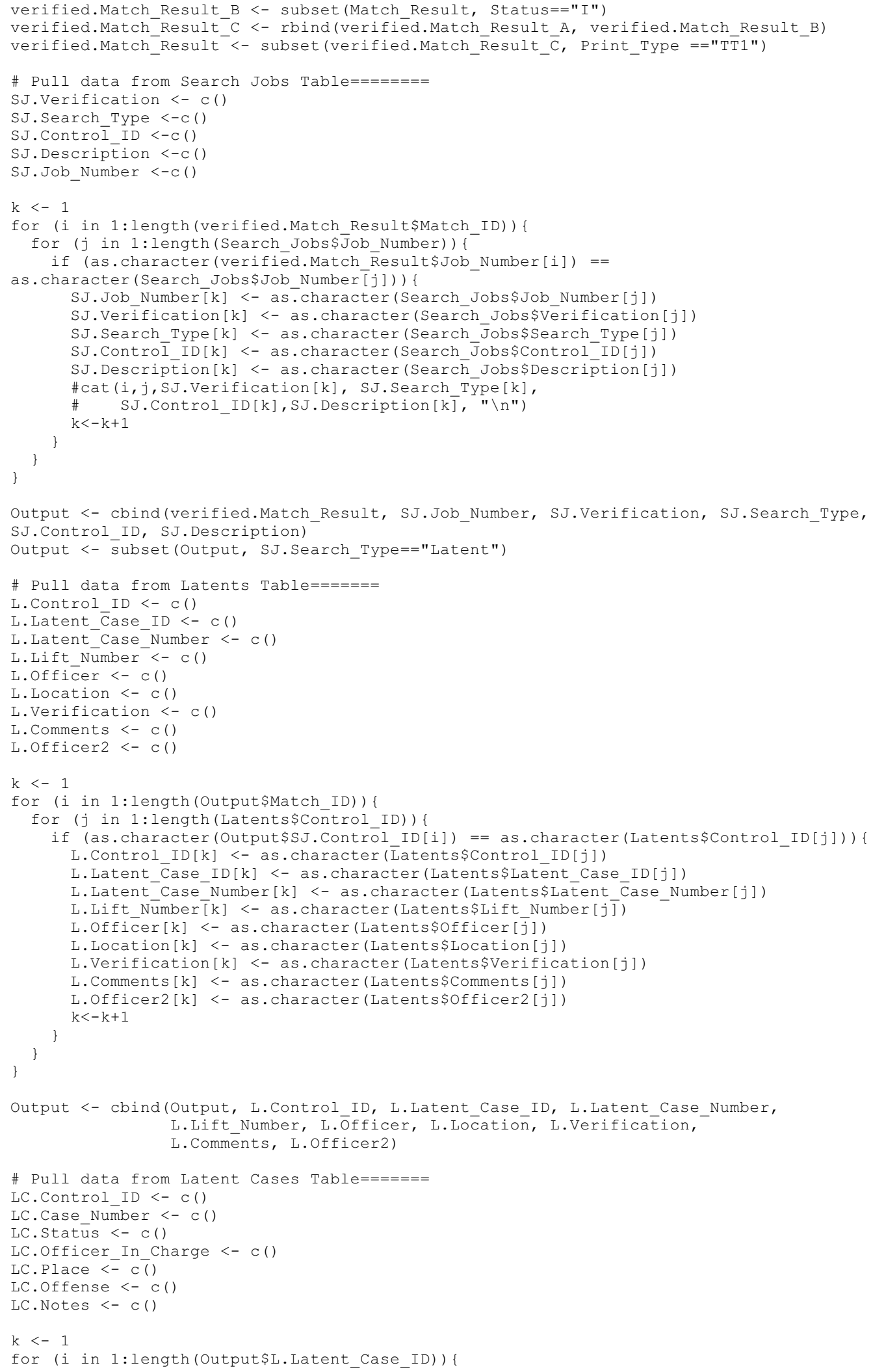




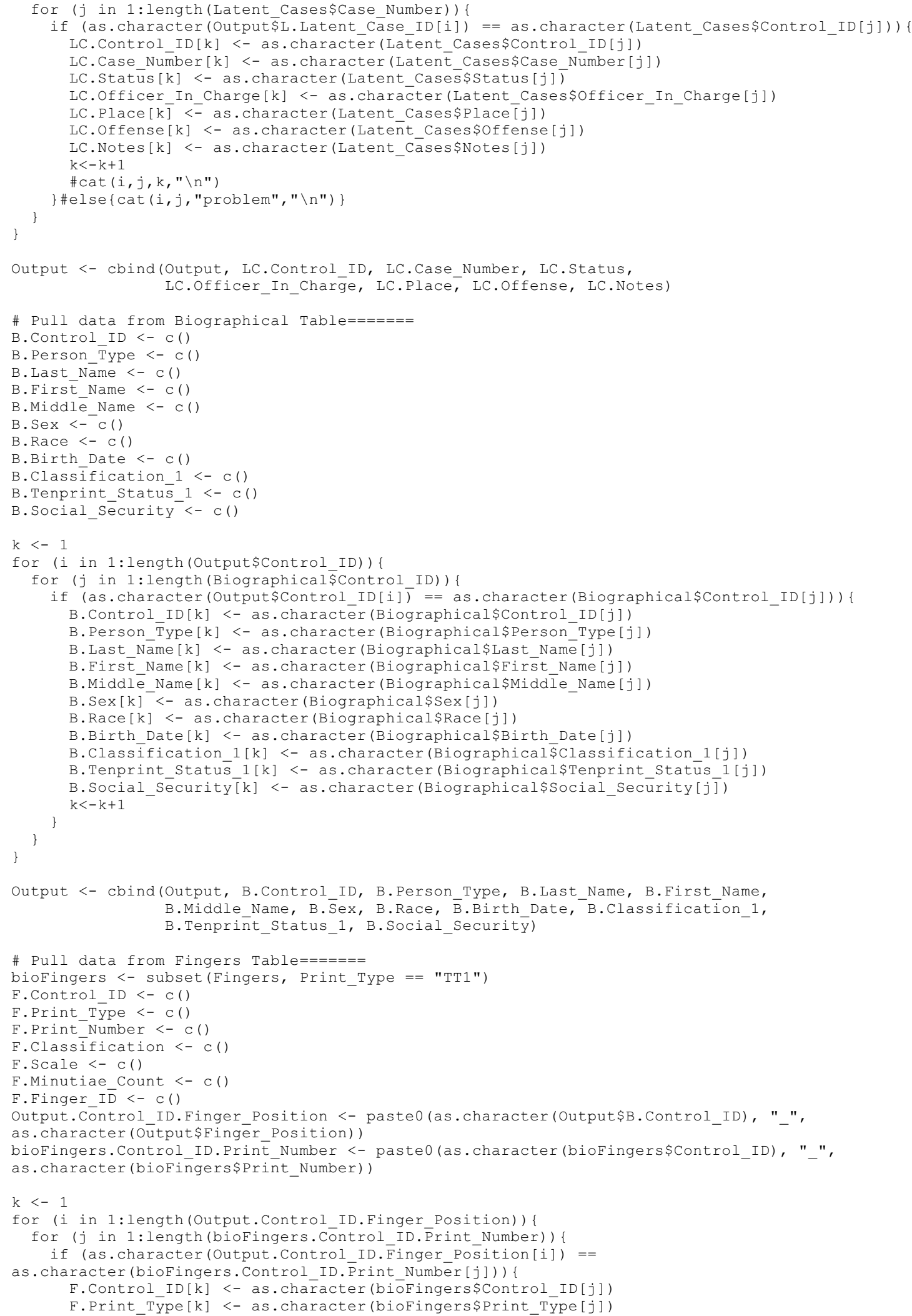




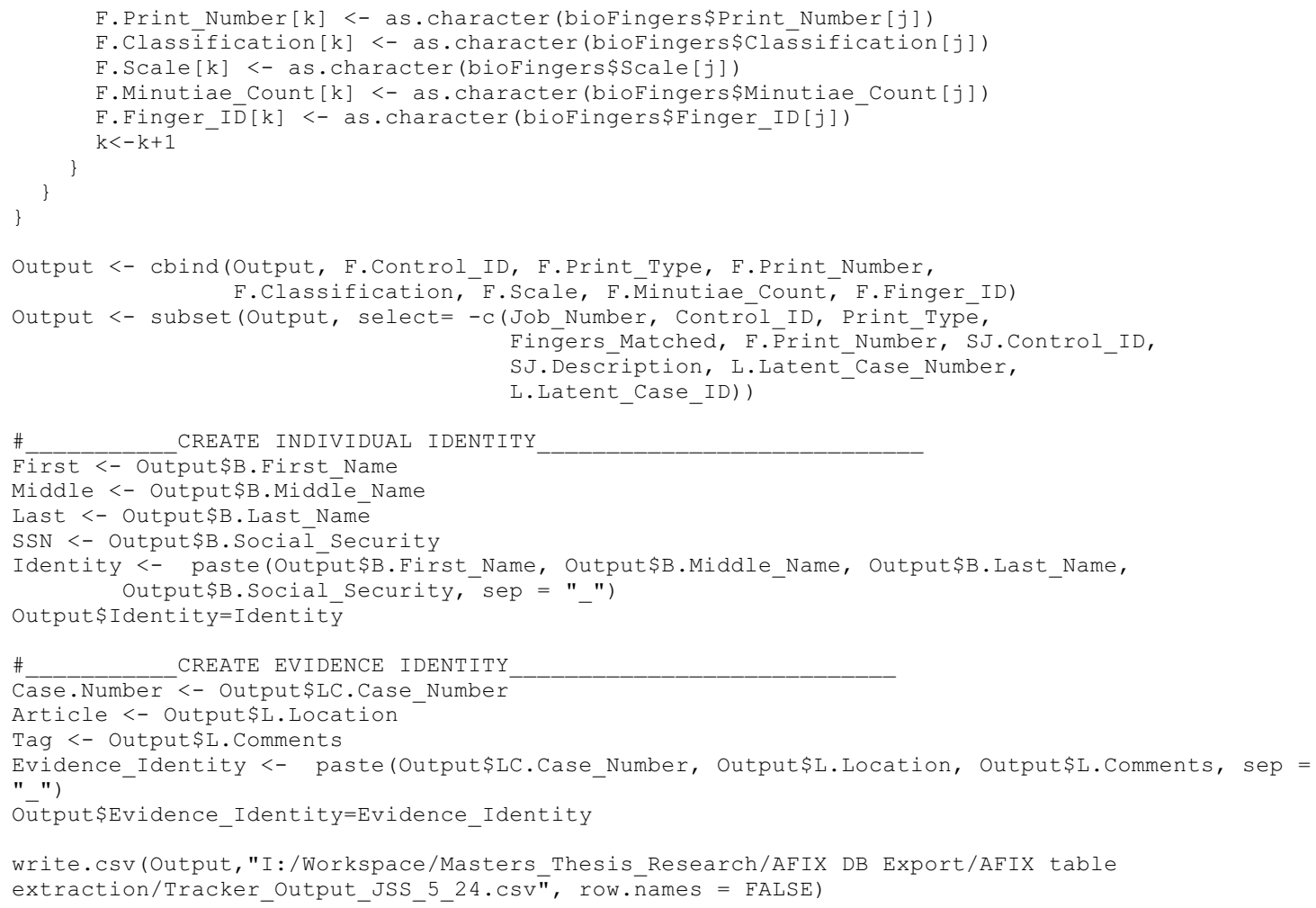




\section{References}

[1] National Commission on Forensic Science, Defining forensic science and related terms (May 2015).

[2] O. Ribaux, S. J. Walsh, P. Margot, The contribution of forensic science to crime analysis and investigation: Forensic intelligence, Forensic Science International 156 (23) (2006) 171 - 181.

[3] G. Jackson, S. Jones, G. Booth, C. Champod, I. Evett, The nature of forensic science opinion-a possible framework to guide thinking and practicce in investigation and in court proceedings, Science \& Justice 46 (1) (2006) $33-44$.

[4] O. Ribaux, C. Roux, F. Crispino, Expressing the value of forensic science in policing, Australian Journal of Forensic Sciences (2016) 1-13.

[5] R. G. Joyal, State Fusion Centers Their Effectiveness in Information Sharing and Intelligence Analysis, LFB Scholarly Publishing LLC, 2012.

[6] Federal Bureau of Investigation, Next Generation Identification (NGI), https://www.fbi.gov/services/cjis/fingerprints-and-other-biometrics/ngi, Date Accessed: 2017-Jun-13 (2017).

[7] Federal Bureau of Investigation, CODIS-NDIS Statistics, https://www.fbi.gov/about-us/lab/biometricanalysis/codis, Date Accessed: 2017-Jun-13 (2017).

[8] Bureau of Alcohol, Tobacco, Firearms, and Explosives, National Integrated Ballistic Information Network (NIBIN), https://www.atf.gov/firearms/national-integrated-ballistic-information-network-nibin, Date Accessed: 2017-Jun-13 (2017).

[9] F. R. Bieber, Turning base hits into earned runs: Improving the effectiveness of forensic dna data bank programs, The Journal of Law, Medicine Ethics 34 (2) (2006) 222-233.

[10] R. Cook, I. Evett, G. Jackson, P. Jones, J. Lambert, A model for case assessment and interpretation, Science and Justice 38 (3) (1998) 151-156.

[11] E. Bruenisholz, S. Prakash, A. Ross, M. Morelato, T. O’Malley, M. A. Raymond, O. Ribaux, C. P. Roux, S. Walsh, The intelligent use of forensic data: An introduction to the principles, Forensic Science Policy \& Management: An International Journal 7 (1-2) (2016) 21-29.

[12] Committee on Identifying the Needs of the Forensic Science Community, National Research Council, Strengthening Forensic Science in the United States: A Path Forward, National Academies Press, 2009.

[13] M. Morelato, S. Baechler, O. Ribaux, A. Beavis, M. Tahtouh, P. Kirkbride, C. Roux, P. Margot, Forensic intelligence framework - part I: Induction of a transversal model by comparing illicit drugs and false identity documents monitoring, Forensic Science International 236 (2014) $181-190$.

[14] S. Baechler, O. Ribaux, P. Margot, 2012 student paper: Toward a novel forensic intelligence model: Systematic profiling of false identity documents, Forensic Science Policy \& Management: An International Journal 3 (2) (2012) 7084.

[15] Q. Rossy, O. Ribaux, A collaborative approach for incorporating forensic case data into crime investigation using criminal intelligence analysis and visualisation, Science \& Justice 54 (2) (2014) 146 153.

[16] B. Gray, Collaborating: finding common ground for multiparty problems, Jossey Bass, 1999.

[17] i2 Limited, i2 Analyst's Notebook User Guide (2009).

[18] The R Foundation, The R project for statistical computing, https://www.r-project.org/, Date Accessed: 2016-Mar-08 (2016).

[19] RStudio, Take control of your R code, https://www.rstudio.com/products/rstudio/ (2016).

[20] C. R. Hill, D. L. Duewer, M. C. Kline, M. D. Coble, J. M. Butler, U.S. population data for 29 autosomal STR loci, Forensic Science International: Genetics 7 (2) (2013) e82e83.

[21] P. Meissner, Making R files executable (under windows) (Feb 2015).

[22] R. B. Santos, Crime analysis with crime mapping, 4th Edition, SAGE Publications, Inc., 2017.

[23] Virginia Department of Forensic Science, CODIS Operating Policies and Procedures Manual (Apr. 2017).

[24] Q. Rossy, S. Ioset, D. Dessimoz, O. Ribaux, Integrating forensic information in a crime intelligence database, Forensic Science International 230 (1) (2013) 137 - 146, eAFS 2012 6th European Academy of Forensic Science Conference The Hague, 20-24 August 2012. 
[25] S.-A. Bradbury, A. Feist, The use of forensic science in volume crime investigations: a review of the research literature, Online Report. London: Home Office (2005).

[26] Presidents Council of Advisors on Science and Technology, Forensic science in criminal courts: Ensuring scientific validity of feature-comparison methods, Executive Office of the Presidents Council of Advisors on Science and Technology (2016). 


\section{Future Directions}

In order to more accurately assess the future directions implementation of the model and throughput of data would be required. This would test the import specifications to a higher degree and refine or troubleshoot any generalizations or misrepresentations existing in the import specification model. A more refined and accurate case assessment model utilizing forensic intelligence networks could result from further utilization of features within IBM ${ }^{\circledR}$ i2 ${ }^{\circledR}$ Analyst's Notebook ${ }^{\circledR}$. Addition of criminal cases with real street addresses would allow for heat mapping and coordinate plotting of incidents. Mobility of subjects or insights regarding crime displacement would be possible with usage of actual crime locations. This would be among the benefits for operational decision making as mentioned above. Introduction of linkage grades could be of use for a more accurate case assessment model. The linkages could receive a grade based upon a likelihood ration established through Bayesian interpretation of the evidence. The grade could then vary based upon the likelihood ratio and a more accurate strength could be given to the associated link. Incorporation of the weight and value of evidence would further the potential for case assessment within the model.

Inclusion of the following will also expand the model to provide incorporation of more potential evidence types:

- Other pieces of evidence analyzed by forensic techniques (e.g. footwear, document examination, trace evidence, drug analysis, etc.)

- Recidivists to determine if entities of the same identity are linked

- Alias information

- Social network analysis

- Cellebrite ${ }^{\circledR}$ cell phone communication information. Exported call data can be directly imported into the framework within IBM ${ }^{\circledR} \mathrm{i} 2^{\circledR}$ Analyst's Notebook ${ }^{\circledR}$.

A final consideration for incorporation of a forensic intelligence framework are the existing legal requirements and statutes within an area. Law enforcement information sharing is becoming increasingly inadequate due to dependence on outdated regulations and statutes. Oversight management of the information flows are critical to the devel-

opment of standard operating procedures. Another concern is that the citizens lack the 
ability to know of, understand, and challenge exchanges of their data [36]. Additional legal issues pertaining to forensic intelligence systems are: ownership of data; storage of information and destruction requirements legality of the intended use of forensic intelligence; evidentiary validity of data in court; human rights and privacy; oversight bodies; and information sharing [36]. A jurisdiction by jurisdiction approach would be necessary for implementation. 


\section{Bibliography}

[1] Presidents Council of Advisors on Science and Technology. Forensic science in criminal courts: Ensuring scientific validity of feature-comparison methods: Report to the president. Forensic Science in Criminal Courts: Ensuring Scientific Validity of Feature-Comparison Methods: Report to the President, page 67, 2016.

[2] R. Milne. Forensic Intelligence. Forensics \& criminal justice. Taylor \& Francis, 2012. ISBN 9781439860380.

[3] Olivier Ribaux, Simon J. Walsh, and Pierre Margot. The contribution of forensic science to crime analysis and investigation: Forensic intelligence. Forensic Science International, 156(23):171 - 181, 2006. ISSN 0379-0738.

[4] Alastair Ross. Elements of a forensic intelligence model. Australian Journal of Forensic Sciences, 47(1):8-15, 2015.

[5] Chris Bell. Concepts and possibilities in forensic intelligence. Forensic Science International, 162(13):38 - 43, 2006. ISSN 0379-0738. 17th Triennial Meeting of The International Association of Forensic Sciences 2005, Hong Kong.

[6] National Commission on Forensic Science. Reflecting back - looking toward the future, April 2017.

[7] Committee on Identifying the Needs of the Forensic Science Community, National Research Council. Strengthening Forensic Science in the United States: A Path Forward. National Academies Press, 2009. ISBN 9780309131308.

[8] T.F. Kiely. Forensic Evidence: Science and the Criminal Law, Second Edition. CRC Press, 2005. ISBN 9781420038064.

[9] Marie Morelato, Simon Baechler, Olivier Ribaux, Alison Beavis, Mark Tahtouh, Paul Kirkbride, Claude Roux, and Pierre Margot. Forensic intelligence framework - Part I: Induction of a transversal model by comparing illicit drugs and false identity documents monitoring. Forensic Science International, 236:181 - 190, 2014. ISSN 03790738 .

[10] Jack H. Friedenthal and Michael Singer. The law of evidence. Foundation Press, 1985. 
[11] Federal Bureau of Investigation. Next generation identification (NGI). https://www.fbi.gov/services/cjis/fingerprints-and-other-biometrics/ngi, 2017. Date Accessed: 2017-Jun-13.

[12] Federal Bureau of Investigation. CODISNDIS Statistics. https://www.fbi.gov/aboutus/lab/biometric-analysis/codis, 2016. Date Accessed: 2016-Feb-29.

[13] Bureau of Alcohol, Tobacco, Firearms, and Explosives. National Integrated Ballistic Information Network (NIBIN). https://www.atf.gov/firearms/national-integratedballistic-information-network-nibin, 2016. Date Accessed: 2016-Feb-29.

[14] Federal Bureau of Investigation. ViCAP- Wanted by the FBI.

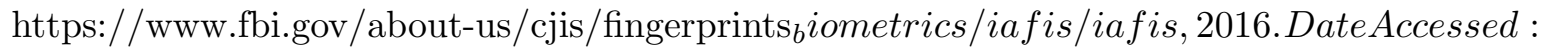
$2016-F e b-29$.

[15] TC Miller. Why can’t the FBI identify serial rapists? The Atlantic, jul 2015.

[16] IBM Analytics. i2 Analyst Notebook. http://www.ibm.com/software/products/en/analystsnotebook, 2016. Date Accessed: 2016-Mar-01.

[17] IBM Analytics. IBM i2 Analyst Notebook white paper. Technical report, IBM, 2016. Date Accessed: 2016-Mar-01.

[18] Quentin Rossy and Olivier Ribaux. A collaborative approach for incorporating forensic case data into crime investigation using criminal intelligence analysis and visualisation. Science \& Justice, 54(2):146 - 153, 2014. ISSN 1355-0306.

[19] The R Foundation. The R project for statistical computing. https://www.r-project.org/, 2016. Date Accessed: 2016-Mar-08.

[20] RStudio. Take control of your R code. https://www.rstudio.com/products/rstudio/, 2016.

[21] Anika Ludwig and Jim Fraser. Effective use of forensic science in volume crime investigations: Identifying recurring themes in the literature. Science $\&$ Justice, 54(1):81 - 88, 2014. ISSN 1355-0306.

[22] Olivier Ribaux, Amlie Baylon, Claude Roux, Olivier Delmont, Eric Lock, Christian Zingg, and Pierre Margot. Intelligence-led crime scene processing. Part I: Forensic intelligence. Forensic Science International, 195(13):10 - 16, 2010. ISSN 0379-0738.

[23] Olivier Ribaux, Amlie Baylon, Eric Lock, Olivier Delmont, Claude Roux, Christian Zingg, and Pierre Margot. Intelligence-led crime scene processing. Part II: Intelligence and crime scene examination. Forensic Science International, 199(13):63-71, 2010. ISSN 0379-0738.

[24] O. Ribaux and P. Margot. Case based reasoning in criminal intelligence using forensic case data. Science $\&$ Justice, 43(3):135 - 143, 2003. ISSN 1355-0306. 
[25] Tim Legrand and Lauren Vogel. The landscape of forensic intelligence research. Australian Journal of Forensic Sciences, 47(1):16-26, 2015.

[26] Olivier Ribaux and Benjamin Talbot Wright. Expanding forensic science through forensic intelligence. Science \& Justice, 54(6):494 - 501, 2014. ISSN 1355-0306.

[27] O Ribaux and P Margot. Inference structures for crime analysis and intelligence: the example of burglary using forensic science data. Forensic Science International, 100(3): 193 - 210, 1999. ISSN 0379-0738.

[28] Quentin Rossy, Sylvain Ioset, Damien Dessimoz, and Olivier Ribaux. Integrating forensic information in a crime intelligence database. Forensic Science International, 230(13):137 - 146, 2013. ISSN 0379-0738. EAFS 2012 6th European Academy of Forensic Science Conference The Hague, 20-24 August 2012.

[29] A. Mozayani and C. Noziglia. The Forensic Laboratory Handbook Procedures and Practice. Humana Press, 2010. ISBN 9781607618720.

[30] W.J. Chisum and B.E. Turvey. Crime Reconstruction. Academic Press/Elsevier, 2011. ISBN 9780123864604.

[31] F. Horvath and R. Meesig. The criminal investigation process and the role of forensic evidence: a review of empirical findings. Journal of Forensic Sciences, 41(6):963-969, nov 1996.

[32] R. Cook, IW. Evett, G. Jackson, PJ. Jones, and JA. Lambert. A model for case assessment and interpretation. Science and Justice, 38(3):151-156, jul 1998.

[33] Graham Jackson and Philip J. Jones. Case assessment and interpretation. Wiley Encyclopedia of Forensic Science, 2009.

[34] B. Robertson. John Henry Wigmore and Arthur Allan Thomas: An Example of Wigmorian Analysis. Victoria University of Wellington Law Review, 1990.

[35] Stuart S. Kind. Scientific Investigation of Crime. Forensic Science Services, 1987.

[36] Carole McCartney. Forensic data exchange: ensuring integrity. Australian Journal of Forensic Sciences, 47(1):36 - 48, 2015. ISSN 00450618. 